\title{
WestVirginiaUniversity
}

THE RESEARCH REPOSITORY @ WVU

Graduate Theses, Dissertations, and Problem Reports

1998

\section{Investigation of the formation of residual ash on candle filters}

Sharath J. Simha

West Virginia University

Follow this and additional works at: https://researchrepository.wvu.edu/etd

\section{Recommended Citation}

Simha, Sharath J., "Investigation of the formation of residual ash on candle filters" (1998). Graduate Theses, Dissertations, and Problem Reports. 936.

https://researchrepository.wvu.edu/etd/936

This Thesis is protected by copyright and/or related rights. It has been brought to you by the The Research Repository @ WVU with permission from the rights-holder(s). You are free to use this Thesis in any way that is permitted by the copyright and related rights legislation that applies to your use. For other uses you must obtain permission from the rights-holder(s) directly, unless additional rights are indicated by a Creative Commons license in the record and/ or on the work itself. This Thesis has been accepted for inclusion in WVU Graduate Theses, Dissertations, and Problem Reports collection by an authorized administrator of The Research Repository @ WVU. For more information, please contact researchrepository@mail.wvu.edu. 


\title{
INVESTIGATION OF THE FORMATION OF RESIDUAL ASH ON CANDLE FILTERS
}

\author{
Thesis \\ Submitted to the College of Engineering and Mineral Resources, \\ Department of Mechanical \& Aerospace Engineering, \\ West Virginia University \\ in Partial Fulfillment of the Requirements for \\ the Degree of Master of Science in Mechanical Engineering \\ by \\ Sharath J. Simha \\ Morgantown \\ West Virginia \\ 1998 \\ Committee Chair: Eric K. Johnson, Ph.D.
}


To my loving family

for all their support and encouragement 


\begin{abstract}
When coal undergoes combustion, not all the carbon in the coal may be consumed. This is due to improper mixing of reactants, proximity of cold surfaces and the desire to operate combustors at lower temperatures. Depending on the type of coal and the operating conditions of the combustor, there may be about 4-6\% of unburned carbon in the refuse. This unburned carbon is carried along in the flow of gases and ash. If the combustion gas products are to pass through a high temperature gas filtration system, ash and unburned carbon are deposited on the wall of a candle filter. Today, candle filters are employed for gas cleanup at temperatures of the order of about $1500^{0} \mathrm{~F}$.

During surface regeneration operation using air, the amount of oxygen available for reaction is at least two orders of magnitude greater than that available in the combustion products. This oxygen, combined with the prevalent temperatures will cause burning of the previously unburned carbon. The heat generated will result in a significant local rise in temperature of the deposits where the oxygen is consumed. These temperatures may lead to local sintering which may then lead to formation of the residual ash.
\end{abstract}

The present research involves:

- Estimating the carbon concentration in the ash deposit;

- Developing a simple combustion model to estimate the volumetric heat generation rate;

- Developing a numerical model to obtain the temperature profile in the ash deposit, during regular filtration and during surface regeneration;

- Determining if sintering occurs in the ash deposit. 


\section{ACKNOWLEDGEMENTS}

I wish to express my gratitude and appreciation to my research advisor and committee chairman, Dr. Eric Johnson, for his patience, constant guidance, support, and invaluable suggestions towards the completion of this research work. I also wish to express deep gratitude and appreciation to my co-advisor, Dr. Bruce Kang for his guidance and support. I also extend profuse thanks to Mr. Richard A. Dennis (FETC, Morgantown, WV), for his valuable technical suggestions and support.

I would like to thank Jim Barberio and Sean Gregory for their help and support.

I would like to thank my roommates; Avinash, Banda, Chethan \& Naveen; and my friends; Venky, 'Hunter', Vikram, Sathish, 'Putta', Sachin, Tangirala, Gayathri and Chittoor for their help and encouragement.

Special words of thanks go to my officemates, Clarence, Sumit, Subhash, Ron and Chandu for seeing me through this ordeal.

I would like to thank my Mother, Father, relatives and friends in India for their emotional support and encouragement. I would also like to convey a special word of thanks to my cousin Vinay for his constant help and advice. 


\section{TABLE OF CONTENTS}

TITLE PAGE

$\begin{array}{lll}\text { ABSTRACT } & \text { iii }\end{array}$

ACKNOWLEDGEMENTS

TABLE OF CONTENTS

LIST OF FIGURES viii

LIST OF TABLES - xii

LIST OF SYMBOLS X xiii

\section{CHAPTER 1 INTRODUCTION}

1.1 Background 1

$\begin{array}{ll}1.2 \text { Objective } & 8\end{array}$

CHAPTER 2 LITERATURE REVIEW

$\begin{array}{ll}2.1 \text { Review of filter literature } & 10\end{array}$

2.2 Review of heat transfer in porous media 21

2.3 Review of ash chemistry literature 22

CHAPTER 3 DEVELOPMENT OF AN ANALYTICAL MODEL

3.1 Introduction 31

$\begin{array}{ll}3.2 \text { Approach } & 35\end{array}$

3.3 Analytical model for heat transfer 37 


\section{CHAPTER 4 DEVELOPMENT OF A NUMERICAL MODEL FOR}

HEAT TRANSFER ANALYSIS

4.1 Introduction

4.2 Numerical Equations

4.2.1 Development of heat transfer equations

4.2.2 Development of flow equations

4.2.3 Estimation of ash permeabilities

4.2.4 Selected start of filtering system

4.3 Selected parameters for this study

58

4.4 A discussion on stability

61

4.5 Results

64

\section{CHAPTER 5 DETERMINATION OF ASH DEPOSIT COMPOSITION}

5.1 Introduction

5.2 Development of a combustion model

5.3 Development of a computer program for estimation of heat generation

\section{CHAPTER 6 POTENTIAL FOR SINTERING}

6.1 Review of reaction rates for sintering

6.2 Frenkel model for sintering in fluidized bed combustion processes 
CHAPTER 7 RESULTS \& CONCLUSIONS

7.1 Results from the combustion model 96

7.2 Results from the heat transfer model 102

7.3 Results from the sintering model 112

7.4 Combine results from 7.1, 7.2 and 7.3 116

$\begin{array}{ll}7.5 \text { Discussion } & 128\end{array}$

CHAPTER 8 CONCLUSIONS AND RECOMMENDATIONS 132

$\begin{array}{ll}\text { REFERENCES } & 134\end{array}$

$\begin{array}{ll}\text { APPENDIX A } & 136\end{array}$

$\begin{array}{ll}\text { APPENDIX B } & 138\end{array}$

$\begin{array}{ll}\text { VITA } & 155\end{array}$

APPROVAL OF EXAMINING COMMITTEE 156 


\section{LIST OF FIGURES}

Figure 1.1 (a) $\quad$ An IGCC based power plant 2

Figure 1.1 (b) $\quad$ A PFBC based power plant 3

$\begin{array}{lll}\text { Figure 1.2 Westinghouse candle filter system concept } & 6\end{array}$

Figure 2.1 Schematic of a ceramic cross-flow filter 15

$\begin{array}{lll}\text { Figure 2.2 } & \text { Idealized filter pressure drop } & 17\end{array}$

Figure 2.3 Ash cenospheres formed in burning pulverized coal 26

Figure 2.4 Plot of temperature for 250-poise viscosity versus

29

base-to-acid ratio, based on a ferric percentage of 20

Figure 2.5 Influence of Iron on coal ash fusion temperature

Figure 3.1 Schematic illustration of surface regeneration event

Figure $3.2 \quad$ Expected temperature distribution in the reaction

zone as a function of time

Figure 3.3 Flow-chart of approach used in the current analysis $\quad 38$

Figure $3.4 \quad$ Calculation procedure used in the current analysis $\quad 39$

Figure 3.5 Representative element for heat transfer in the system 37

$\begin{array}{lll}\text { Figure 4.1 } & \text { Flow-chart of computer program } & 44\end{array}$

Figure 4.2 Representation of gaseous and porous regions for 45

cylindrical co-ordinate formulation

Figure 4.3 Schematic representation of heat transfer in a finite

Region 
Figure 4.4

Figure 4.5

Figure 4.6

Figure 4.7

Figure 4.8

Figure 4.9

Figure 4.10

for pressure drop model

Temperature drop with time along inner surface of

Schumacher filter during surface regeneration

Temperature distribution along the outside surface of

67

Schumacher filter during surface regeneration

Temperature distribution at edge of a residual ash layer

68

during surface regeneration

Temperature distribution in residual ash during

69

surface regeneration

Temperature distribution across the system, during

70

surface regeneration

Temperature distribution near the inside wall of

Schumacher filter during surface regeneration

Figure 4.11

Temperature drop along outside surface of Schumacher

72

filter during filtration

Figure 4.12

Temperature drop at the edge of a residual ash layer

73

during filtration

Figure 5.1

Bubbling Fluidized Bed Schematic

75

Figure 5.2

Schematic representation of the combustion process

77

Figure 6.1

Viscous flow sintering of two particles

Figure 6.2

Measured surface tension/viscosity ratio versus

87 
base-to-acid ratio, determined in air and a

$\mathrm{CO} / \mathrm{CO}_{2}$ atmosphere

Figure 6.3

Compressive strengths of pellets sintered at

88

$1370 \mathrm{~K}$ in air, versus the surface tension/viscosity

ratio for selected homogeneous coal ashes

Figure 6.4 Viscous flow sintering of two spheres

89

Figure 6.5

Effect of temperature on ash-sintering

92

parameters

Figure 7.1

Temperature distribution in a layer of ash

106

after one cycle of operation

Figure 7.2

Temperature distributions in a layer of ash, after

107

different number of cycles of operation

Figure 7.3

Temperature distribution at the edge of residual ash layer,

$\mathrm{UC}=2 \%$, filtration temperature $=800{ }^{0} \mathrm{C}$

Figure 7.4

Temperature distribution in an ash layer, $\mathrm{UC}=4 \%$ and

filtration temperature $=700 \mathrm{C}$

Figure 7.5

Effect of unburned carbon $\%$ and filtration temperature

on temperature distribution in an ash layer

Figure 7.6

Temperature dependence of viscosity of ash particles

113

Figure 7.7

Times needed for different degrees of sintering, as a

114

function of temperature

Figure 7.8

Effect of particle size on sintering times 
Figure 7.9

Temperature distribution and sintering curves

after 1 cycle of operation

Figure 7.10

Temperature distribution and sintering curves

after 5 cycles of operation

Figure 7.11

Temperature distribution and sintering curves

after 10 cycles of operation

Figure 7.12

Temperature distribution and sintering curves

after 15 cycles of operation

Figure 7.13

Temperature distribution and sintering curves

after 20 cycles of operation

Figure 7.14

Temperature distribution and sintering curves

after 25 cycles of operation

Figure 7.15

Temperature distribution and sintering curves

after 30 cycles of operation

Figure 7.16

Temperature distribution and sintering curves

after 1 cycle of operation, unburned carbon $=2 \%$

Figure 7.17

Temperature distribution and sintering curves

after 1 cycle of operation, filtration temperature $=700^{\circ} \mathrm{C}$

Figure A1.1 Temperature distribution near the inside wall of filter

after 0.3 seconds

136 


\section{LIST OF TABLES}

Table 2.1 Composition of laboratory combustion ashes of

bituminous coals and anthracites

Table 2.2 Comparison of ash from two lignites with

wood ash

Table 6.1 Degree of sintering based on the ratio of neck

bond radius to particle radius

95

Table 7.1 Combustion parameters employed in this study

97

Table 7.2 Composition of coal used in this study

97

Table 7.3 Values of combustion parameters used in this research

98

Table 7.4 Calculated Composition of Combustion Products

99

Table 7.5(a) Growth of residual ash thickness with cycles of

101

operation, with $4 \%$ unburned carbon

Table 7.5(b) Growth of residual ash thickness with cycles of

operation with $2 \%$ unburned carbon

Table 7.6 Material and physical properties of Schumacher filter

103

Table 7.7 Physical properties of gases at $800^{\circ} \mathrm{C}$

104 


\section{LIST OF SYMBOLS}

\section{English Letters}

$\dot{q} \quad$ Heat flow rate

$\dot{q} \quad$ Volumetric heat generation rate

$\dot{m}_{\text {air }} \quad$ Mass-flow rate of air

$\dot{m}_{\mathrm{O}_{2}} \quad$ Mass-flow rate of oxygen

A Cross-sectional area for heat flow

B/A Base to Acid ratio of coal ashes

c Specific heat

$\mathrm{dV} \quad$ Elemental volume of a representative element

E/R exponential constant, determined empirically

EA Excess air percentage

K Thermal conductivity

k Permeability

L Length of filter

M Mass flow rate (used in derivations)

$\mathrm{M}$ (pulse) Mass flow rate during surface regeneration (used in charts)

$\mathrm{m}_{\text {carbon }} \quad$ Mass of carbon in ash deposit required for complete consumption of oxygen, during surface regeneration

$\mathrm{m}_{\text {deposit }} \quad$ Mass of deposit required for complete consumption of oxygen, during surface regeneration 


$\begin{array}{ll}\mathrm{P}_{1} & \text { Pressure inside filter } \\ \mathrm{P}_{4} & \text { Chamber pressure } \\ \mathrm{R} & \text { radius of ash particles } \\ \mathrm{R} & \text { Calcium to Sulfur ratio } \\ \mathrm{R}_{\mathrm{a}} & \text { Universal Gas Constant } \\ \mathrm{r}_{\mathrm{m}} & \text { Radius of node ' } \mathrm{m} \text { ' } \\ \mathrm{T} & \text { Temperature } \\ \mathrm{T}(\mathrm{fil}) & \text { Filtration temperature (used in charts) } \\ \mathrm{T}_{\mathrm{S}} & \text { Sintering temperature } \\ \mathrm{t}_{\mathrm{s}} & \text { Time required for sintering } \\ \mathrm{U} & \text { Face velocity of filtration gases } \\ \mathrm{UC} & \text { Unburned carbon percentage (used in charts) } \\ \mathrm{V}_{\text {deposit }} & \text { Volume of deposit required for complete consumption of oxygen, during } \\ & \text { surface regeneration } \\ \mathrm{x} & \text { Neck-radius during viscous-flow sintering } \\ \mathrm{x} / \mathrm{r} & \text { A parameter for characterizing the degree of sintering } \\ \end{array}$

\section{Greek Letters}

$\varepsilon \quad$ Porosity

$\tau \quad$ Interval number

$\eta \quad$ Absolute Viscosity of ash

$\mu \quad$ Absolute Viscosity of gas

$\gamma \quad$ Surface tension 
$\alpha \quad$ Thermal diffusivity of air

$\mu_{0} \quad$ Co-efficient in viscosity equation

$\rho \quad$ Density

$\Delta \mathrm{E} \quad$ Change in internal energy of an elemental node

$\Delta \mathrm{H} \quad$ Enthalpy of conversion of carbon to carbon dioxide

$\Delta \mathrm{r} \quad$ Nodal increment

$\Delta \mathrm{t} \quad$ Time increment

$v^{-} \quad$ Apparent linear flow rate

\section{Subscripts}

a Ash

f Filter

g Gas

ha Hard Ash

sa Soft Ash

m Node number 


\section{CHAPTER 1}

\section{INTRODUCTION}

\subsection{Background}

Some of the advanced coal conversion systems in use today are the Pressurized Fluidized Bed Combustion (PFBC) and the Integrated Gasification Combined Cycle (IGCC). In these applications, gases from the combustion and/or gasification system are directed towards a gas turbine to achieve a high efficiency power plant cycle. This requires the removal of a sufficient amount of ash and other particulate matter from the gas stream to protect downstream equipment from particle fouling and erosion effects. Further, increased environmental concerns and the passage of the 'U.S. Clean Air Act' have stressed attention on the removal of pollutants from power plants [2].

At the present time, a barrier filter appears to be the most appropriate method for removing particulate matter from the high temperature gas stream. The hot gas particle filter may also be integrated with the sulfur, alkali, or other gas phase contaminant removal processes. This is accomplished by injecting appropriate sorbent particles upstream of the filter. These particles react with the gas phase contaminant, and are collected as part of the filter cake. The filter cake is removed by pulse jet cleaning methods. In this integrated approach, the particle filter may serve as either the primary device, or as a polishing device in the gas phase contaminant removal process.Figures 1.1(a) and 1.1(b) [1] illustrate schematically the working of IGCC and PFBC based 


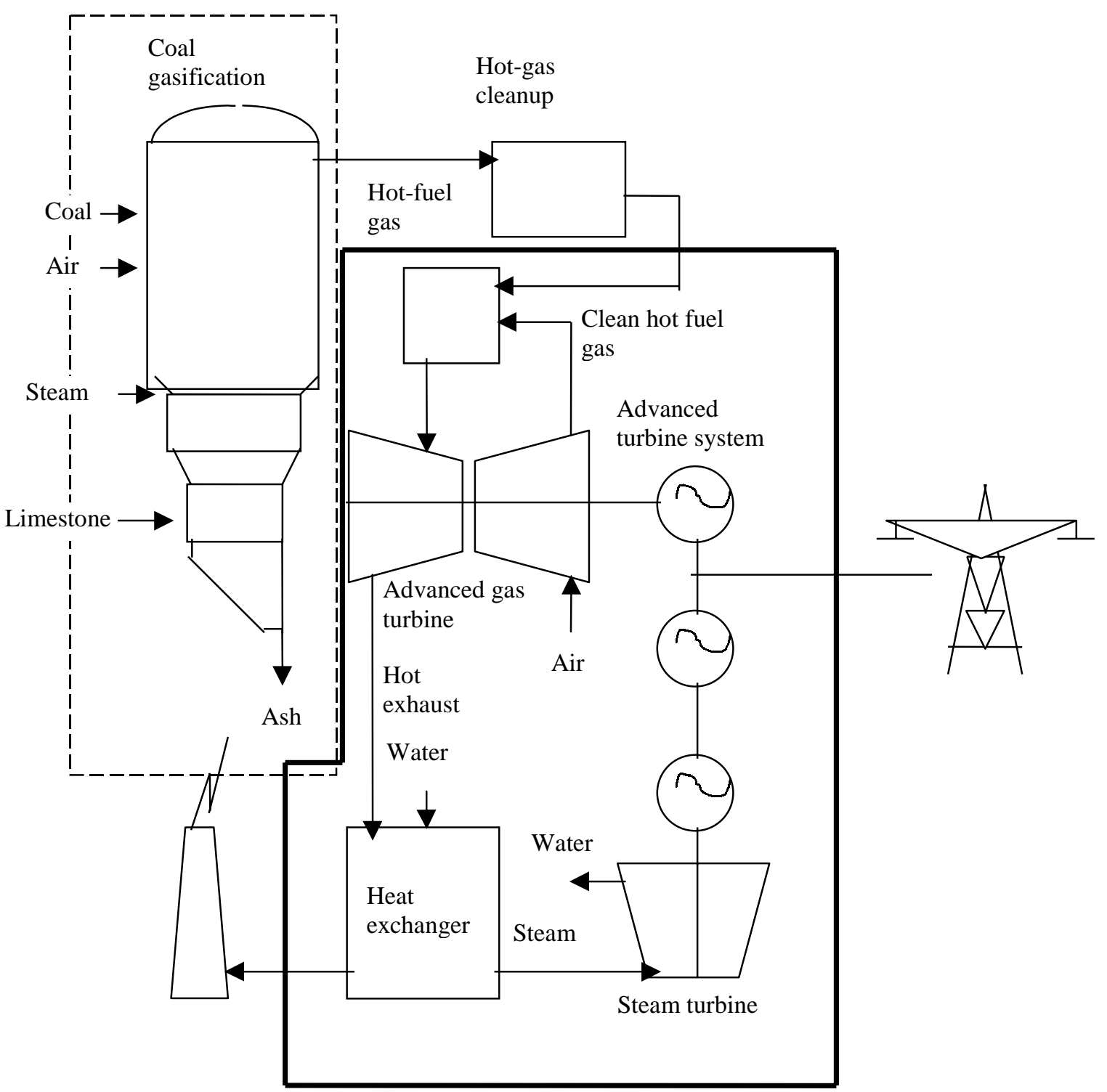

Fig 1.1 (a) An IGCC based power plant [1] 


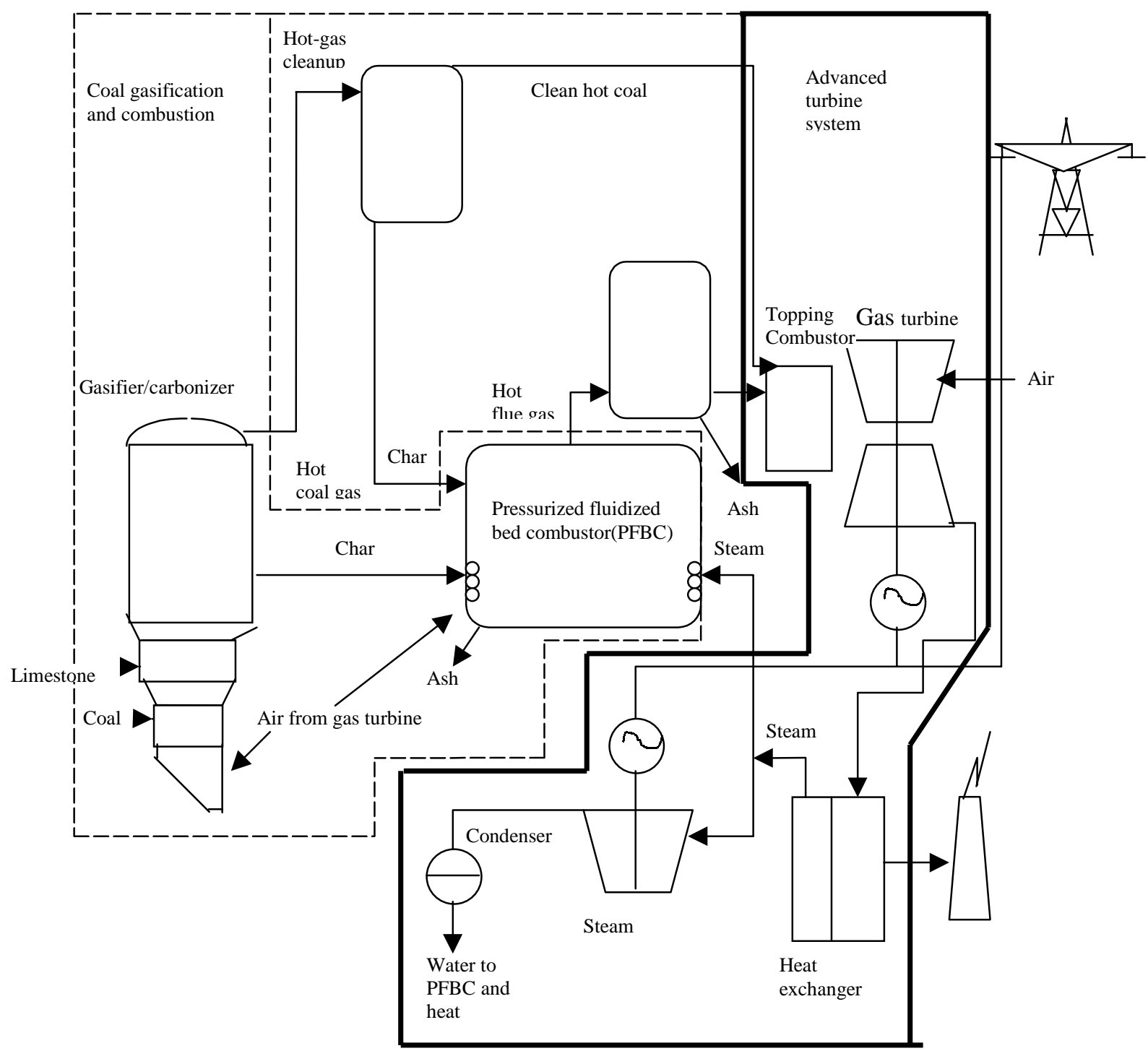

Fig 1.1 (b) A PFBC based power plant [1]

power plants. In an IGCC system, fuel gas, which is composed of hydrogen and carbon oxides, is generated in a gasifier by coal reacting with steam and air or oxygen. The pressurized fuel gas is then cleaned and fed to a high-efficiency combustion gas turbine/generator. The hot gas turbine exhaust gas is then passed through a heat 
exchanger to produce steam to drive a steam turbine/generator. More than 99 percent of the coal's sulfur and particulate contaminants are to be removed from the gaseous fuel by gas cleanup processes before being burned in the gas turbine. In the PFBC process, jets of air in a fluidized bed suspend a mixture of coal and limestone or dolomite during combustion, converting the mixture into a suspension of red-hot particles that flows like a fluid. The limestone captures sulfur oxides that are released by the burning of coal.

Particulate removal for PFBC and IGCC applications differ in particle morphology and process conditions. In the PFBC application shown in fig 1.1(b), two particulate-removal systems are required: one for the combustor and one for the partial gasification process. In the combustion application, particulate loading will range between 5,000 and 12,000 parts per million by weight, with a mean particle size between 7 and 10 micrometers [1]. Particulates evolving from IGCC and partial gasification of advanced PFBC systems vary dramatically in characteristics. IGCC-produced particles or char tend to be smaller ( 2 to 5 micrometers), less spherical, and less cohesive than PFBCproduced dust. The smaller non-spherical particles produce a higher resistance to flow when collected on a filter. The lack of cohesive forces between the collected particles can produce re-entrainment during filter cleaning. [1].

IGCC filter system particulate loading varies widely with gasifier type and char recycle arrangements but generally range from 1000 to 4000 parts per million weight. In IGCC systems, the operating pressures can be two to four times higher than the PFBC operating pressures, resulting in higher pressure requirements for filter cleaning blowback gas. IGCC filters will typically be smaller than PFBC filters per unit of energy produced due to the higher system pressures. In IGCC applications, filtration 
temperatures are usually lower, 1000 to $1200^{\circ} \mathrm{F}\left(595^{0}\right.$ to $\left.650^{\circ} \mathrm{C}\right)$. The chemically reduced and lower-temperature conditions of IGCC systems are not as detrimental to the ceramic filter materials when compared to the higher PFBC temperatures of 1500 to $1600^{0} \mathrm{~F}\left(815^{0}\right.$ to $\left.870^{0} \mathrm{C}\right)[1]$.

Today, ceramic barrier filtration is the leading technology that is being employed for high temperature gas particulate removal at temperatures of the order of about 1500 ${ }^{0} \mathrm{~F}$. Ceramic barrier filter devices currently under development include candles, crossflow, tubes and granular beds. Ceramic filter materials that are used in the manufacturing of porous hot gas filters include [3]:

(A) Oxides such as alumina/mullite $\left(\mathrm{Al}_{2} \mathrm{O}_{3} / 3 \mathrm{Al}_{2} \mathrm{O}_{3} \cdot 2 \mathrm{SiO}_{2}\right)$, cordierite and aluminosilicate foam;

(B) Non-oxides such as clay bonded silicon carbide ( $\mathrm{SiC}$ ), and reaction bonded or sintered silicon nitride and

(C) Metals such as Iron-Aluminite

Today, the most popular type of ceramic filters is the candle filter, which is usually in the form of a long cylindrical tube. Figure 1.2 schematically shows a Westinghouse hot gas filter system [3]. The system consists of a refractory lined, pressure vessel that contains arrays of the ceramic filter element assemblies. The arrays are formed by attaching individual candle elements to a common plenum and discharge pipe. The arrays are cleaned from a single pulse nozzle source. The hot (\& dirty) gas enters the side of the vessel radially and flows through the candle elements and the tube sheet. The dust is retained on the outer surface of the element and the clean gas exits the unit from the top of the vessel head. The elements are cleaned by a reverse pulse of air in 
combustion gas filter systems. This gas (air) comes from a pressure vessel located outside the filter vessel. The pulse gas is directed axially down the inside of the filter elements.

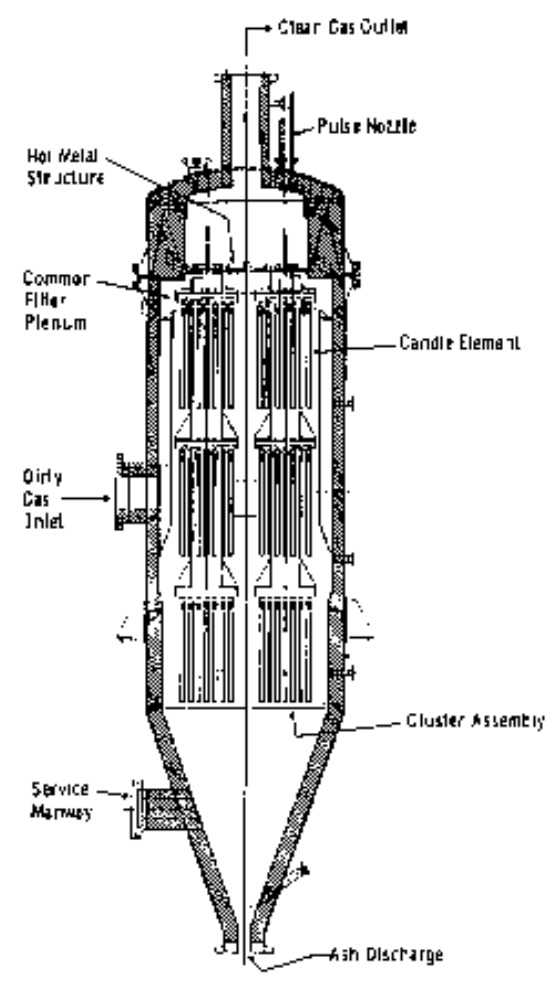

Figure 1.2 Westinghouse candle filter system concept [3]

The dislodged dust cake then falls down the vessel and into a collection hopper, not shown in the figure.

Ceramic barrier filters in general, and candle filters in particular, have excellent cleaning capabilities. In fact, hot gas filtration using rigid porous ceramic filters has demonstrated dust removal at high efficiency and an acceptable pressure loss [4]. However, these filters also have certain drawbacks. One of the main problems associated with them is the long-term build up, or accumulation of residual ash and other undesirable particulate matter. Dust accumulates on the outside of the candles, and is periodically removed by a pulse of air into the candle interior, which then flows outward 
through the candle wall in the reverse direction to the normal flow of the combustion gas. However, the entire dust cake is not blown off by the pulse jet, leaving behind a residual layer.

Stringer and Leitch [4] conducted extensive tests on a pilot hot-gas particulate removal system, based on positive porous ceramic candle filters, on the Grimethorpe Pressurized Fluidized Bed Combustor facility. The amount of gas flowing through each filter element was varied, and the time between cleaning pulses also was varied. The pressure drop through each filter element rose as the dust accumulated on the outer wall, and was recovered after the cleaning pulse. However, the post-cleaning pressure drop does not recover to the original clean candle value, but rather increases with time.

Further, on several occasions during the blow-back operation, combustion of the collected dust has occurred within the filter chamber not only in the dust accumulations in the collection hopper, but also on the ceramic element surfaces, giving rise to what are termed as 'filter fires' [5].

Therefore, successful application of ceramic filters in hot gas filtration for advanced power generation systems is dependent on a stable cleaning of the filter elements by the back pulse jet cleaning. Sufficient amount of cake should be removed during the pulse cleaning event otherwise, this excessive ash accumulation leads to abnormal pressure drops and bridging, and in the long run will affect the performance of the power plant.

The optimization of the back-pulse jet cleaning process is thus an important aspect for a stable cleaning of filter elements. Among other things, this requires a good 
understanding of the mechanism of the formation of residual ash on the filter, and the subsequent development of strength in these deposits.

\subsection{Research Objective}

The objective of this research is to develop a preliminary understanding of the development of residual ash deposits on ceramic candle filters. The research focuses primarily on the potential combustion of unburned carbon in the accumulated dust on the candle filter wall and it's possible consequences on strength development of the residual ash.

First, a conceptual model was formulated. This model outlined the system to be analyzed and illustrated the different phenomena being considered in the system. Then, a basic heat transfer model was formulated in order to estimate the temperature distribution as a function of both time and position, across the system.

A chemistry model was then developed, in order to estimate the amount of unburned carbon in the ash deposit on the filter wall. This model takes into consideration the chemical composition of the coal being burnt, and the addition of sorbent particles that react with the gas phase contaminant.

In order to obtain an estimate of the local temperature rise in the ash deposit due to this combustion, the heat generation term in the previously formulated heat transfer model is formulated in terms of the combustion of the unburned carbon. A numerical approach was used to generate a solution. Factors taken into consideration include not only the initial temperatures in the filter and the deposit, but also effects of mass flow during blow-back, and heat generated in the deposit due to combustion. A second 
numerical model was also developed in order to study the temperature drop in the system once the blow-back operation is complete and normal filtration operation is resumed.

Finally, a model to estimate the times required for sintering to occur in the ash deposits was developed. These times were then related to the temperature history in the ash deposit, in order to examine the potential for sintering. 


\section{CHAPTER 2}

\section{LITERATURE REVIEW}

\subsection{Review of filter literature}

\section{Hot Gas Cleanup}

The purpose of advanced power generation systems is to improve the efficiency of thermal to electrical conversion of the existing coal-fired power stations. Pressurized Fluidized Bed Combustion (PFBC), and Integrated Gasification Combined-Cycle (IGCC), are two examples of new generation advanced coal-fired power plants. Other concepts being developed are: incorporating combustion turbines in a coal-fueled combined cycle for Advanced Pressurized Fluidized Bed (APFB), and Direct Coal Fired (DCF) technologies. These systems will achieve an estimated efficiency ranging from 45 to $52 \%$ [6]. However, all components must perform as desired. This is especially true for the high temperature filters.

The benefits of cleaning gases at high temperatures and pressures derive from combined-cycle concept, wherein temperature and pressures of the gasifier, combustor and turbine are matched. This approach requires the gasifier and cleanup system temperatures and pressures to be compatible with the turbine system while simultaneously meeting fuel specifications. Cost and environmental concern are minimized through this temperature and pressure compatibility. Hot gas cleanup improves overall system efficiency leading to production of more power by burning less coal. 
Simultaneous high temperature and high pressure conditions present serious challenges to the commercialization of gas cleanup technologies because of;

1. The limited choices available in the selection of materials that can provide protection from high temperature erosion and corrosion

2. The lack of adequate design data to allow for thermal embrittlement of internals and resistance to thermal shock, and

3. The potential long term loss of strength due to high temperature and cyclic operation.

Several hot gas cleanup devices have been under development to perform this particulate collection under very hostile conditions. Future commercial success of high efficiency power generating systems will ultimately depend on the performance and reliability of these devices.

\section{Particulate collection at high temperature and high pressure}

Many different types of particulate collection devices are being developed for applications in advanced power generation systems. Some of the prominent ones are [6]:

1. High performance mechanical collectors

2. High efficiency barrier filtration filters

(a) Bag filters

(b) Ceramic candle filters

(c) Ceramic cross flow filters

3. Electrostatic precipitators

4. Sonic agglomerators

5. Electrostatic agglomerators 


\section{Mechanical Collectors}

Mechanical collectors such as cyclones utilize the inertial separating force on the particles resulting from high velocity axial or tangential entry of flue gas into the collector vessel. The inertial force drives the particles to the collector walls, and its magnitude is dependent on the particle size. The commercial practice of high temperature high pressure cyclones has been made especially in the collection of catalytic dust ahead of single stage gas expanders in fluid catalyst cracker applications. The cyclones are considered to be the most reliable and least expensive of most other devices, although they are least efficient in terms of collection of fine particulates.

The collection efficiency of cyclones suffers for size ranges below 5 to 10 microns because of the rapid decrease of inertial forces. Experience with PFBC applications suggests that it is difficult to limit the overall particulate loadings below 100 to $200 \mathrm{ppm}$ ahead of the gas turbine at practical tangential velocities around 70 to 90 feet/second [6]. Both the operating pressure drop and materials erosion become objectionable beyond these velocities.

Additional particulate control is therefore necessary to meet the environmental requirements.

\section{Barrier Filtration}

In barrier filtration devices, there is a mechanical medium between the dirty and clean gas. Fabric filters, cross-flow filters, and candle filters are the most widely studied barrier filtration devices. As the filtration process continues, the cake layer builds up on 
the filters which also increases the pressure drop across the filter. At a certain point of peak acceptable pressure drop, some type of cleaning is necessary to restore the original pressure drop. Conventional techniques such as reverse gas or shake deflate cleaning are not suitable because of the need for isolation of filters in compartments at high temperature and high pressure. Reverse gas flow cleaning requires complex piping and is not practical for high pressure and high temperature applications. On-line pulse jet cleaning is the only practical technique available. Pulse jet cleaning appears to be the only cleaning technique employed in all the test programs on barrier filtration designs.

In pulse jet filtration, the dirty flue gas enters from outside of the bags. High pressure compressed air is used in short bursts of pulses from the clean, inside of bags or candle tubes to dislodge the cake for subsequent gravity transport down into the hopper. Dusts with strong cohesive properties will be more difficult to remove, and tend to require higher pulse jet pressure and increased frequency of cleaning. The wear and tear on the bags, or tubes in the case of candle filters is influenced by the cleaning cycle and it's intensity.

\section{Fabric Filtration}

Particulate collection in the case of fabric filtration process occurs initially by interception and impaction on the bag fibers which act as the barrier. Subsequent filtration occurs on the dust cake itself which typically has smaller interstitial pores than the bag weave. Conventional fabrics such as fiberglass utilized in commercial bag-house installations are limited to a temperature of $260{ }^{0} \mathrm{C}\left(500{ }^{0} \mathrm{~F}\right)[6]$. Fabric materials utilized 
for PFBC applications are made of ceramic woven fabrics to resist flexural stresses at high temperatures.

Failure of bag filters has been observed [6] due to pulsed jet cleaning at $800{ }^{0} \mathrm{C}$ $\left(1472{ }^{0} \mathrm{~F}\right)$. Mechanical degradation of ceramic threads that were used to stitch the bag seams resulted in failure. The mechanical degradation was considered to be time and temperature dependent. Fabric degradation has also been caused when exposed to high temperatures. Frictional abrasion and reaction with constituents of flue gas are other reasons for the loss of strength.

Additional concerns are the ability to clean the fabric over the long term, and the impact of cleaning pulses of compressed air on bag life and pressure drop.

\section{Ceramic Cross Flow Filters}

Figure 2.1 [6] shows the schematic of a ceramic cross-flow filter. The construction of the ceramic cross flow filter is significantly different from the candle filters. The arrangement of the porous parallel plates forces the gas upwards through the porous layer where filtration takes place. Clean gas moves upward and out in a direction perpendicular to the entering dirty gas flow. Failure of dust seals installed between the filter body and the mounting flange has been observed. Delamination of the filter body has also been a consistent occurrence. Further, results of other test programs on gasifiers revealed crushed corners and longitudinal cracks on cross flow filter bodies. Because the design of cross-flow filter elements involve many sharp corners, stress concentration is considered to be especially severe at these places, making them vulnerable to localized failures. 


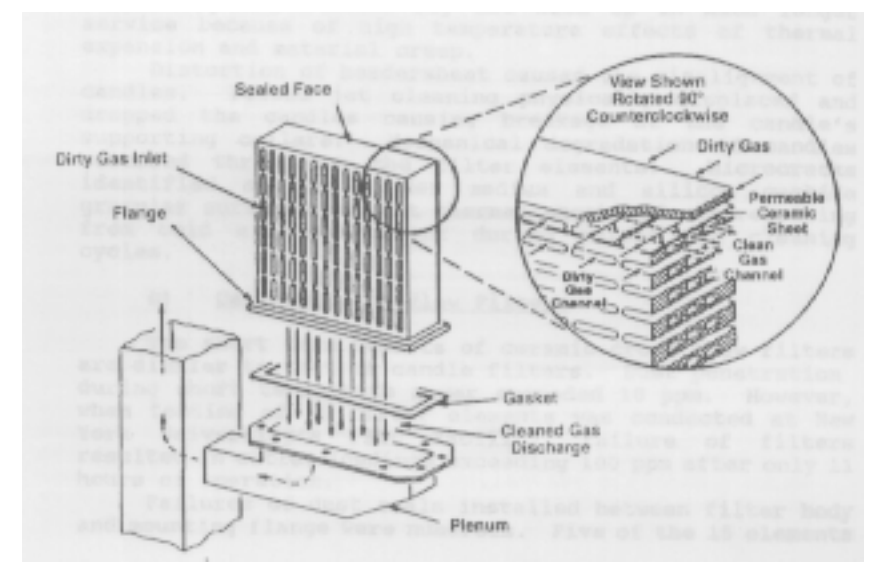

Fig 2.1 Schematic of a ceramic cross-flow filter

\section{Candle Filters}

Candle filters are generally long cylinders closed at one end and open at the other end. The open end is usually flanged to allow the mounting of the candle on a header plate. Porous ceramic candle filters are commercial manufactured from clay bonded silicon carbide, and alumina/mullite. The use of aluminosilicate fibers, clay binded alumina, fireclay, recrystallized silicon carbide, chemical vapor infiltrated alumina or silicon carbide, and continuous fiber ceramic composites for candle filters are under development [2]. They rely less on the formation of dust cake and more on a barrier itself for filtration. These filters are relatively stable at high temperatures and can operate continuously at temperatures of up to $1000{ }^{0} \mathrm{C}$. They are inert to aggressive chemicals like steam and acid gases. The collection efficiency of candle filters is very high but in time, mechanical degradation of candles has occurred throughout the filter elements. Failure of candle filters was observed due to internal ceramic reactions, creep and thermal shock [6]. 
During filtration, dirty gas flowing inwards, along the inner clean side of the candle and out of the plenum chamber. Dust is deposited on the outer candle surface and builds up into a cake, which is periodically detached by a reverse pulse of gas. The usefulness of the filter in practice does not depend significantly on the efficiency with which it removes incoming particles, this is close to $100 \%$. It depends to a much greater extent on its long term pressure drop history which is shown in Figure 2.2. After each cleaning pulse, the resistance to flow decreases to it's residual value. During this period, a residual layer of dust builds up on the surface of the filter. This layer may have a different composition or void fraction from the rest of the filter cake and may not be removed by the cleaning pulse. When cleaning occurs, the filter cake therefore detaches from a layer of deposited dust rather than the filter itself. While the residual layer is probably essential to prevent penetration of dust into the medium, it is important that it does not build up so much as to cause intolerably high operating pressure drops. Therefore, the filter pulse cleaning system should be sufficiently effective to remove the filter cake, but not to remove all of the residual layer, or to re-disperse the dust cake so that it simply goes back onto the filter cleaning [7].

\section{Filter fires}

Another problem associated with barrier filters has been instances of flaming of filters, during the cleaning operation. A paper by Jones and Rogers [5] describes tests conducted on a low density ceramic filter at Coventry Homefire works, in which it has been mentioned that on several occasions during the operation of the filter, combustion of the collected dust occurred within the filter chamber. These involved not only the burning 


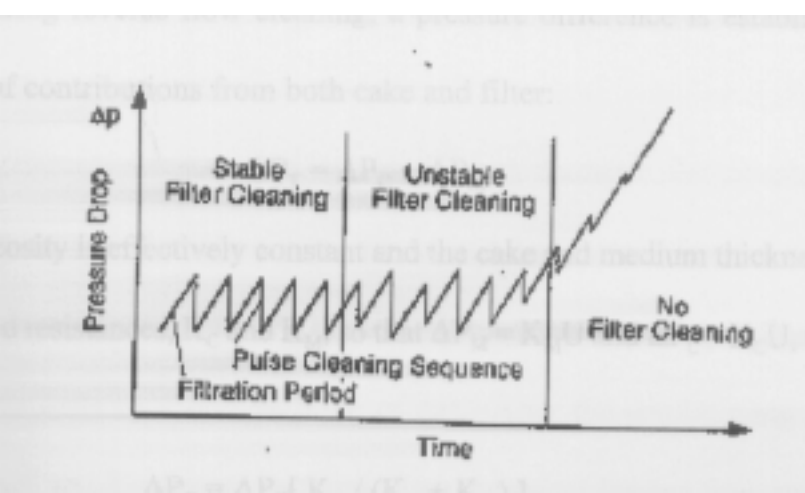

Figure 2.2 Idealized pressure drop [21]

of dust accumulations in the collection hopper, but also, combustion of dust on the ceramic element surfaces. As a result of two particularly intense fires, sintering of the ash on the ceramic elements took place. As the ash sintering phenomenon had occurred during boiler soot-blowing and at higher than normal firing rates, it was concluded that a combination of extremely high dust burdens with a high carbon content and higher than average gas temperatures were the cause of the ignitions. The constant passage of compressed air was thought to have supplied the necessary oxygen for combustion to take place.

\section{Electrostatic Precipitators}

Electrostatic precipitators have been used for particulate collection in coal and oil fired power plant applications for more than 50 years [6]. Current applications have been limited to atmospheric pressure, at temperatures between 121 to $427{ }^{0} \mathrm{C}\left(250\right.$ to $\left.800{ }^{0} \mathrm{~F}\right)$.

Electrostatic precipitation utilizes the forces acting on electrically charged particles in the presence of an electric field to effect the separation of solid or liquid aerosols from a gas stream. In the precipitation process, dust suspended in the gas is electrically charged and passed through an electric field where electrical forces cause the 
particles to migrate toward the collection electrode where they are subsequently removed from the precipitator. The three basic operations are charging, collection, and removal [6].

Some of the materials problems associated with high pressure high temperature electrostatic precipitators (ESP) are;

1. Because ESP internals for PFBC applications are made of steel and not ceramic, designs must consider high strength steels that will withstand the mechanical stresses at operating conditions. Poor choice of materials in early pilot programs have resulted in material warping and poor inter-electrode clearances [6].

2. Allowance has to be made in the design for thermal expansion of materials exposed to high temperature. Thermal expansion of steel resulted in earlier designs which did not include this allowance, leading to serious buckling of header-sheet, resulting in deflection of collector tubes and attendant precipitator performance problems.

3. Proper design of high voltage insulator assembly is critical for the success of the ESP operation. Alumina insulators with at least $90 \%$ alumina content are recommended. Because these insulators can function adequately at exposure temperatures only up to $426{ }^{0} \mathrm{C}\left(800{ }^{0} \mathrm{~F}\right)$, care must be taken to locate these insulators away from the gas stream and cooled to assure that temperatures are limited to safe operating levels.

\section{Agglomeration concepts}

Agglomeration concepts are geared to improve the performance of high efficiency cyclones. By the application of external forces such as sonic or electric fields, interparticulate contact is established in the agglomerator. Subsequent growth of fine 
particulates through inter-particulate contact is essential for the success of agglomeration concepts. For successful agglomeration, the particulates have to be sticky or molten enough for cohesive growth to take place. Further, the larger aggregates must be robust enough to withstand the mechanical forces experienced in a cyclone operating with tangential velocities in the range of 70 to 90 feet per second. Such velocities would be necessary for achieving high particulate control efficiencies to meet strict environmental compliance limits.

\section{Sonic Agglomeration}

In a sonic agglomeration, an air siren is used to generate high frequency sound waves at 800 to 900 cycles per second, and at amplitudes up to $157 \mathrm{~dB}$. Tests conducted at Pennsylvania State University on re-dispersed PFBC flyash confirmed the feasibility of the sonic agglomeration concept [6]. Particulate growth due to sonic agglomeration was significant at .1 to 10 micron sizes.

\section{Electrostatic Agglomeration}

In the concept of electrostatic agglomeration, both particle collision and particle adhesion are utilized to the fullest extent possible. The ElectroStatic Agglomerator (ESA), performs the following functions necessary for effective removal of particulate matter:

1. Promotes inter-particle contact by particle charging and particle migration to a collection surface 
2. Provides a collection surface for adhesion by electrical, capillary and molecular forces

3. Utilizes a smaller volume, as compared to an ESP, and a high velocity gas to scour the surface of the collection electrode so that agglomerates can be captured downstream by a cyclone. 


\subsection{Review of heat transfer in porous media}

\section{Introduction}

Porous materials have become increasingly attractive for application in such structures as high-temperature heat exchangers, conduits for transporting hightemperature fluids, turbine blades, rocket nozzles, etc. These applications are chiefly stimulated by the lack of commercially available materials suitable for sustained operation at elevated temperatures, and the general inadequacy of the method of cooling, in which a solid is in contact with a cooling fluid on only one or more of it's face surfaces. In practice, the cooling of porous structures is accomplished by forcing a liquid or gas through the capillary passages of the solid materials. With this type of cooling, referred to as 'porous cooling', the specimen is maintained at a low temperature because it is essentially flooded with the coolant, and therefore a larger proportion of the cooling fluid is in wetted contact with the solid than is possible when the coolant is in contact with only the face or free surfaces of the structure.

For the analysis of solid-fluid heat transfer by porous cooling, the actual heterogeneous network of pores is replaced by a simple equivalent system consisting of identical and parallel cylindrical passages or channels which serve to transport the coolant through the porous structure. Further, it is also assumed that all heat conducted in the interior of the specimen takes place in the solid portion only. Weinbaum and Wheeler [23] have demonstrated on the basis of these assumptions that solid and coolant temperatures are nearly indistinguishable throughout the porous structure. With this 
result, the analysis is greatly simplified if solid and coolant temperatures within the specimen are assumed equal.

\subsection{Review of ash chemistry literature}

From the beginning of the application of combustion of fossil fuels for the production of power, much attention has been devoted to the problems created by the residues of such combustion, broadly known as "ash" [9]. When burned, all but a few fuels have solid residues and in some instances the quantity is considerable.

For continuous operations, removal of ash is essential to all methods of firing. In stoker firing with a fuel bed, this is accomplished by the intermittent shaking or dumping of grate sections or by the continuous movement of the ash residue toward a point of discharge. In suspension firing, the ash particles are carried out of the furnace by the gas stream or retained in part by settling or by adhering to boiler surfaces. Retained material of solid form is removed by periodic cleaning. If temperatures are sufficiently high, the retained ash is molten and may be drained continuously from the furnace. Some of the ash may form deposits of slag on the furnace walls (slagging), and a portion of the ash that is carried from the furnace by the flue gases may form deposits on the tubes in the gas passes (fouling). Also, under some conditions, the deposits may lead to corrosion of these surfaces [9].

The nature and the amount of ash in the fuel to be used are, therefore, of major concern to the designer and the operator. 


\section{Ash content of coal}

The ash content of coal varies over a wide range [9]. This variation occurs not only in coal from different parts of the world or from different seams in the same region, but also in coal from different parts of the same mine. Further, before marketing, some commercial coals are cleaned or washed to remove a portion of what would be reported as ash in laboratory determinations. The ash determinations of significance to the user are those made at the point of use.

The bulk of bituminous coal used for power generation in the U.S has an ash content within the range of 6 to $20 \%$. Low values of 3 or $4 \%$ are encountered sometimes. On the other hand, some coals may have an ash content as high as 30\% [9]

\section{Nature of coal ash}

The term 'Inorganic components' is generally used to describe all ash-forming constituents, including both organically associated inorganic species and mineral grains. Since quantitative evaluation of mineral forms is extremely difficult, the composition of coal ash is customarily determined by chemical analysis of the residue produced by burning a sample of coal at a slow rate and at moderate temperature $\left(1350{ }^{0} \mathrm{~F}\right)$ under oxidizing conditions in a laboratory furnace. It is thus found to be composed chiefly of compounds of silicon, aluminum, iron, and calcium, with smaller amounts of magnesium, titanium, sodium, potassium and sulfur. Table 2.1 [10] lists the analyses of some coal ashes 


\begin{tabular}{|c|c|c|c|c|c|c|c|c|c|}
\hline \multirow{2}{*}{$\begin{array}{l}\text { Sample } \\
\text { number }\end{array}$} & \multicolumn{9}{|c|}{ Constituent weight percent by ash } \\
\hline & $\mathrm{SiO}_{2}$ & $\mathrm{Al}_{2} \mathbf{O}_{3}$ & $\mathrm{Fe}_{2} \mathrm{O}_{3}$ & $\mathrm{TiO}_{2}$ & $\mathrm{CaO}$ & $\mathrm{MgO}$ & $\mathrm{Na}_{2} \mathrm{O}$ & $\mathbf{K}_{2} \mathbf{O}$ & $\mathrm{SO}_{3}$ \\
\hline 2 & 59.6 & 26.7 & 4.2 & 3.4 & 2.3 & 0.7 & 0.8 & 0.1 & 1.8 \\
\hline 3 & 68.5 & 20.8 & 2.6 & 3.6 & 1.4 & 0.4 & 0.6 & $<0.1$ & 1.7 \\
\hline 26 & 17.5 & 9.2 & 64.1 & 0.4 & 4.1 & 0.4 & 0.3 & 1.0 & 1.8 \\
\hline 67 & 25.6 & 21.0 & 20.5 & 0.6 & 15.8 & 0.7 & 2.0 & 0.2 & 10.9 \\
\hline 124 & 42.0 & 26.5 & 7.5 & 1.2 & 7.9 & 1.6 & 1.2 & 1.6 & 9.5 \\
\hline 142 & 46.1 & 34.5 & 7.5 & 1.5 & 2.5 & 0.7 & 0.3 & 2.0 & 3.0 \\
\hline 143 & 19.4 & 10.5 & 36.6 & 0.4 & 8.9 & 5.8 & 0.4 & 1.1 & 15.9 \\
\hline \multirow[t]{2}{*}{2,3} & 29.2 & 14.2 & 27.8 & 0.5 & 7.1 & 5.1 & 0.6 & 1.5 & 14.0 \\
\hline & \multicolumn{4}{|c|}{ Origin } & \multicolumn{5}{|c|}{ Comments } \\
\hline $\begin{array}{l}2 \\
3\end{array}$ & \multicolumn{4}{|c|}{ Kentucky, Deane } & \multicolumn{5}{|c|}{ High in Silica } \\
\hline $\begin{array}{l}26 \\
67\end{array}$ & \multicolumn{4}{|c|}{$\begin{array}{l}\text { Illinois, Carrier Mills } \\
\text { Utah, Horse Canyon }\end{array}$} & \multicolumn{5}{|c|}{$\begin{array}{l}\text { Low in Silica, sample 26, exceptionally } \\
\text { high in Iron; sample } 67 \text { moderately high } \\
\text { in Iron and calcium }\end{array}$} \\
\hline $\begin{array}{l}124 \\
127\end{array}$ & \multicolumn{4}{|c|}{$\begin{array}{l}\text { West Virginia, Bickmore, } \\
\text { Pennsylvania, Ebensburg }\end{array}$} & \multicolumn{5}{|c|}{ Moderately high in Silica } \\
\hline 142,143 & \multicolumn{4}{|c|}{ Oklahoma, Redstone } & \multicolumn{5}{|c|}{ Low in Silica, exceptionally high in Iron } \\
\hline
\end{tabular}

Table 2.1 Composition of laboratory combustion ashes of bituminous coals and anthracites [10]

from various areas of the United States. The ash analyses do not always total 100\% since the analysis does not include all constituents.

The element sulfur is present in practically all coal. Sulfur itself burns as a fuel with a very low heating value (3980 $\mathrm{Btu} / \mathrm{lb}$ when burned to $\mathrm{SO}_{2}$ ) [9], but this is offset by the creation of operating problems, usually as the result of it's chemical combination with 
other elements. Some of the sulfur in coal is in combination with iron as $\mathrm{FeS}_{2}$. Sulfur may also be present in the form of complex organic compounds and, in minor amounts, in combination with alkaline earths (calcium and magnesium). When the fuel is burned, the sulfur compounds are normally converted to more or less stable mineral oxides and sulfur dioxide gas, $\mathrm{SO}_{2}$. A very small part of the $\mathrm{SO}_{2}$ thus formed is further oxidized to $\mathrm{SO}_{3}$. The sulfur gases are carried along with the other combustion gases, and their presence, under certain conditions contribute to corrosion of boiler heating surfaces and air pollution problems. A major significance of sulfur in the coal, and the subsequent formation of $\mathrm{SO}_{2}$ and $\mathrm{SO}_{3}$ is the effect on the environment.

\section{Ash fusibility}

Ash melts when heated to a sufficiently high temperature. Following combustion as in pulverized coal fired boilers, individual ash particles are generally in the form of tiny spheres (cenospheres) that appear hollow when viewed under a microscope, as shown in Fig 2.3 [9]. The form of ash particles indicates that during combustion of the coal, the particles were actually liquid and the hollow spheres were formed by tiny bubbles of evolved gases trying to escape. What happens to these particles depends on their physical and chemical characteristics and on furnace conditions. If cooled promptly and sufficiently, the result is a dusty ash that may travel through the equipment, lodge on heating surfaces, drop out in soot hoppers and along flues, or collect at the base of the stack. Those particles that remain in suspension are carried out with the flue gases to the particulate-removal equipment and stack. The individual ash particles do not, however, always cool quickly to a solid state. If insufficiently cooled, they remain molten or sticky 
and tend to coalesce into large masses in the boiler furnace or other heat-absorption surfaces. This problem is dealt with by adequate design of burners and furnace arrangement for the fuels to be burned and by proper attention to boiler operation.

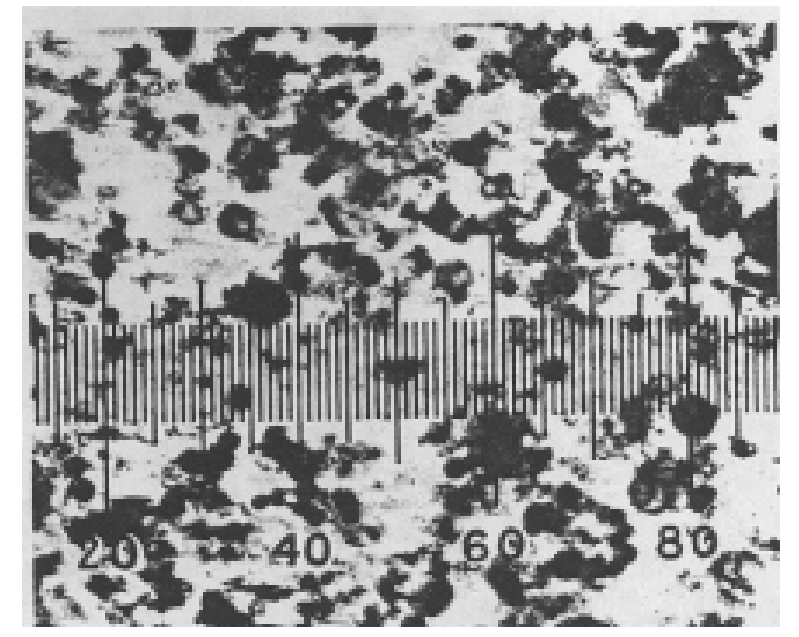

Fig 2.3 Ash cenospheres formed in burning pulverized coal [9]

The ASTM standard D-1857 outlines the following definitions for ash-fusibility determination [9]:

1. Initial deformation temperature, at which the first rounding of the apex of the cone occurs.

2. Softening temperature, at which the cone has fused down to a spherical lump in which the height is equal to the width at the base.

3. Hemispherical temperature, at which the cone has fused down to a hemispherical lump at which point the height is one half the width of the base.

4. Fluid temperature, at which the fused mass has spread out in a nearly flat layer with a maximum height of one-sixteenth inch. 


\section{Viscosity of coal-ash slag and Acid-Base ratios}

Measurement of viscosity of coal-ash slags provides reliable data that can be used

for determining suitability of coals for use in slag-tap type boilers. Since viscosity measurements require a considerable amount of coal ash that may not be readily available and, in addition, are costly and time consuming, it is desirable to calculate viscosity from chemical analysis of the coal ash.

The constituents of a coal ash can be classed as either basic or acidic. Basic constituents are the $\mathrm{Fe}_{2} \mathrm{O}_{3}, \mathrm{CaO}, \mathrm{MgO}, \mathrm{Na}_{2} \mathrm{O}$ and $\mathrm{K}_{2} \mathrm{O}$. The acidic constituents are $\mathrm{SiO}_{2}$, $\mathrm{Al}_{2} \mathrm{O}_{3}$ and $\mathrm{TiO}_{2}$. Laboratory studies have shown that the relative amounts of the basic and acidic constituents in the ash can be used as a means of predicting the viscosity of the slag, as shown in Figure 2.4[9]. The viscosity of a slag decreases as the base-to-acid ratio increases to 1.0.

$$
\frac{B}{A}=\frac{\mathrm{Fe}_{2} \mathrm{O}_{3}+\mathrm{CaO}+\mathrm{MgO}+\mathrm{Na}_{2} \mathrm{O}+\mathrm{K}_{2} \mathrm{O}}{\mathrm{SiO}_{2}+\mathrm{Al}_{2} \mathrm{O}_{3}+\mathrm{TiO}_{2}}
$$

This correlation takes into account the $\mathrm{SiO}_{2}$ to $\mathrm{Al}_{2} \mathrm{O}_{3}$ ratio, which has an effect with slags having a low base-to-acid ratio. For bituminous type coal ash and for lignite type coal ash having an acidic content in excess of $60 \%$, the base-to-acid ratio method is used in preference to the silica-ratio method to estimate the viscosity.

\section{Effect of Iron on ash behavior}

Coals having bituminous-type ash usually contain Iron and its compounds as a principle component. The iron may exist in more than one state, i.e., metallic $(\mathrm{Fe})$, ferrous $(\mathrm{FeO})$ or ferric $\left(\mathrm{Fe}_{2} \mathrm{O}_{3}\right)$. The $\mathrm{Fe}_{2} \mathrm{O}_{3}$ representing the sum of $\mathrm{Fe}, \mathrm{FeO}$ and $\mathrm{Fe}_{2} \mathrm{O}_{3}$ is expressed as $\mathrm{Fe}_{2} \mathrm{O}_{3}$. Iron has been found to have a dominating influence on the behavior of ash in the furnace. 
The specific effect of iron in coal ash is interesting. In completely oxidized form $\left(\mathrm{Fe}_{2} \mathrm{O}_{3}\right)$, iron tends to raise all four values of ash fusion temperatures namely initial deformation, softening, hemispherical and fluid, while in the lesser oxidized form $(\mathrm{FeO})$, it tends to lower all four of these values. The effect of iron, in each of the two forms, on initial deformation and hemispherical temperatures is indicated in Fig. 2.5 [9], plotted for a large number of ash samples from US coals. The figure indicates that as the amount of iron in the ash increases, there is a greater difference in ash fusibility between oxidizing and reducing conditions. This effect may be negligible with coal ash containing small amounts of iron. Lignite type ash generally contains small amounts of iron and the ashfusion temperatures are affected very little by the state of oxidation of the iron in the slag. In fact, lignite type ash having a high basic content and high dolomite percentage may have ash fusion temperatures that are lower on an oxidizing basis than a reducing basis. Ash hemispherical temperatures and ash analyses of lignites appearing in Table 2.2 illustrate this effect. 


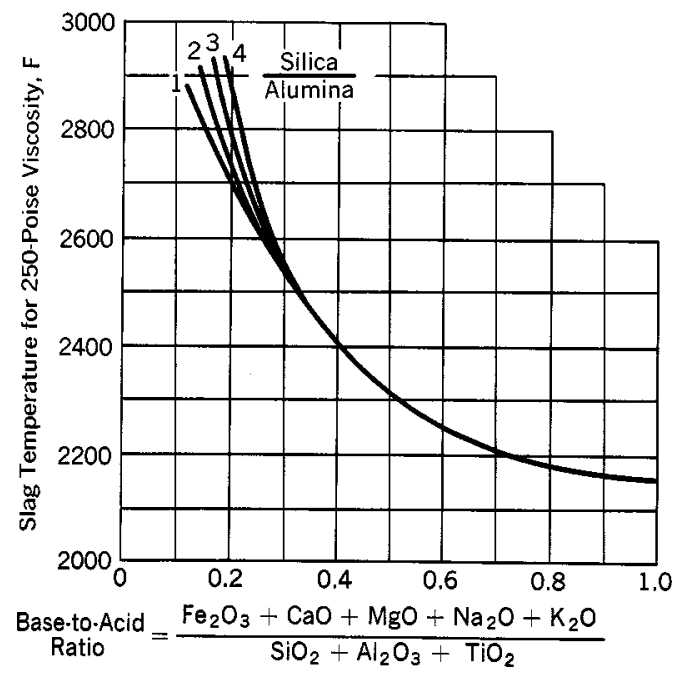

Fig 2.4 Plot of temperature for 250-poise viscosity versus base-to-acid ratio, based on a ferric percentage of 20 [9]
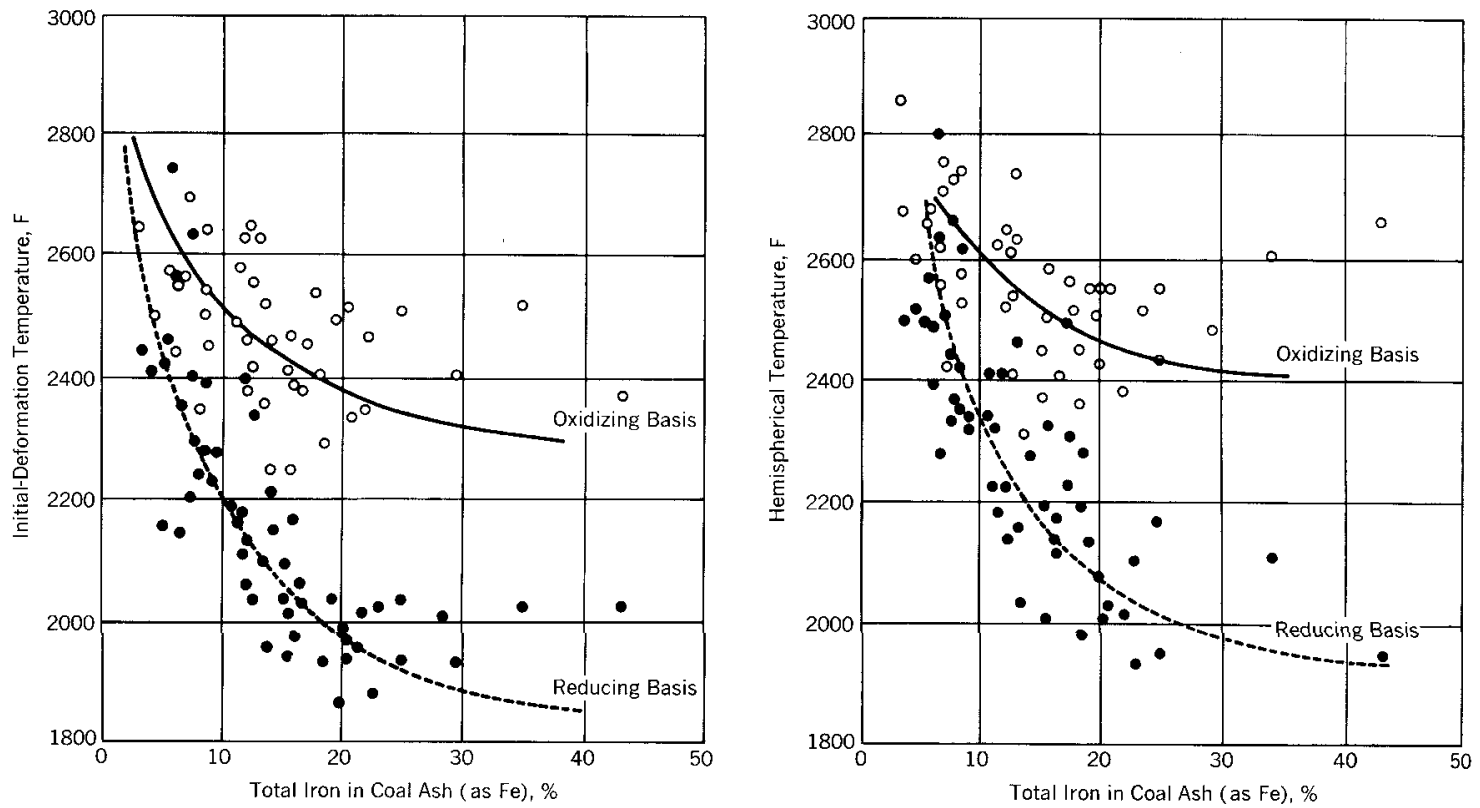

Figure 2.5 Influence of Iron on coal ash fusion temperature [9] 


\begin{tabular}{|c|c|c|c|}
\hline & Lignite-type ash-1 & Lignite-type ash-2 & Wood \\
\hline Ash, dry basis, \% & 5.0 & 6.0 & 1.0 \\
\hline Sulfur, dry basis, $\%$ & 1.0 & 1.0 & 0.1 \\
\hline \multicolumn{4}{|l|}{$\begin{array}{l}\text { Analysis of ash, \% } \\
\text { by weight }\end{array}$} \\
\hline $\mathrm{SiO}_{2}$ & 17.9 & 18.9 & 33.8 \\
\hline $\mathrm{Al}_{2} \mathrm{O}_{3}$ & 13.2 & 19.5 & 2.6 \\
\hline $\mathrm{TiO}_{2}$ & 0.5 & 0.6 & 0.2 \\
\hline $\mathrm{Fe}_{2} \mathrm{O}_{3}$ & 6.0 & 6.4 & 1.6 \\
\hline $\mathrm{CaO}$ & 59.7 & 40.8 & 56.5 \\
\hline $\mathrm{MgO}$ & 2.0 & 12.7 & 4.7 \\
\hline $\mathrm{Na}_{2} \mathrm{O}$ & 0.2 & 1.0 & 0.5 \\
\hline $\mathrm{K}_{2} \mathrm{O}$ & 0.5 & 0.1 & 0.1 \\
\hline Total & 100.0 & 100.0 & 100.0 \\
\hline \multicolumn{4}{|l|}{$\begin{array}{l}\text { Ash Fusibility- } \\
\text { Hemispherical } \\
\text { temperature, }{ }^{0} \mathrm{~F}\end{array}$} \\
\hline Reducing & 2680 & 2470 & 2580 \\
\hline Oxidizing & 2650 & 2470 & 2550 \\
\hline
\end{tabular}

Table 2.2 Comparison of ash from two lignites with wood ash [9] 


\section{CHAPTER 3}

\section{ANALYTICAL MODEL}

\subsection{Introduction}

The primary focus of this research is to develop an understanding of the problem of the formation of residual ash deposits on hot gas filtration systems. In particular, the potential of sintering occurring and contributing to the development of strength in the residual ash is being examined.

This chapter describes the rational employed in developing the basic model to understand the formation of residual ash. The following chapters describe in detail how the various quantities required for this model are determined. Chapter 7 then describes the analysis employed in combining the various quantities previously determined.

When coal undergoes combustion, the products of combustion are not only gaseous, but are also solid in nature. Further, the addition of suitable sorbents in order to remove $\mathrm{SO}_{2}$, results in the formation of more solid mater. When these gases are passed through a hot-gas filtration system, the solid products of combustion are deposited on the walls of a barrier filter. The extent of deposition depends on the coal-composition and the amount of sorbents added. Formation of the deposit increases the subsequent necessary pressure drop for the hot-gas filtration system which may reduce the efficiency of the power plant.

In order to remove the ash deposit, a high-pressure back-pulse of a gas is blown from inside of the filter, radially outwards. This operation is denoted as the surface regeneration process. This high-pressure pulse of gas is intended to dislodge the ash 
deposit from the walls of the filter. The most convenient gas to employ is air and in this study, only air is considered in the surface regeneration process.

In reality however, the surface regeneration process is not $100 \%$ effective and a residual layer of ash deposit remains on the filter. This residual ash layer usually grows with every cycle of operation.

In order to maximize the effectiveness of the surface regeneration process, a sound understanding of the mechanism of residual ash formation is needed.

When coal undergoes combustion, not all the carbon in the coal is consumed. A certain percentage of carbon remains unburned, and exists as a part of the deposit on the filter wall. During the surface regeneration event, if air is used, the oxygen concentration is at least two orders of magnitude greater than that in the products of combustion of coal. Hence, the unburned carbon in the deposit may now be combusted resulting in heat generation accompanied by a rise in local ash temperature. In this study, it has been assumed that all of the oxygen in the back-pulse air is consumed by the unburned carbon in the deposit. This region of combustion in the deposit is referred to as the 'reaction zone'. The remaining region of the soft ash deposit, in which there is no combustion, is blown off by the back-pulse air and is collected in an ash-hopper. Figure (3.1) schematically illustrates the surface regeneration event. The cycle continues with the reaction zone now becoming part of the residual layer, if sintering has occurred. The soft ash layer forms again during the filtration period and the new soft ash layer formed is assumed to be thicker than the reaction zone. 


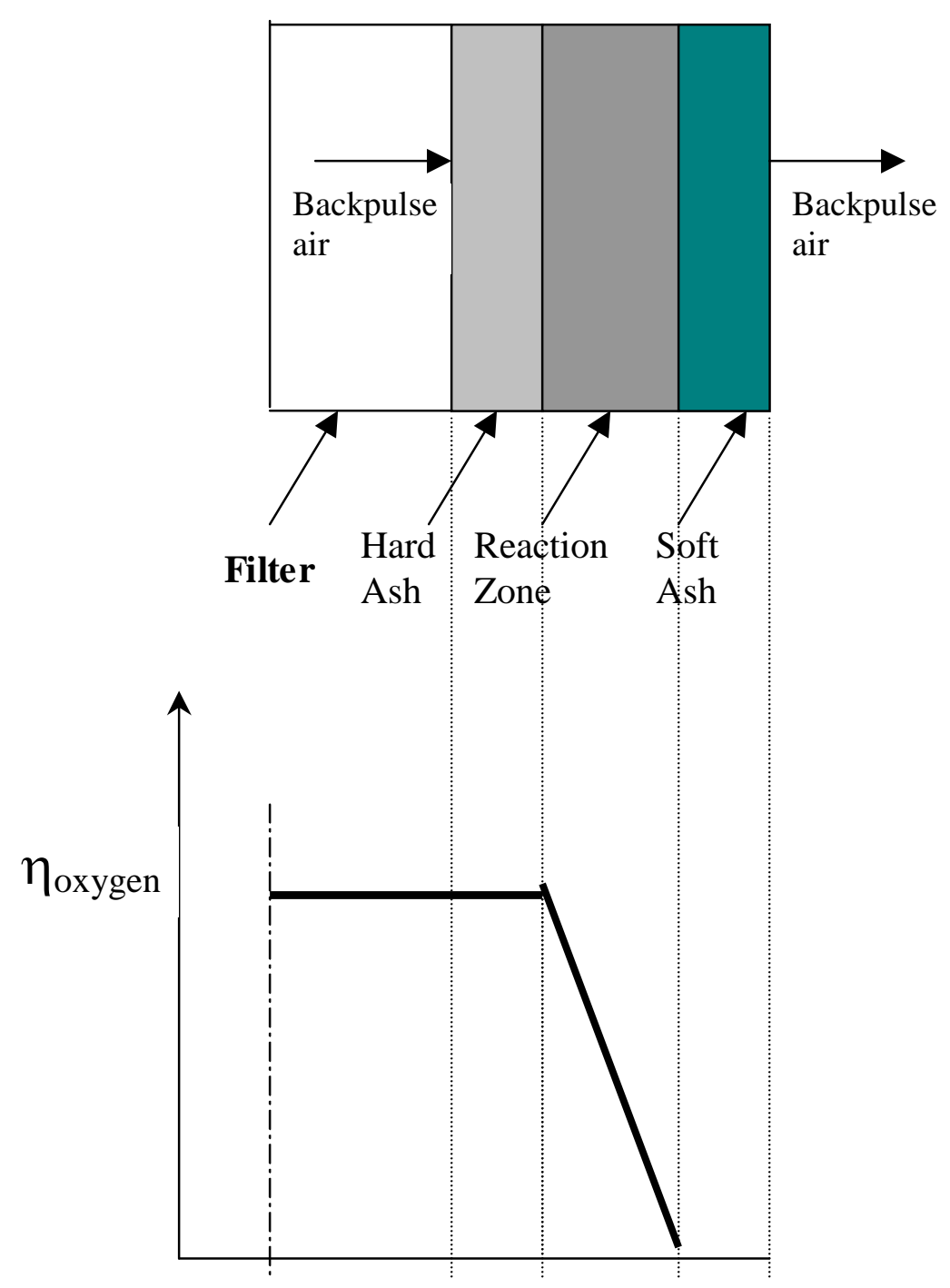

Fig 3.1 Schematic illustration of surface

regeneration event 
This heat generation in the ash deposit results in a local rise in deposit temperature. When the filtration operation is resumed, deposit temperatures will drop back to the operating temperature of the hot gases entering the filter chamber. However in the surface regeneration process, if high enough temperatures occur in the deposits for a sufficient period of time to cause sintering, then it is possible to identify sintering as the primary mechanism contributing to strength development in the residual ash.

There appears to be little information on the sintering of ash particles. The only appropriate data involves the strength of sintered bonds between particles that are kept at constant temperature. The strength of the bond is related to how long the particles have been kept at a constant temperature, particle size, viscosity of the collection of particles, and surface tension. This type of relationship does not take into account quantities that influence (or are effected) by temperature changes. With this information, it was concluded that if the strength of the bond was specified, then at a given temperature, the time required to reach the specified strength could be calculated. This time would be a maximum time because the ash particles reach higher temperatures than the given temperature before they return to the given temperature.

To illustrate this approach, consider the temperature history of the reaction zone as a function of time. A reference temperature in the reaction zone, ' $\mathrm{T}_{\mathrm{S}}$ ' is reached at time ' $\mathrm{t}_{\mathrm{b}}$ ' during the surface regeneration event. Reaction zone temperature is expected to climb to a peak value, ' $\mathrm{T}_{\max }$ ' at the end of the event. When the surface regeneration event is stopped and regular filtration operation is resumed, the temperature is expected to start dropping and reaches $T_{S}$ again, at a time $t_{f}$. Hence, the total time for which the layer sees a temperature of $T_{S}$ or higher is $(\Delta t)_{\text {actual }}=t_{f}-t_{b}$. In a similar way, for different 
temperatures, the corresponding values of $\Delta \mathrm{t}$ are calculated. These values of $\Delta \mathrm{t}$ represent the duration for which the corresponding temperatures should exist or be exceeded in the reaction zone.

The period of time required to achieve a specified bonding between particles at constant temperature $\mathrm{T}_{\mathrm{S}}$ is now calculated. The two time periods are now compared and a decision is made on the occurrence of sintering. This is illustrated in Figure 3.2.

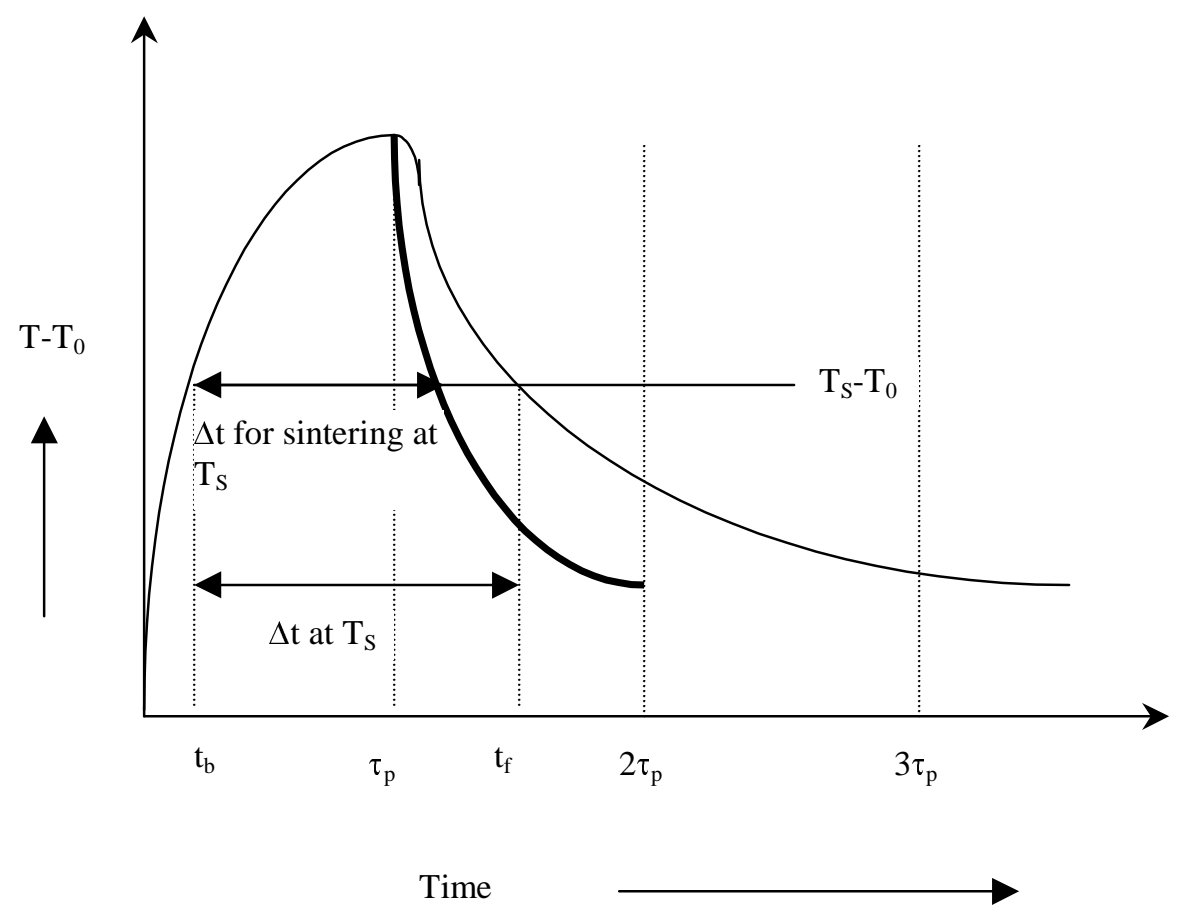

Figure 3.2 Expected temperature distribution in the reaction zone as a function of time

\subsection{Approach}

The approach is to first select the operating conditions for the filtering system. Quantities to be selected are face velocity, operating temperature, filter dimensions, 
operating pressures, surface regeneration period and filtering operation period (or allowable pressure drop across the filter).

Next, the coal composition, pollutant absorbents, percent air and percent unburned carbon must be selected to determine the flow rate of solids to the candle filter. The soft ash accumulated during the filtering time is calculated as well as the mass fraction of carbon in the ash.

The mass flow rate of the air for surface regeneration is then calculated assuming that the soft ash layer is present. This flow rate remains constant during the surface regeneration period. The mass of oxygen in this period is assumed to consume a stoichiometric amount of carbon. Using ash density values from the literature, the calculated mass fraction of carbon in the ash, the thickness of the reaction zone may be calculated. The volumetric heat generation rate may now also be calculated based on the enthalpy of combustion of carbon.

In the next step, a heat transfer analysis is carried out in order to estimate the temperature profile across the deposited ash. This heat transfer analysis takes into account heat generation in the ash and the mass flow during surface regeneration. A numerical approach to the heat transfer problem has been considered.

Finally, a simple sintering model is set up to examine the possibility of sintering occurring in the ash deposits. Properties of ash particles namely surface tension, particle size and viscosity are first selected. In this study, analysis is being made for a strongly sintered bond to occur. The times needed for such a degree of sintering to occur in the ash deposits are calculated as a function of temperature. These times are then compared with the times for which the ash deposits experience the corresponding temperatures. Based on 
this comparison, a conclusion is arrived at, regarding the occurrence of sintering in the ash deposits, to the selected extent. The overall scheme employed in this research is illustrated in Figure 3.4. The calculation procedure used is illustrated in Figure 3.5.

\subsection{Analytical model for heat transfer}

The present section presents a brief analytical discussion on the heat transfer model employed in this research and outlines a derivation of the characteristic differential equation governing the heat transfer in the system.

Since both the filter and ash are porous in nature, heat transfer in a porous solid with mass-flow and internal heat generation is analyzed.

For the porous solid shown in Figure 3.3, application of the first law of thermodynamics gives;

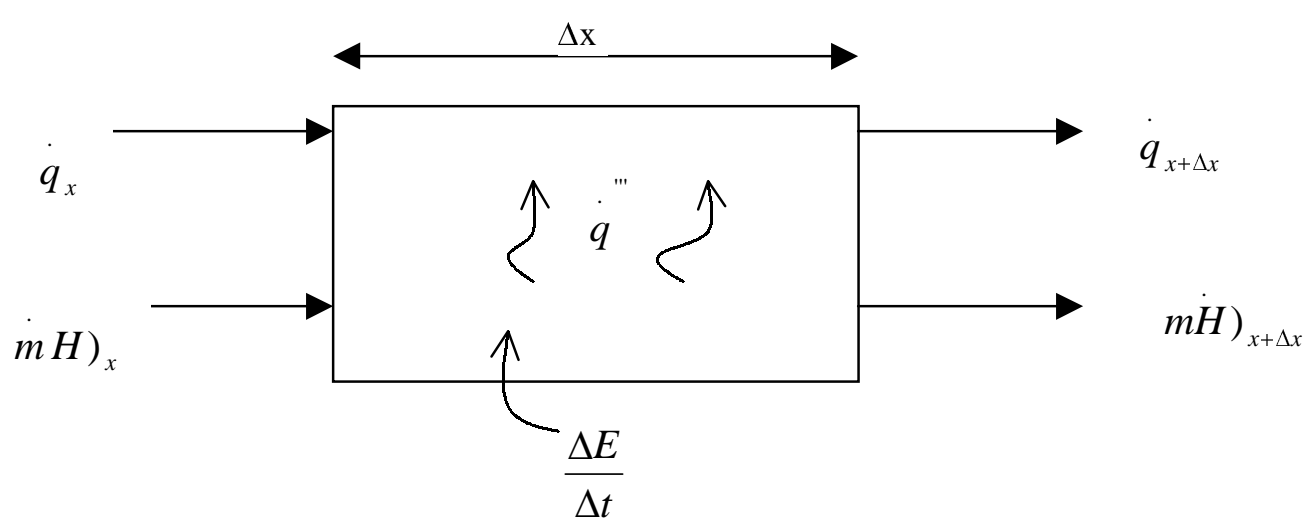

Fig 3.3 Representative element for heat transfer in the system 


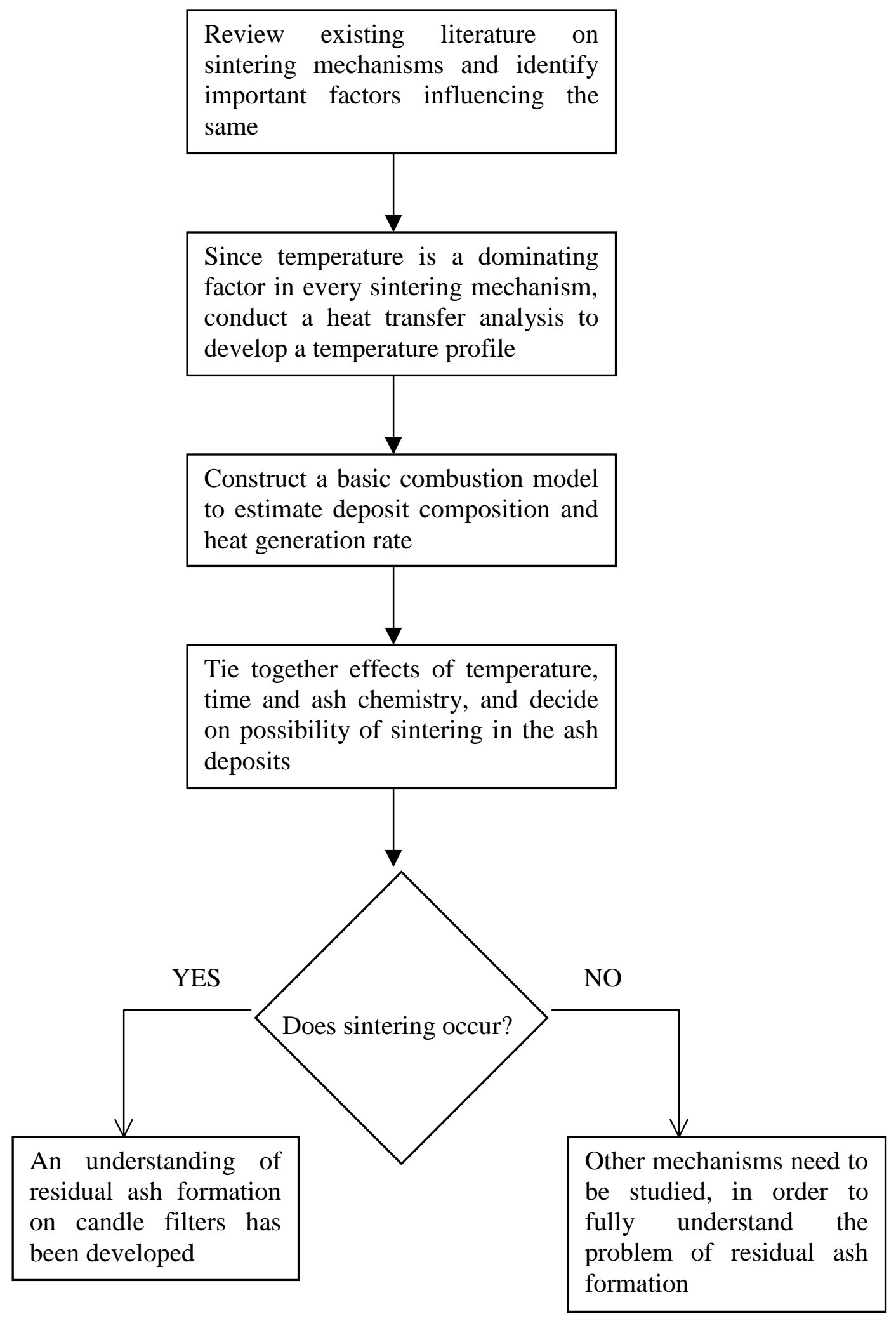

Figure 3.4 Flow-chart of approach used in the current analysis 


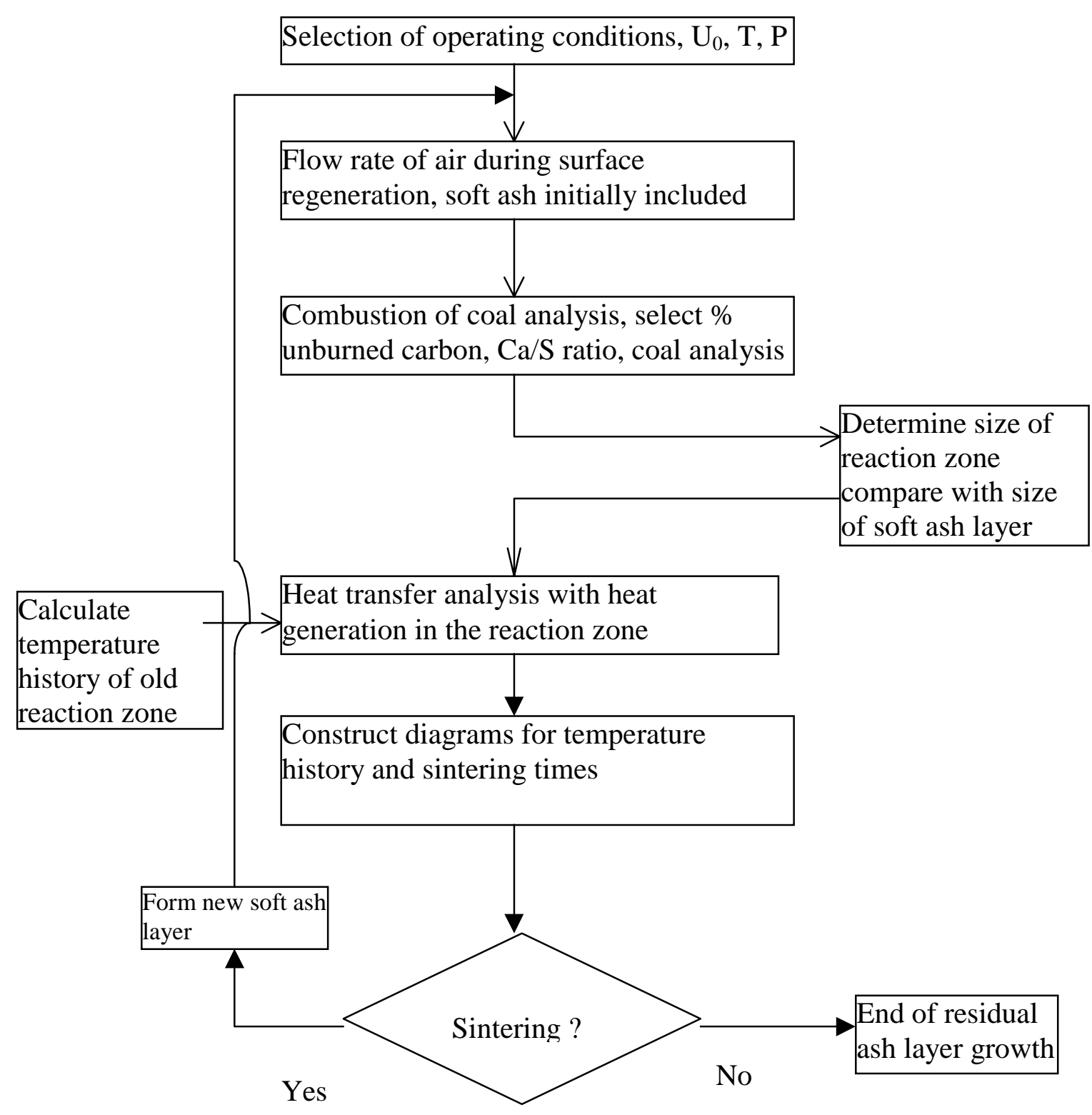

Figure 3.5 Calculation procedure 


$$
\left.\left.\dot{q}_{x}+\dot{m} H\right)_{x}+\dot{q} d V=\dot{q}_{x+\Delta x}+\dot{m} H\right)_{x+\Delta x}+\frac{\Delta E}{\Delta t}
$$

If ' $\varepsilon$ ' represents the porosity of the solid, then equation (3.1) can be expanded by applying the 'Fourier' law of conduction and rewritten as:

$$
\begin{aligned}
& \left.\left.-k A(1-\varepsilon) \frac{\partial T}{\partial x}\right)_{x}+m c_{g} \Delta T\right)_{x}+\dot{q} d V= \\
& \left.\left.-k A(1-\varepsilon) \frac{\partial T}{\partial x}\right)_{x+\Delta x}+m c_{g} \Delta T\right)_{x+\Delta x}+\left[\rho_{g} c_{g} \varepsilon+\rho_{s} c_{s}(1-\varepsilon)\right] d V \frac{\partial T}{\partial t}
\end{aligned}
$$

where,

$$
\begin{aligned}
& \mathrm{k}=\text { thermal conductivity of the porous solid } \\
& \mathrm{A}=\text { cross-sectional area for heat flow } \\
& \varepsilon=\text { porosity of the solid } \\
& \mathrm{m}=\text { mass-flow rate } \\
& \mathrm{c}_{\mathrm{g}}=\text { specific heat of the gas at constant pressure } \\
& \mathrm{c}_{\mathrm{s}}=\text { specific heat of the solid at constant pressure } \\
& \rho_{\mathrm{g}}=\text { density of the gas } \\
& \rho_{\mathrm{s}}=\text { density of the solid } \\
& q ",=\text { volumetric rate of heat generation }
\end{aligned}
$$

Dividing equation (3.2) by $\mathrm{dV}(=\mathrm{A} \Delta \mathrm{x})$ and simplifying we get, 
$\frac{k A(1-\varepsilon)}{A}\left[\frac{\left.\left.\frac{\partial T}{\partial x}\right)_{x+\Delta x}-\frac{\partial T}{\partial x}\right)_{x}}{\Delta x}\right]-\frac{m c_{g}}{A}\left[\frac{\left.\Delta T)_{x+\Delta x}-\Delta T\right)_{x}}{\Delta x}\right]+\dot{q}=\left[\rho_{g} c_{g} \varepsilon+\rho_{s} c_{s}(1-\varepsilon)\right] \frac{\partial T}{\partial t}$

Equation (3.3) can be simplified and written in the differential form as,

$k(1-\varepsilon) \frac{\partial^{2} T}{\partial x^{2}}-\frac{m c_{g}}{A} \frac{\partial T}{\partial x}+\dot{q}=\left[\rho_{g} c_{g} \varepsilon+\rho_{s} c_{s}(1-\varepsilon)\right] \frac{\partial T}{\partial t}$

Equation (3.4) represents the differential equation for heat transfer throughout the system, and is modified for:

1) Gases inside the filter

2) The porous wall filter

3) The residual ash

4) The reaction zone and

5) The gases to be filtered. 


\section{CHAPTER 4}

\section{DEVELOPMENT OF A NUMERICAL MODEL FOR HEAT TRANSFER}

\subsection{Introduction}

Numerical methods provide the basis for analyzing many complex heat transfer problems, including those involving conduction. The finite-difference method and the finite-element method are the two basic approaches generally used in numerical analysis. The finite-difference method has been made employed, in the current analysis.

The finite-difference approach involves the use of :

1) Nodal networks

2) Finite-difference approximations for derivatives in space and time

3) Standard energy conservation formulation concepts and

4) Computer solution of systems of algebraic nodal equations

During the surface regeneration, a high pressure pulse of a gas was used to clean the ceramic candle filter. In this research, the gas that has been employed was air. An initial ash deposit thickness, calculated using a computer program, was considered attached to the filter wall. The initial temperature of the filter, as well as the ash layer was $800^{\circ} \mathrm{C}$. The initial temperature of the back-pulse air was considered to be about $200^{\circ} \mathrm{C}$. A one-dimensional transient heat transfer process was assumed in the analysis of temperature drop during the back-pulse cleaning event. Effects of heat generation due to combustion of the unburned carbon in the ash deposit, during blow-back was also considered. A typical ceramic candle filter was considered, which is a hollow cylinder 
and the pulse-cleaning gas is sent through the hollow portion. The system was thus divided into 3 distinct regions viz.

1. The gaseous region, i.e. the flow corresponding to the hollow portion of the candle filter, which is upstream of the porous region

2. The porous filter region

3. The ash-deposit region

Rectangular co-ordinates were first employed in order to understand the stability aspects in the problem. Once this was done, a cylindrical co-ordinate system was used to obtain the final solution.

Figure 4.1 depicts the flow-chart for the computer program being used for the numerical analysis of the system. 


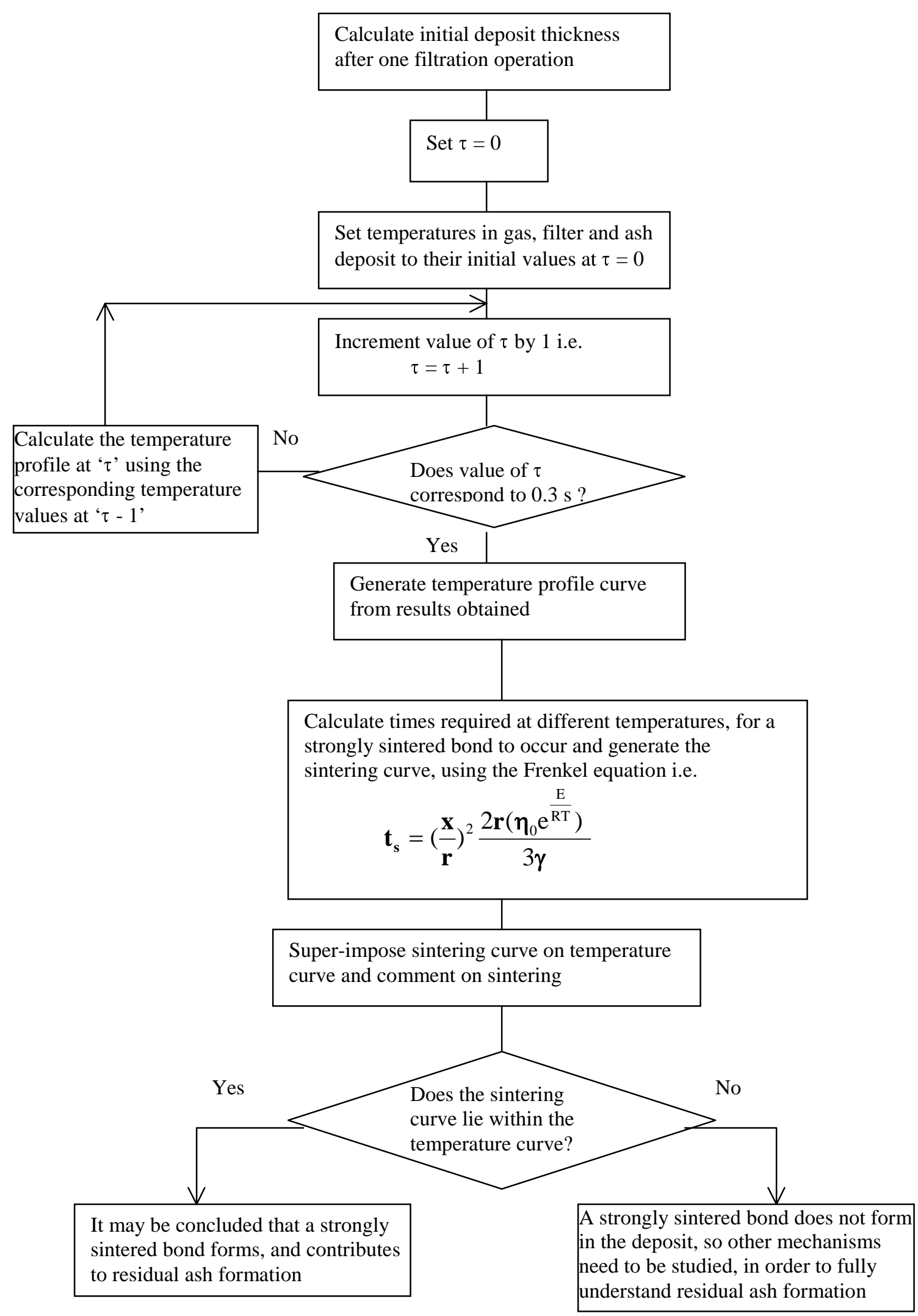

Figure 4.1 Flow-chart of computer program 


\subsection{Numerical Equations}

\subsubsection{Development of heat transfer equations}

The ceramic candle filter is a hollow cylinder closed at one end and open at the other end. Hence, the finite difference formulation for calculating temperature drop is based on cylindrical co-ordinate system. In this system, the gaseous and porous regions were divided into grids or elements. Each element was at a distance of ' $r_{m}$ ' from the center of the filter, where the subscript ' $\mathrm{m}$ ' represents the $\mathrm{m}^{\text {th }}$ element, and $\Delta \mathrm{r}$ represents the distance between this node and an adjacent node. The region upstream of the filter is designated as the gaseous region.

Gas

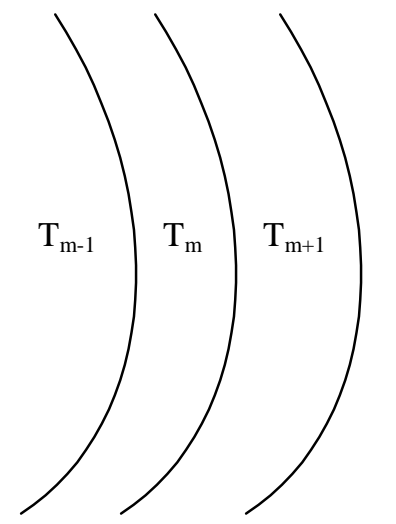

$\left|\Delta \mathrm{r}_{\mathrm{g}}\right| \Delta \mathrm{r}_{\mathrm{g}} \mid$
Filter

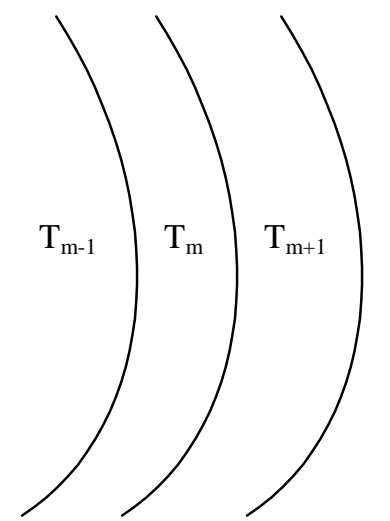

$\left|\Delta \mathrm{r}_{\mathrm{f}}\right| \Delta \mathrm{r}_{\mathrm{f}}$
Ash

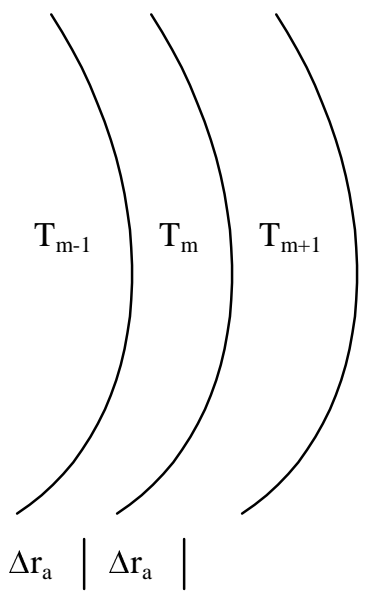

Figure 4.2 Representation of gaseous and porous regions for cylindrical co-ordinate formulation 
The region from the inner radius of the filter to it's outer radius was designated as the porous filter region and the region inside the ash deposit is designated as the porous ash region. The temperature of each node at an instant is represented as $T_{m}{ }^{\tau}$, where ' $m$ ' represents the node number under consideration and ' $\tau$ ' represents the instant.
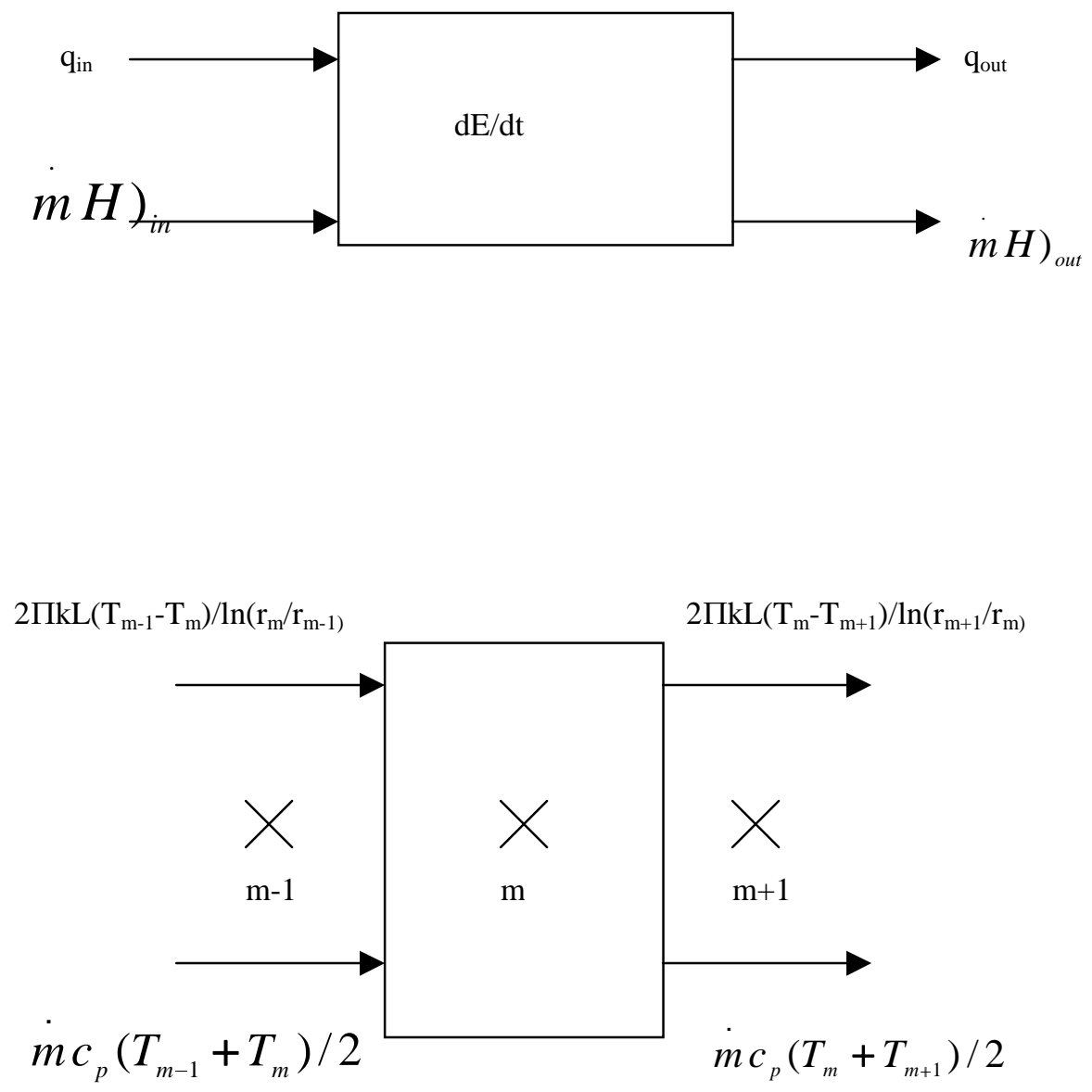

Figure 4.3 Schematic representation of heat transfer in a finite region 
The division of nodes in different regions of the system is illustrated in Figure 4.2. The surface area at node ' $\mathrm{m}$ ' is given by $2 \mathrm{rr}_{\mathrm{m}} \mathrm{L}$, where ' $\mathrm{r}_{\mathrm{m}}$ ' is the node radius and ' $\mathrm{L}$ ' was the filter length. In cylindrical co-ordinate formulation, $\mathrm{r}_{\mathrm{m}}$ changes for every node and hence the surface area also correspondingly changes. Therefore, stability criterion has to be satisfied for every node individually.

The temperature of the first node in the gaseous region was assumed to remain constant throughout the analysis. Since the heat transfer is a transient process, the finite difference formulation was based on the rate of change of internal energy of a finite volume $(\Delta \mathrm{E} / \Delta \mathrm{t})$, which should be equal to the heat conducted into the system and energy absorbed by gases flowing out of the system. A schematic diagram of the heat transfer process is shown in Figure 4.3.

\section{Case 1) Inside gaseous region}

For a node ' $m$ ' with finite volume inside the gaseous region, the rate of change of internal energy or total heat content of this node is given by :

$$
\frac{\Delta E}{\Delta t}=\rho_{g} c_{g}\left\{2 \pi r_{m} L\right\} \frac{\left[T_{m}^{\tau+1}-T_{m}^{\tau}\right]}{\Delta t}
$$

The total heat conducted is given by the difference of heat conducted into the system from node ' $\mathrm{m}-1$ ' to the heat conducted out of the system to node ' $\mathrm{m}+1$ ' as; 


$$
2 \pi k_{g} L \frac{T_{m-1}^{\tau}-T_{m}^{\tau}}{\ln \left(\frac{r_{m}}{r_{m-1}}\right)}-2 \pi k_{g} L \frac{T_{m}^{\tau}-T_{m+1}^{\tau}}{\ln \left(\frac{r_{m+1}}{r_{m}}\right)}
$$

The heat transfer due to the mass-flow of the blow-back air is given by;

$$
\dot{m c_{g}}\left[\frac{T_{m-1}^{\tau}-T_{m+1}^{\tau}}{2}\right]
$$

By using equations (4.1), (4.2) and (4.3), the finite difference formulation using the explicit transient analysis for the heat transfer in the gaseous region can be expressed as;

$$
\begin{aligned}
\rho_{g} c_{g}\left\{2 \pi r_{m} \Delta r L\right\} \frac{\left[T_{m}^{\tau+1}-T_{m}^{\tau}\right]}{\Delta t}= & 2 \pi k_{g} L \frac{T_{m-1}^{\tau}-T_{m}^{\tau}}{\ln \left(\frac{r_{m}}{r_{m-1}}\right)}-2 \pi k_{g} L \frac{T_{m}^{\tau}-T_{m+1}^{\tau}}{\ln \left(\frac{r_{m+1}}{r_{m}}\right)} \\
& +\dot{m} c_{g}\left[\frac{T_{m-1}^{\tau}-T_{m+1}^{\tau}}{2}\right]
\end{aligned}
$$

where $\mathrm{t}=\tau \Delta \mathrm{t}$

In the explicit finite difference formulation, temperature of any node, 'm' at an instant, ' $\tau$ ' depends on;

1. Temperature of node ' $m$ ' at the previous instant (i.e $\mathrm{T}_{\mathrm{m}}{ }^{\tau-1}$ )

2. Temperature of the previous node ' $\mathrm{m}-1$ ' at the previous instant (i.e. $\mathrm{T}_{\mathrm{m}-1}{ }^{\tau-1}$ ) 
3. Temperature of the next node ' $m+1$ ' at the previous instant (i.e. $\mathrm{T}_{\mathrm{m}+1}{ }^{\tau-1}$ )

Equation (4.4) can be simplified in order to obtain the temperature of node ' $\mathrm{m}$ ' at instant ' $\tau+1$ ' as;

$$
\mathrm{T}_{\mathrm{m}}^{\tau+1}=\mathrm{T}_{\mathrm{m}}^{\tau}[1-\mathrm{C}-\mathrm{D}]+\mathrm{T}_{\mathrm{m}-1}{ }^{\tau}[\mathrm{C}+\mathrm{E}]+\mathrm{T}_{\mathrm{m}+1}{ }^{\tau}[\mathrm{D}-\mathrm{E}]
$$

where,

$$
\begin{aligned}
& C=\frac{\alpha(\Delta t) r_{m-1}}{r_{m}(\Delta r)^{2}} \\
& D=\frac{\alpha(\Delta t)}{(\Delta r)^{2}} \\
& E=\frac{\dot{m}(\Delta t)}{4 \rho_{g} \pi L r_{m}(\Delta r)}
\end{aligned}
$$

\section{Case 2) At the Gas-Filter interface}

For the node at the interface between the gas and the filter, one half of the subvolume lies inside the gaseous region, while the other half lies inside the filter. Hence, the heat content of the gas as well as the porous filter has to be taken into consideration. If ' $\varepsilon$ ' is the porosity of the filter, then $(1-\varepsilon)$ represents the porous filter, while $\varepsilon$ represents air.

Hence, the corresponding equations for this node may be written as; 


$$
\begin{aligned}
& 2 \pi k_{g} L \frac{T_{m-1}^{\tau}-T_{m}^{\tau}}{\ln \left(\frac{r_{m}}{r_{m-1}}\right)}-2 \pi k_{f} L \frac{T_{m}^{\tau}-T_{m+1}^{\tau}}{\ln \left(\frac{r_{m+1}}{r_{m}}\right)}+\dot{m} c_{g}\left[\frac{\left.T_{m-1}^{\tau}-T_{m+1}^{\tau}\right]}{2}\right] \\
& =\left[\rho_{g} c_{g} \frac{\Delta r_{g}}{2}+\left\{\rho_{g} c_{g} \varepsilon+\rho_{f} c_{f}(1-\varepsilon)\right\} \frac{\Delta r_{f}}{2}\right]\left(2 \pi r_{m} L\right)\left[\frac{T_{m}^{\tau+1}-T_{m}^{\tau}}{\Delta t}\right]
\end{aligned}
$$

Equation (4.6) may be simplified to obtain the expression for the temperature distribution for this node as;

$$
\mathrm{T}_{\mathrm{m}}^{\tau-1}=\mathrm{T}_{\mathrm{m}}{ }^{\tau}[1-\mathrm{C}-\mathrm{D}]+\mathrm{T}_{\mathrm{m}-1}{ }^{\tau}[\mathrm{C}+\mathrm{E}]+\mathrm{T}_{\mathrm{m}+1}{ }^{\tau}[\mathrm{D}-\mathrm{E}]
$$

where;

$$
\begin{aligned}
& B=\rho_{g} c_{g} \frac{\Delta r_{g}}{2}+\left\{\rho_{g} c_{g} \varepsilon+\rho_{f} c_{f}(1-\varepsilon)\right\} \frac{\Delta r_{f}}{2} \\
& C=\frac{k_{g}(\Delta t) r_{m-1}}{B r_{m}\left(\Delta r_{g}\right)} \\
& D=\frac{k_{f} \Delta t}{B \Delta r_{f}} \\
& E=\frac{\dot{m} c_{g}(\Delta t)}{4 B \pi r_{m} L}
\end{aligned}
$$




\section{Case 3) Node inside porous filter region}

The explicit finite difference formulation for a node inside the porous filter region may be written as;

$$
\begin{aligned}
& 2 \pi k_{f} L \frac{T_{m-1}^{\tau}-T_{m}^{\tau}}{\ln \left(\frac{r_{m}}{r_{m-1}}\right)}-2 \pi k_{f} L \frac{T_{m}^{\tau}-T_{m+1}^{\tau}}{\ln \left(\frac{r_{m+1}}{r_{m}}\right)}+\dot{m} c_{g}\left[\frac{T_{m-1}^{\tau}-T_{m+1}^{\tau}}{2}\right] \\
& =\left[\left\{\rho_{g} c_{g} \varepsilon+\rho_{f} c_{f}(1-\varepsilon)\right\}\right]\left(2 \pi r_{m} \Delta r_{f} L\right)\left[\frac{T_{m}^{\tau+1}-T_{m}^{\tau}}{\Delta t}\right]
\end{aligned}
$$

Equation (4.8) may be simplified to obtain the expression for the temperature distribution for a node inside the filter region as;

$$
T_{m}^{\tau+1}=T_{m}^{\tau}[1-C-D]+T_{m-1}^{\tau}[C+E]+T_{m+1}^{\tau}[D-E]
$$

where,

$$
\begin{aligned}
& B=\rho_{g} c_{g} \varepsilon+\rho_{f} c_{f}(1-\varepsilon) \\
& C=\frac{k_{f}(\Delta t) r_{m-1}}{B r_{m}\left(\Delta r_{f}\right)^{2}} \\
& D=\frac{k_{f}(\Delta t)}{B\left(\Delta r_{f}\right)^{2}} \\
& E=\frac{\dot{m} c_{g}(\Delta t)}{4 B \pi r_{m}\left(\Delta r_{f}\right) L}
\end{aligned}
$$




\section{Case 4) At the interface between filter and ash}

For the node at the interface between the filter and the ash, one half of the subvolume lies in the filter, while the other half lies in the ash. The explicit finite difference formulation for this node may be written as;

$$
\begin{aligned}
& 2 \pi k_{f} L \frac{T_{m-1}^{\tau}-T_{m}^{\tau}}{\ln \left(\frac{r_{m}}{r_{m-1}}\right)}-2 \pi k_{a} L \frac{T_{m}^{\tau}-T_{m+1}^{\tau}}{\ln \left(\frac{r_{m+1}}{r_{m}}\right)}+\dot{m} c_{g}\left[\frac{T_{m-1}^{\tau}-T_{m+1}^{\tau}}{2}\right]+\dot{Q}\left(2 \pi r_{m} L\right)\left(\frac{\Delta r_{a}}{2}\right) \\
& =\left[\left[\left\{\rho_{g} c_{g} \varepsilon+\rho_{f} c_{f}(1-\varepsilon)\right\} \frac{\Delta r_{f}}{2}\right]+\left\{\rho_{g} c_{g} \varepsilon+\rho_{a} c_{a}(1-\varepsilon)\right\} \frac{\Delta r_{a}}{2}\right]\left(2 \pi r_{m} L\right)\left[\frac{T_{m}^{\tau+1}-T_{m}^{\tau}}{\Delta t}\right]
\end{aligned}
$$

Equation (4.10) may be simplified to obtain the expression for the temperature distribution for a node in this region as;

$$
T_{m}^{\tau+1}=T_{m}^{\tau}[1-C-D]+T_{m-1}^{\tau}[C+E]+T_{m+1}^{\tau}[D-E]+G
$$

where,

$$
\begin{aligned}
& B=\left[\rho_{g} c_{g} \varepsilon+\rho_{f} c_{f}(1-\varepsilon)\right] \frac{\Delta r_{f}}{2}+\left[\rho_{g} c_{g} \varepsilon+\rho_{a} c_{a}(1-\varepsilon)\right] \frac{\Delta r_{a}}{2} \\
& C=\frac{k_{f}(\Delta t) r_{m-1}}{B r_{m}\left(\Delta r_{f}\right)}
\end{aligned}
$$




$$
\begin{aligned}
& D=\frac{k_{a}(\Delta t)}{B\left(\Delta r_{a}\right)} \\
& E=\frac{\dot{m} c_{g}(\Delta t)}{4 B \pi r_{m} L} \\
& G=\frac{\dot{Q}\left(\Delta r_{a}\right)(\Delta t)}{2 B}
\end{aligned}
$$

\section{Case 5) Inside Ash}

The ash is porous in nature, like the filter. Taking into consideration effects of heat generation inside the ash, the equations for the temperature distribution may be written as;

$$
\begin{aligned}
& 2 \pi k_{a} L \frac{T_{m-1}^{\tau}-T_{m}^{\tau}}{\ln \left(\frac{r_{m}}{r_{m-1}}\right)}-2 \pi k_{a} L \frac{T_{m}^{\tau}-T_{m+1}^{\tau}}{\ln \left(\frac{r_{m+1}}{r_{m}}\right)}+\dot{m} c_{g}\left[\frac{\left.T_{m-1}^{\tau}-T_{m+1}^{\tau}\right]}{2}\right]+\dot{Q}\left(2 \pi r_{m} L\right) \Delta r_{a} \\
& =\left[\left\{\rho_{g} c_{g} \varepsilon+\rho_{a} c_{a}(1-\varepsilon)\right\}\right]\left(2 \pi r_{m} \Delta r_{a} L\right)\left[\frac{T_{m}^{\tau+1}-T_{m}^{\tau}}{\Delta t}\right]
\end{aligned}
$$

Equation (4.12) may be simplified in order to obtain the expression for the temperature distribution for a node inside the ash region as;

$$
T_{m}^{\tau+1}=T_{m}^{\tau}[1-C-D]+T_{m-1}^{\tau}[C+E]+T_{m+1}^{\tau}[D-E]+G
$$


where,

$$
\begin{aligned}
& B=\rho_{g} c_{g} \varepsilon+\rho_{a} c_{a}(1-\varepsilon) \\
& C=\frac{k_{a}(\Delta t) r_{m-1}}{B r_{m}\left(\Delta r_{a}\right)^{2}} \\
& D=\frac{k_{a}(\Delta t)}{B\left(\Delta r_{a}\right)^{2}} \\
& E=\frac{\dot{m} c_{g}(\Delta t)}{4 B \pi r_{m}\left(\Delta r_{a}\right) L} \\
& G=\frac{\dot{Q}{ }^{\prime \prime}}{B}
\end{aligned}
$$

\section{Case 6) Exterior node on ash}

The equations for the exterior node on the ash may be written as;

$$
\begin{aligned}
& 2 \pi k_{a} L \frac{T_{m-1}^{\tau}-T_{m}^{\tau}}{\ln \left(\frac{r_{m}}{r_{m-1}}\right)}+\dot{m} c_{g}\left[\frac{T_{m-1}^{\tau}-T_{m}^{\tau}}{2}\right]+\dot{Q}\left(2 \pi r_{m} L\right)\left(\frac{\Delta r_{a}}{2}\right) \\
& =\left[\left\{\rho_{g} c_{g} \varepsilon+\rho_{a} c_{a}(1-\varepsilon)\right\}\right]\left(2 \pi r_{m} L\right)\left(\frac{\Delta r_{a}}{2}\right)\left[\frac{T_{m}^{\tau+1}-T_{m}^{\tau}}{\Delta t}\right]
\end{aligned}
$$

Equation (4.14) may be simplified to obtain the expression for the temperature distribution in this node as; 


$$
T_{m}^{\tau+1}=T_{m}^{\tau}[1-C-D]+T_{m-1}^{\tau}[C+E]+T_{m+1}^{\tau}[D-E]+G
$$

where,

$$
\begin{aligned}
& B=\rho_{g} c_{g} \varepsilon+\rho_{a} c_{a}(1-\varepsilon) \\
& C=\frac{2 k_{a}(\Delta t) r_{m-1}}{B r_{m}\left(\Delta r_{a}\right)^{2}} \\
& E=\frac{\dot{m} c_{g}(\Delta t)}{2 B \pi r_{m}\left(\Delta r_{a}\right) L} \\
& G=\frac{\dot{Q} \Delta t}{B}
\end{aligned}
$$

\subsubsection{Development of flow equations}

Figure (4.4) is a schematic representation of the pressure-drop model being used for estimating the mass-flow rate through the filter and ash deposits.

For the flow of fluid through a porous medium the equations of continuity and motion can be written as:

$$
\varepsilon \frac{\partial \rho}{\partial t}=-\left(\nabla \cdot \rho v^{-}\right)
$$

Darcy's law states that the rate of flow is directly proportional to the pressure gradient causing the flow. If a volume ' $Q$ ' flows in ' $t$ ' seconds across a cross-sectional area, 'A', the apparent linear flow rate is $\mathrm{v}^{-}=\mathrm{Q} / \mathrm{At}$. Darcy's law is then given as: 


$$
v^{-}=-\frac{k}{\mu}(\Delta p)
$$

where,

$$
\begin{aligned}
& \varepsilon=\text { porosity (ratio of pore volume to total volume) } \\
& \mathrm{k}=\text { permeability of porous medium. } \\
& \mu=\text { viscosity } \\
& \mathrm{v}^{-}=\text {flow rate (velocity) } \\
& \mathrm{p}=\text { pressure } \\
& \rho=\text { density }
\end{aligned}
$$

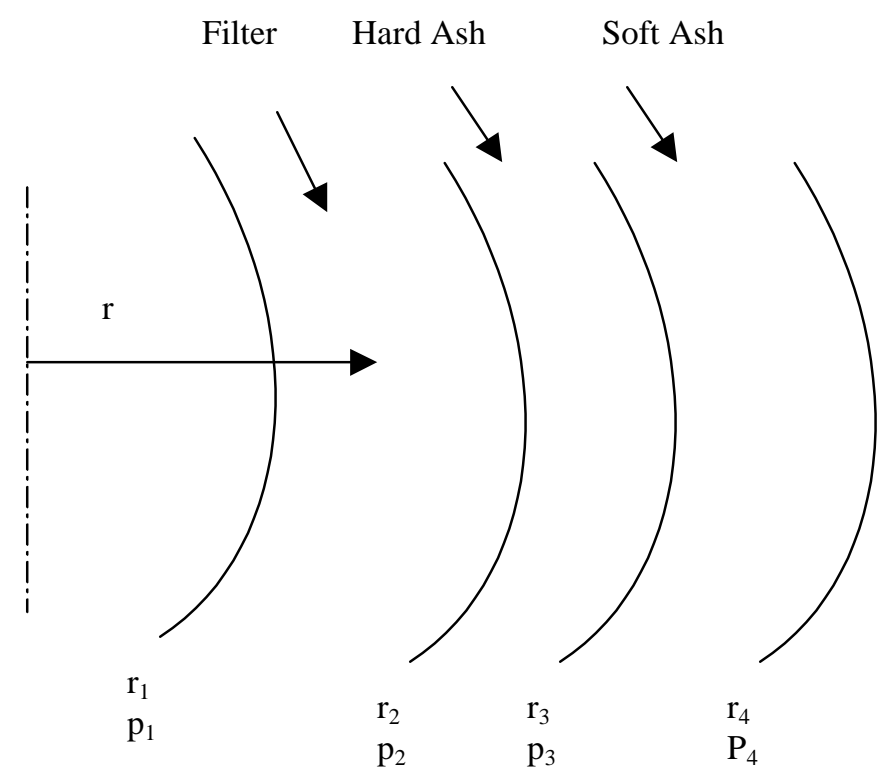

Fig 4.4 Schematic representation of filter and ash deposits for pressure drop model 
For a steady state process with constant temperature, Darcy's equation of flow can be modified and written in terms of mass flow rate $(\mathrm{M})$ and pressure drop which is given as:

$$
M=\frac{k_{f} \pi L}{\mu R_{a} T}\left(\frac{p_{1}^{2}-p_{2}^{2}}{\ln \left(\frac{r_{2}}{r_{1}}\right)}\right)
$$

The above equation may be modified by taking into consideration the interface pressures and the equation for the mass flow rate may be written as:

$$
M=\frac{\pi L}{\mu R_{a} T}\left(p_{1}^{2}-p_{4}^{2}\right) \frac{1}{\left[\frac{1}{k_{f}} \ln \left(\frac{r_{2}}{r_{1}}\right)+\frac{1}{k_{h a}} \ln \left(\frac{r_{3}}{r_{2}}\right)+\frac{1}{k_{s a}} \ln \left(\frac{r_{4}}{r_{3}}\right)\right]}
$$

where,

$$
\begin{aligned}
& \mathrm{k}_{\mathrm{f}}=\text { permeability of the filter } \\
& \mathrm{k}_{\mathrm{ha}}=\text { permeability of the hard-ash } \\
& \mathrm{k}_{\mathrm{sa}}=\text { permeability of the soft-ash }
\end{aligned}
$$

\subsubsection{Estimation of ash permeabilities}

An estimation of the mass-flow during the blow-back operation, from equation (4.29) requires that the permeabilities of the hard and soft ash be known.

Laux et al [12] have conducted several tests to determine permabilities of softashes and have suggested that typical values for the soft-ash permeability lie in the range of $(6-8) 10^{-13} \mathrm{~m}^{2}$. However, they have also suggested that permeability of hard-ash 
strongly depends on the filter cleaning strategy and hence cannot be determined without experimental data for each operating condition.

Mudd et al [13] have conducted extensive tests at the Tidd PFBC Hot Gas Clean Up (HGCU) test facility, in a project sponsored by the US Department of Energy (DOE). They have presented in a paper [13], a description of the system and results of all test runs conducted in the project. From these results, by knowing the pressure drops experienced during filtration due to residual ash deposits alone, the hard ash permeability was calculated using equation (4.29), to be about $6.5 \times 10^{-13} \mathrm{~m}^{2}$.

\subsubsection{Selected start of the filtering system}

The analysis of the current problem is started initially with a clean filter, with no ash accumulation. Filtration of the hot gases, at about $800^{\circ} \mathrm{C}$ is performed and soft ash starts accumulating on the filter, thereby causing a pressure drop. In this research, it is assumed that when a pre-set pressure drop in encountered, filter cleaning operation with a pulse of air at around $200^{\circ} \mathrm{C}$ is initiated. At the start of this surface regeneration operation, a uniform temperature of about $800^{\circ} \mathrm{C}$ is assumed to have been attained in the filter and in the accumulated ash.

\subsection{Selected parameters for this study}

\subsubsection{Estimation of mass-flow rate during the surface regeneration operation}

The values of the permeabilities of soft ash and hard ash considered in this

research are very close to each other, of the order of $6.5 \times 10^{-13} \mathrm{~m}^{2}$. Hence, the 
permeabilities of the soft and hard ash may be combined in the equation for the massflow rate (4.29), which may now be reduced to the following form :

$$
M=\frac{\pi L}{\mu R_{a} T}\left(p_{1}^{2}-p_{4}^{2}\right) \frac{1}{\left[\frac{1}{k_{f}} \ln \left(\frac{r_{2}}{r_{1}}\right)+\frac{1}{k_{\text {ash }}} \ln \left(\frac{r_{3}}{r_{2}}\right)\right]}
$$

In this research, blow-back cleaning operation is assumed to be initiated whenever a pre-set pressure drop during filtration is encountered. Since permeabilities of hard and soft ashes are the same, the thickness of the deposit as a whole, required to cause this pressure drop remains constant. In other words, the value of ' $r 3$ ' in the above equation (4.15) at the start of the pulse cleaning process is the same.

If we denote $\left[\frac{\ln \left(\frac{r_{2}}{r_{1}}\right)}{k_{f}}+\frac{\ln \left(\frac{r_{3}}{r_{2}}\right)}{k_{\text {ash }}}\right]$ by a constant ' $\mathrm{A}$ ', then the equation for the massflow rate during surface regeneration can now be written as:

$$
M=\frac{\pi L}{\mu \mathrm{R}_{a} T} \frac{\left(p_{1}^{2}-p_{4}^{2}\right)}{A}
$$

For fixed values of the chamber-pressure $\left(\mathrm{p}_{4}\right)$ and pressure inside the filter $\left(\mathrm{p}_{1}\right)$, the mass-flow rate as calculated from equation (4.31) will be constant. Hence, in the present research, the mass-flow rate during the pulse-cleaning operation essentially remains the same. 


\subsubsection{Estimation of physical and thermal properties of ash deposits}

Heat transfer analysis in the ash deposit requires a knowledge of certain physical and thermal properties of the deposit. These properties are porosity, thermal-conductivity, specific heat and density.

In a paper on the effective thermal conductivity of coal ash deposits, Anderson et al [14] have stated that heat transfer through a porous coal ash deposit occurs by both conduction and thermal radiation. They have also stated that since conductive and radiative heat transfer in the ash deposit occur both in parallel and in series, the concept of an 'effective' thermal conductivity should be used. They have performed effective thermal conductivity measurements over a wide range of temperatures for fly ash and presented the appropriate results in this paper. Examination of the results indicates that the variation in effective thermal conductivity with deposit temperature is negligible, ranging from about $0.20 \mathrm{~W} / \mathrm{m}-\mathrm{K}$ at $300^{\circ} \mathrm{C}$ to about $0.24 \mathrm{~W} / \mathrm{m}-\mathrm{K}$ at $800^{\circ} \mathrm{C}$. Hence, for the purposes of this study, a value of $0.24 \mathrm{~W} / \mathrm{m}-\mathrm{K}$ is selected and is assumed to remain constant.

The porosity of the deposits used in this experiment (by Anderson et al) was 58\%, and the same is chosen as the constant porosity (of the ash deposit) in this study also. The particle specific gravity was 2.38 . Based on the particle specific gravity, the bulk-density corresponding to the chosen porosity may now be calculated from,

$$
\rho_{\text {bulk }}=\rho_{\text {true }}(1-\varepsilon)+\rho_{\text {air }} \varepsilon
$$


The ash used in these experiments had a silica ratio as high as about $60 \%$. Hence, in order to estimate the specific heat of the deposits, the specific heat of silica was used as the value for ' $c_{\text {particle' }}$, in the equation,

$$
\left(c_{p}\right)_{\text {deposit }}=\frac{(1-\varepsilon) \rho_{\text {particle }} c_{\text {particle }}+\varepsilon \rho_{\text {air }} c_{\text {air }}}{(1-\varepsilon) \rho_{\text {particle }}+\varepsilon \rho_{\text {air }}}
$$

\subsection{A discussion on stability of the solution}

In the finite difference solution of unsteady conduction heat transfer problems, two methods may be used. These are the 'Implicit' method and the 'Explicit' method. In the implicit method, the temperature of a node depends upon the temperatures of that node and it's adjacent nodes, both at the same instant and also at the preceding instant. Hence, the entire system of equations has to be solved simultaneously. In the explicit method, the temperature of a node at any instant depends upon the temperatures of that node and it's adjacent nodes, all at the previous instant only. Since the problem on hand is an initial value problem, wherein the initial temperatures are known, the explicit method can be used to calculate the nodal temperatures directly. The advantage of the implicit method is that it is stable for all values of the time increment. In the explicit method however, the possibility of loss of stability has to be first considered and careful attention needs to be paid while selecting both the nodal increments as well as the time increment. This procedure is explained below:

In connection with the specification of the finite-difference increments $\Delta \mathrm{r}$ and $\Delta \mathrm{t}$, these increments must be selected such that the nodal calculations do not violate the 
physical requirements represented by the second law of thermodynamics. Otherwise, the resulting finite-difference "solution" will become unstable and blow up after a certain number of time steps have been taken. The finite difference equations used in the explicit analysis of the current problem are of the form;

$$
T_{m}^{\tau+1}=T_{m}^{\tau}[1-C-D]+T_{m-1}^{\tau}[C+E]+T_{m+1}^{\tau}[D-E]
$$

where,

$$
\begin{aligned}
& C=\frac{\alpha(\Delta t) r_{m-1}}{r_{m}(\Delta r)^{2}} \\
& D=\frac{\alpha(\Delta t)}{(\Delta r)^{2}} \\
& E=\frac{\dot{m}(\Delta t)}{4 \rho_{g} \pi L r_{m}(\Delta r)}
\end{aligned}
$$

In order for stability to be assured, the coefficients associated with the temperatures must be greater than zero, or at least equal to zero, in the limiting case. Hence, the stability criterion may now be formulated as;

$$
\begin{array}{r}
\mathrm{D}-\mathrm{E}=0 \\
\text { and } \quad \mathrm{C}+\mathrm{D}=1
\end{array}
$$

To satisfy equation (4.25), 


$$
\frac{\alpha \Delta t}{(\Delta r)^{2}}=\frac{\dot{m} \Delta t}{(4 \rho \pi L)\left(r_{m} \Delta r\right)}
$$

or;

$$
\Delta r=\frac{\alpha(4 \rho \pi L) r_{m}}{\dot{m}}
$$

Using this value of $\Delta \mathrm{r}$, the minimum value of $\Delta \mathrm{t}$ may be calculated from equation (4.26) as,

$$
\frac{(\alpha \Delta t) r_{m-1}}{r_{m}(\Delta r)^{2}}+\frac{\alpha \Delta t}{(\Delta r)^{2}}=1
$$

or,

$$
\frac{\alpha \Delta t}{(\Delta r)^{2}}\left[\frac{r_{m-1}}{r_{m}}+1\right]=0
$$

$$
\Delta t=\frac{(\Delta r)^{2}}{\alpha\left[1+\frac{r_{m-1}}{r_{m}}\right]}
$$

Using equations (4.27) and (4.28), the values of $\Delta \mathrm{r}$ and $\Delta \mathrm{t}$ that were needed to satisfy the stability criterion and thus guarantee a solution, are calculated. Knowing the total time of the surface regeneration, the actual number of intervals to be used may then be calculated from; 


\subsection{Results of heat transfer analysis}

This section presents the results obtained from the numerical heat transfer analysis. A one-dimensional transient finite difference model for heat transfer in porous media was developed. The model was then divided into 3 regions viz.:

1. Gaseous region

2. Porous filter region

3. Porous ash region

Finite difference equations were formulated for heat transfer in gaseous region, gaseous and porous boundaries, porous region and finally for the porous boundary. These equations are given in (4.5) through (4.15).

Initially, the finite difference formulation was done using rectangular co-ordinate system and later cylindrical co-ordinates were used. In the finite difference method, the number of sub-divisions or the grid size of the entire region plays an important role in the convergence of the solution. Since the surface regeneration process lasts only for 0.3 seconds and involves relatively high mass-flow rates, the process may be highly unstable for numerical work. The above reasons prompted the use of a rectangular co-ordinate system initially to investigate convergence. This is due to the fact that in the rectangular co-ordinate system, the mass flow rate per unit area is constant as the area does not change. In the cylindrical co-ordinate system however, the mass flow rate per unit area changes for each node as the radius $\left(\mathrm{r}_{\mathrm{i}}\right)$ changes from one node to another, but the mass 
flow rate is constant. So, rectangular co-ordinate system was used to determine approximately, the grid size $(\Delta \mathrm{r})$ in both gaseous and porous regions.

A few assumptions were made in this finite difference heat transfer analysis which are now restated:

1. A One-dimensional model filter was considered and hence there is no temperature gradient in the axial direction.

2. The initial temperature of the gases just prior to the surface regeneration was $200^{\circ} \mathrm{C}$, and that of the filter and the deposited ash was $800^{\circ} \mathrm{C}$.

3. In the cylindrical formulation for the surface regeneration, only half the gaseous region was considered, but in the rectangular co-ordinate system, whole gaseous region was considered. This is because of the fact that in cylindrical co-ordinate formulation, the solution becomes unstable if the whole region is considered. Further, this assumption is justified by examining the results from the rectangular co-ordinate formulation, where in temperatures in the first half of the gaseous region remain virtually constant throughout the pulse-cleaning event.

The number of nodes and intervals that were made use of, were calculated based on satisfying the stability criterion, which is discussed in section 4.4. Accordingly, the following values were used:

No. of nodes in gaseous region $=450$

No. of nodes in filter region $=200$

No. of time intervals used $=11000$

Figures 4.5 through 4.11 outline the results obtained from the numerical heat transfer analysis. 
Temperature distribution along inner wall of filter during pulse-cleaning

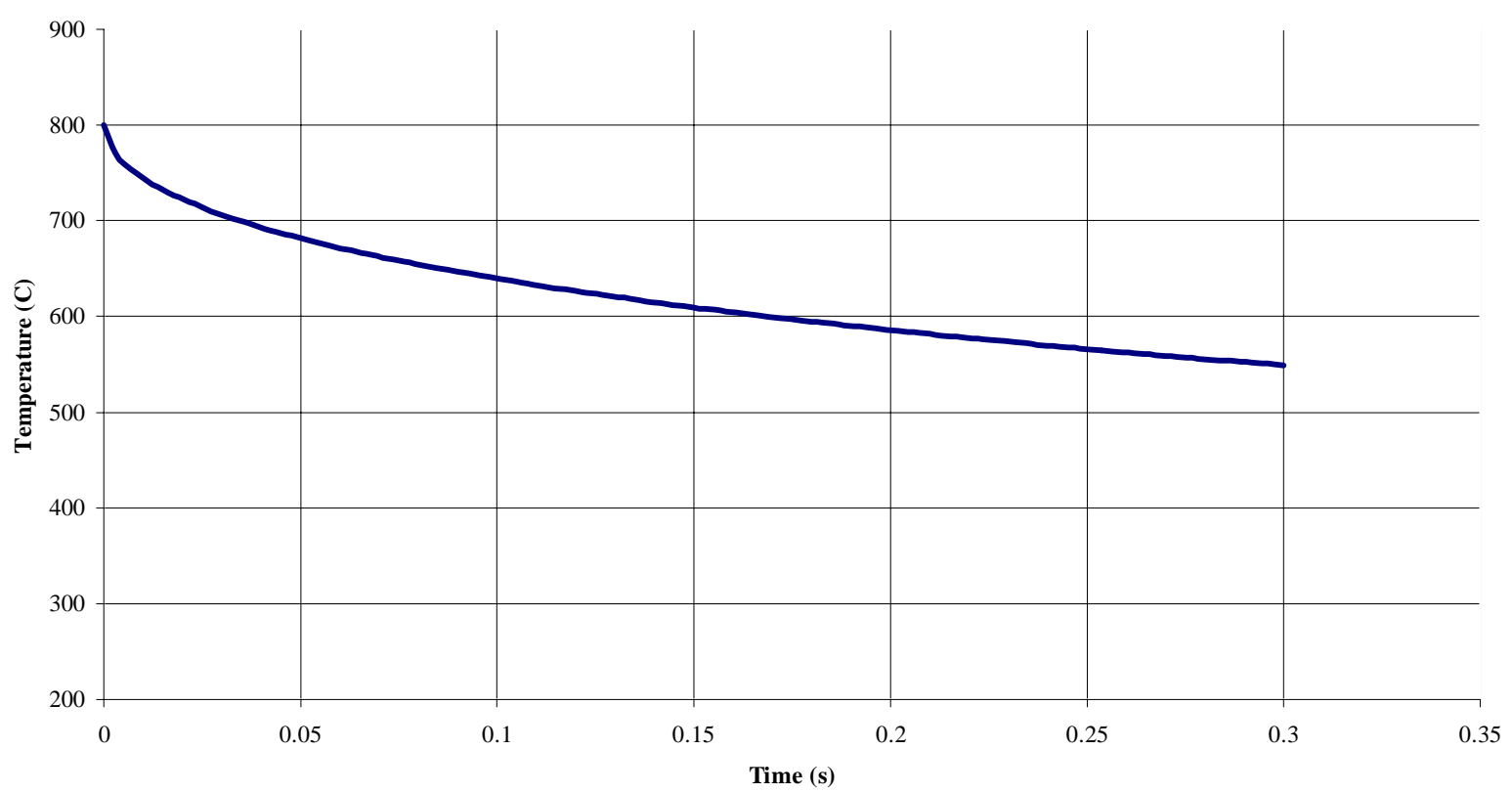

Figure 4.5 Temperature drop with time in Schumacher filter during surface regeneration, $U=3.6 \mathrm{~cm} / \mathrm{s}$, $\mathrm{M}($ pulse $)=0.27 \mathrm{~kg} / \mathrm{s}, \mathrm{T}(\mathrm{fil})=800 \mathrm{C}, \mathrm{UC}=4 \%$ 
Temperature distribution along outer wall of filter during pulse-cleaning

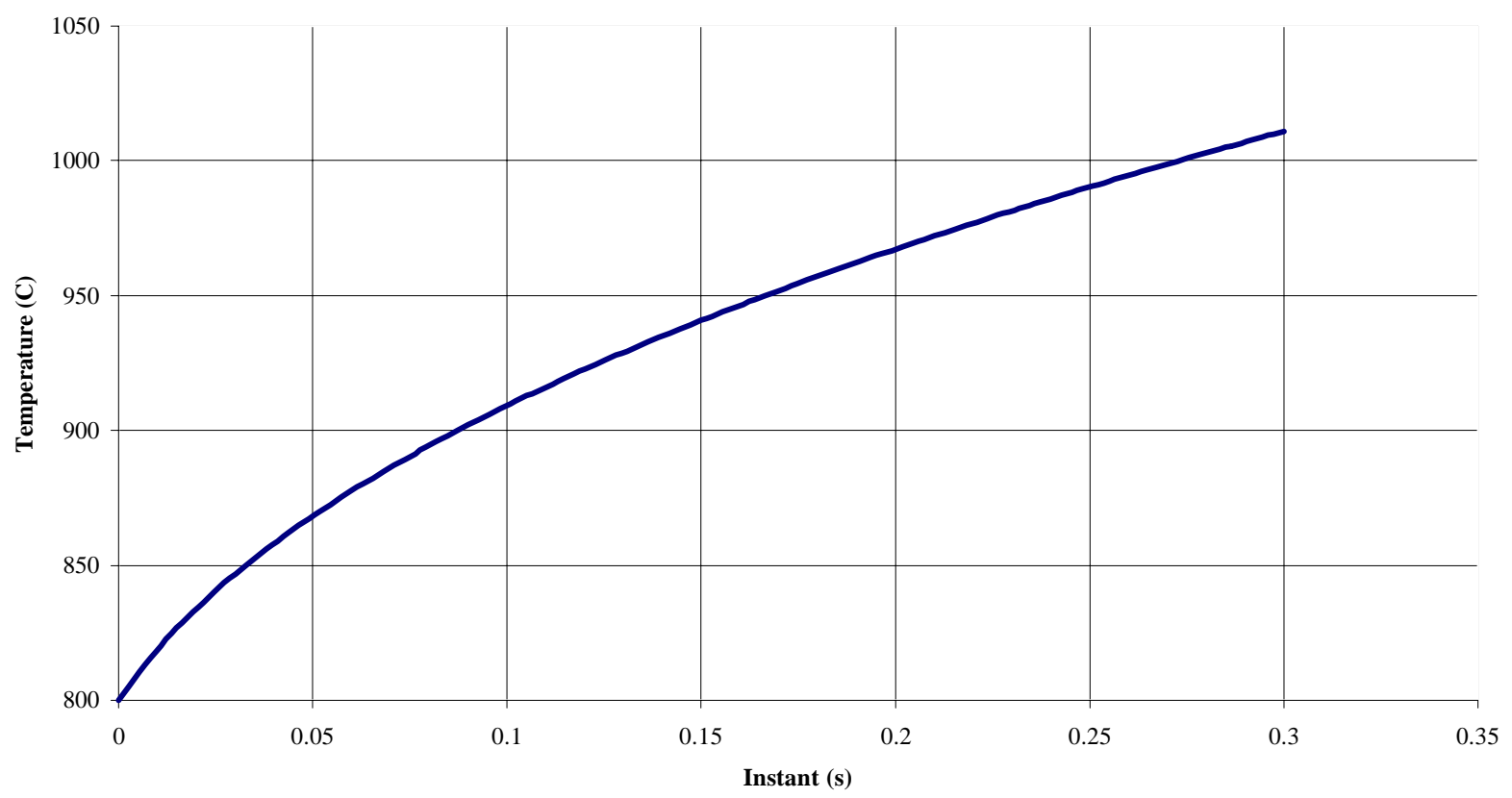

Fig 4.6 Temperature distribution along the outside wall of Schumacher filter during surface regeneration, $\mathrm{U}=3.6 \mathrm{~cm} / \mathrm{s}, \mathrm{M}($ pulse $)=0.27 \mathrm{~kg} / \mathrm{s}, \mathrm{T}(\mathrm{fil})=800 \mathrm{C}, \mathrm{UC}=4 \%$ 
Temperature rise in ash layer at $0.2 \mathrm{~mm}$ from outer wall of filter, during pulse. cleaning

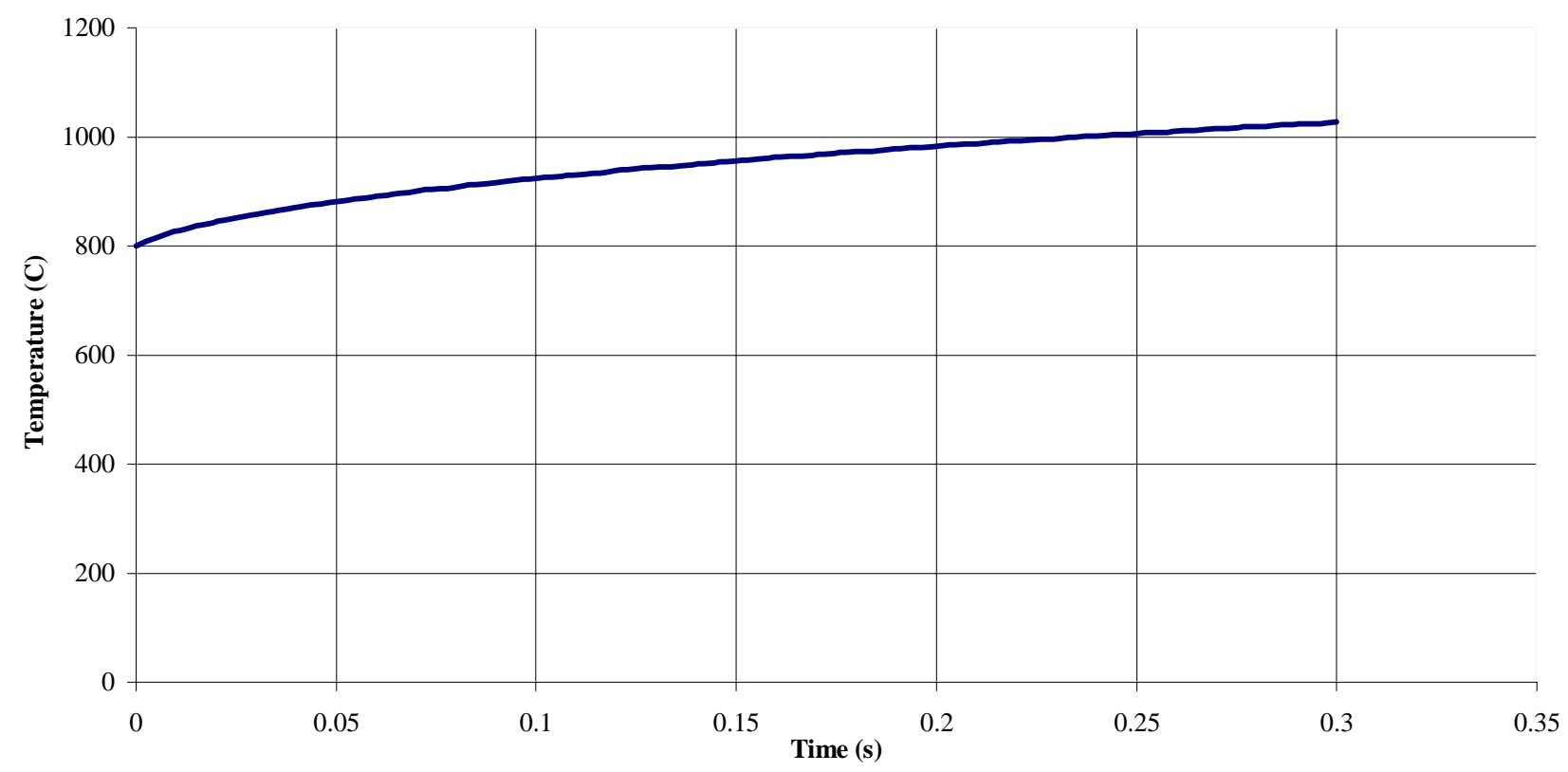

Figure 4.7 Temperature distribution at edge of a residual ash layer, $0.2 \mathrm{~mm}$ thick, $\mathrm{U}=3.6 \mathrm{~cm} / \mathrm{s}, \mathrm{M}(\mathrm{pulse})=0.27$ $\mathrm{kg} / \mathrm{s}, \mathrm{T}(\mathrm{fil})=800 \mathrm{C}, \mathrm{UC}=4 \%$ 


\section{Temperature distribution across residual ash during pulse-cleaning}

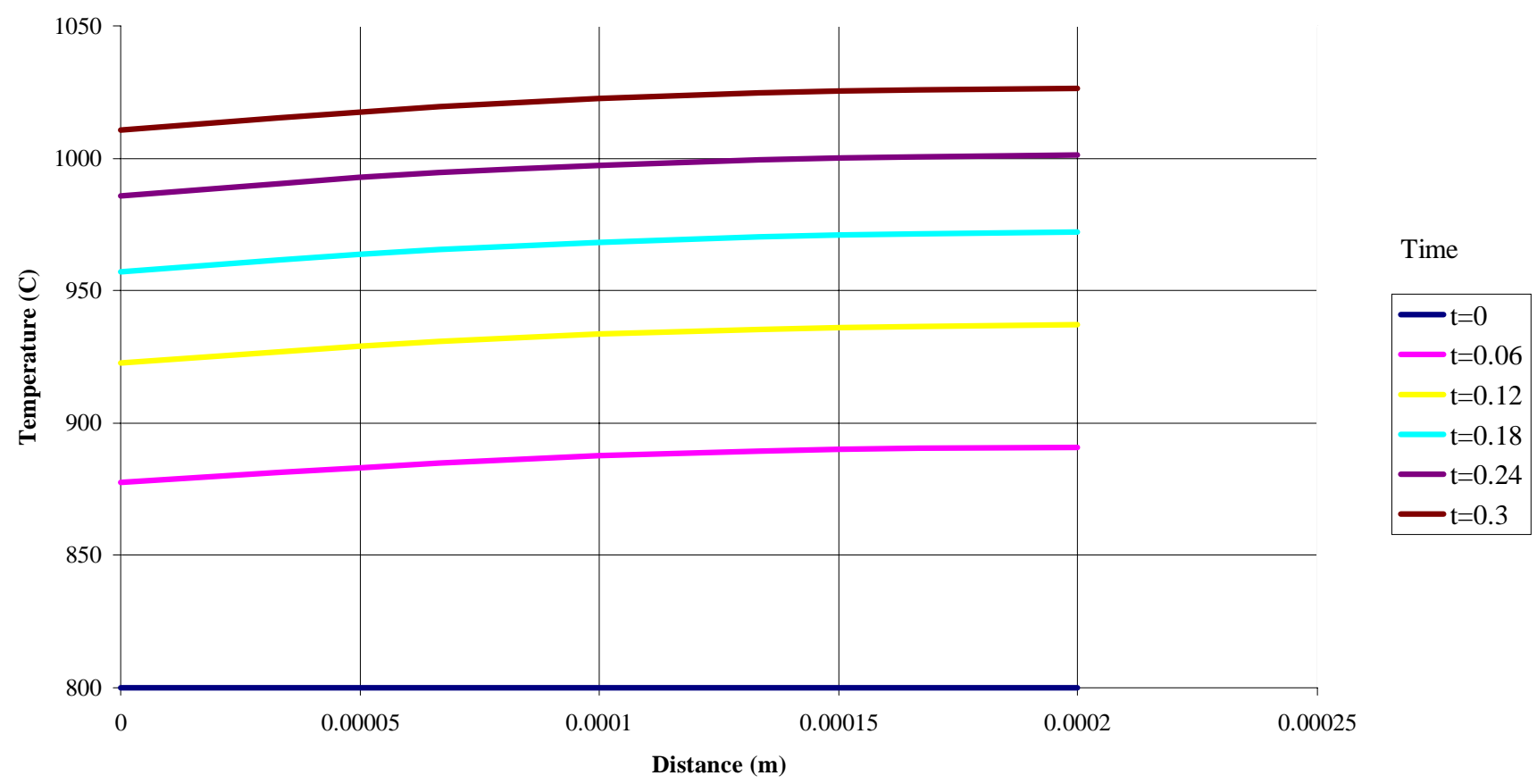

Figure 4.8 Temperature distribution in residual ash during pulse-cleaning, $U=3.6 \mathrm{~cm} / \mathrm{s}$, $\mathrm{M}($ pulse $)=0.27 \mathrm{~kg} / \mathrm{s}, \mathrm{T}($ fil $)=800 \mathrm{C}, \mathrm{UC}=4 \%$ 
Temperature distribution across the system during pulse-cleaning

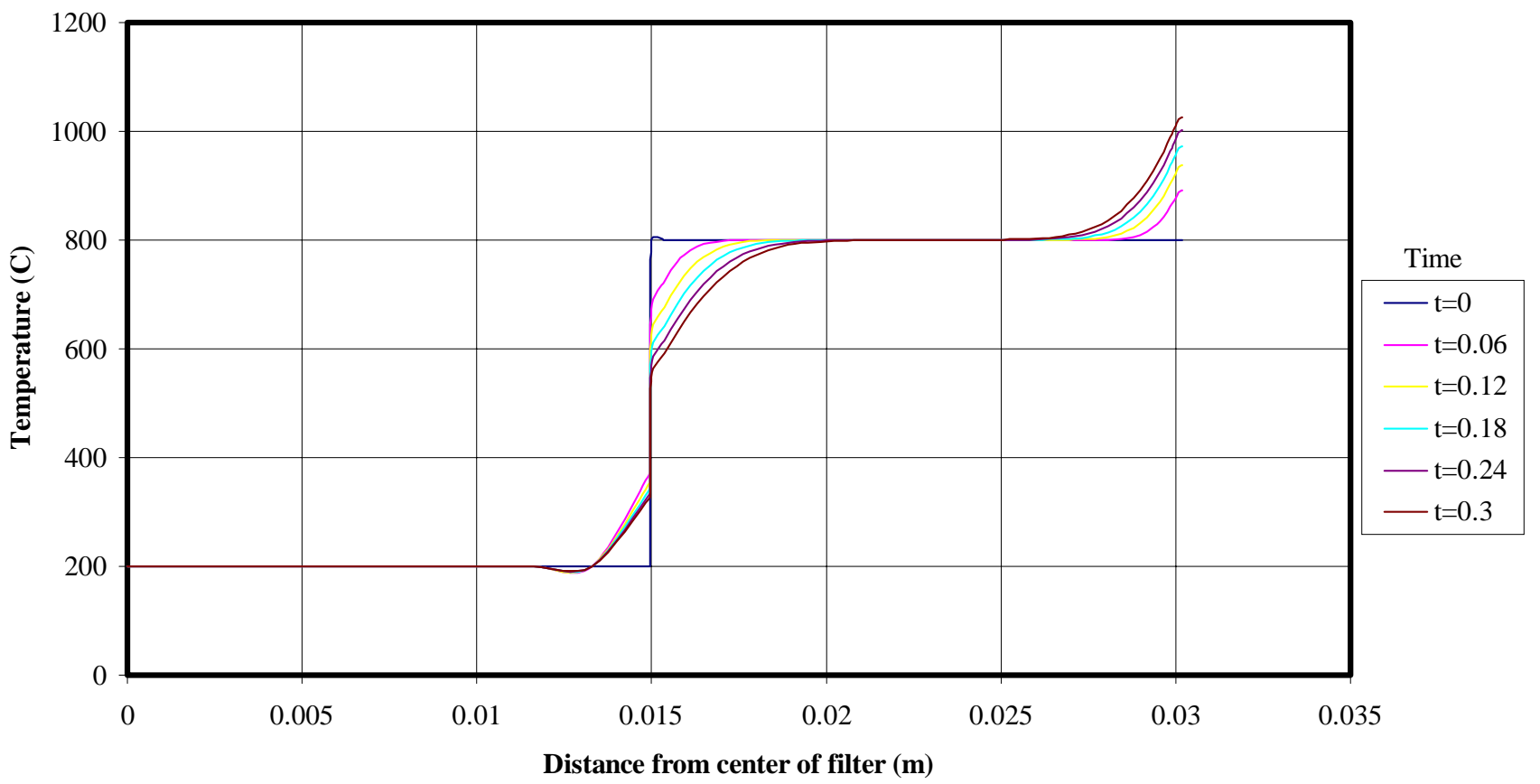

Figure 4.9 Temperature distribution across the system at different instances of time, $U=3.6$ $\mathrm{cm} / \mathrm{s}, \mathrm{M}($ pulse $)=0.27 \mathrm{~kg} / \mathrm{s}, \mathrm{T}(\mathrm{fil})=800 \mathrm{C}, \mathrm{UC}=4 \%$ 
Temperature distribution near inner wall of filter

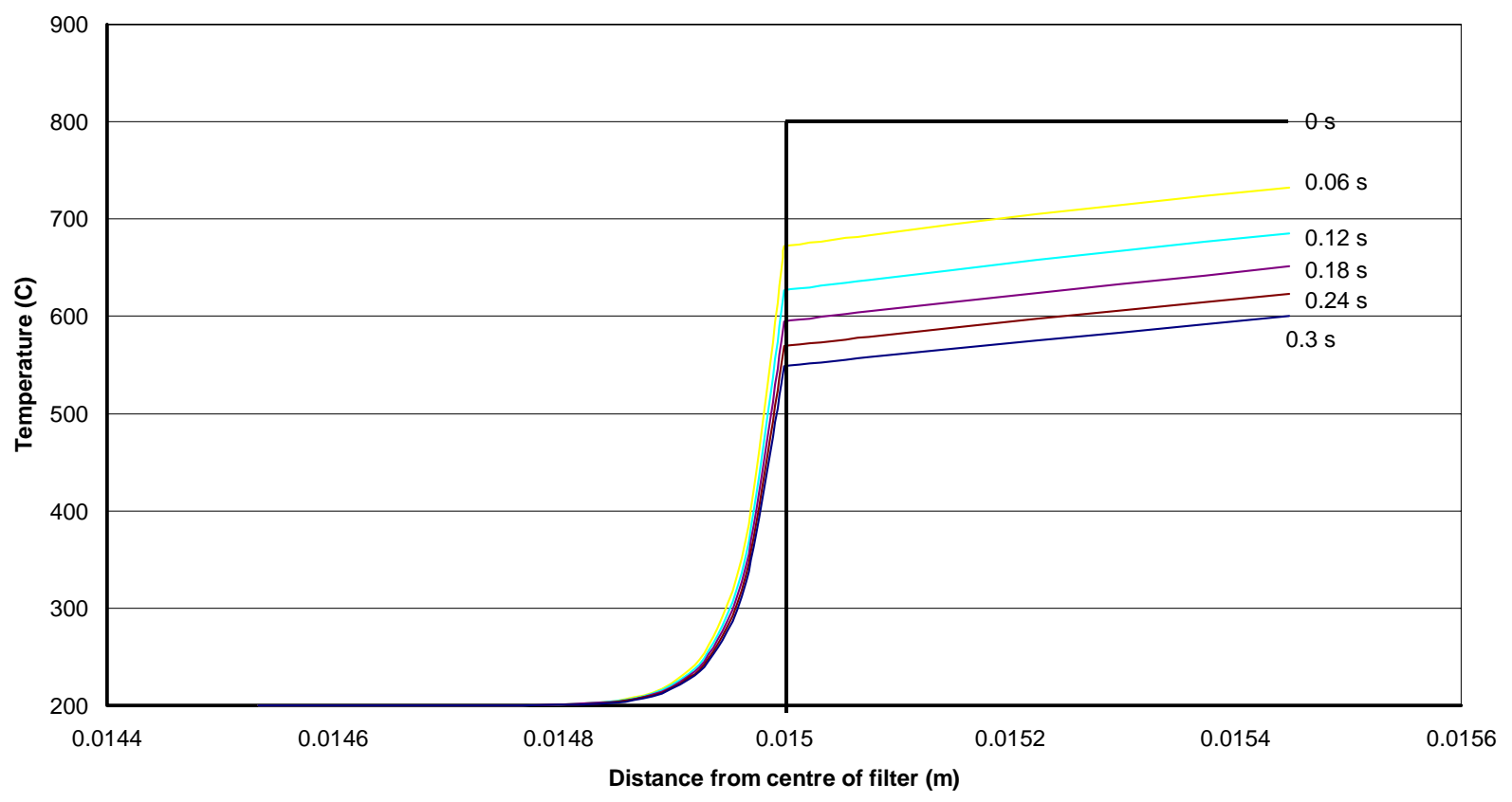

Figure 4.10 Temperature distributions in the vicinity of the inside wall of filter, $\mathrm{U}=\mathbf{3 . 6}$ $\mathrm{cm} / \mathrm{s}, \mathrm{M}($ Pulse $)=0.27 \mathrm{~kg} / \mathrm{s}, \mathrm{T}(\mathrm{fil})=800 \mathrm{C}, \mathrm{UC}=4 \%$ 


\section{Temperature drop along filter/ash interface during regular filtration}

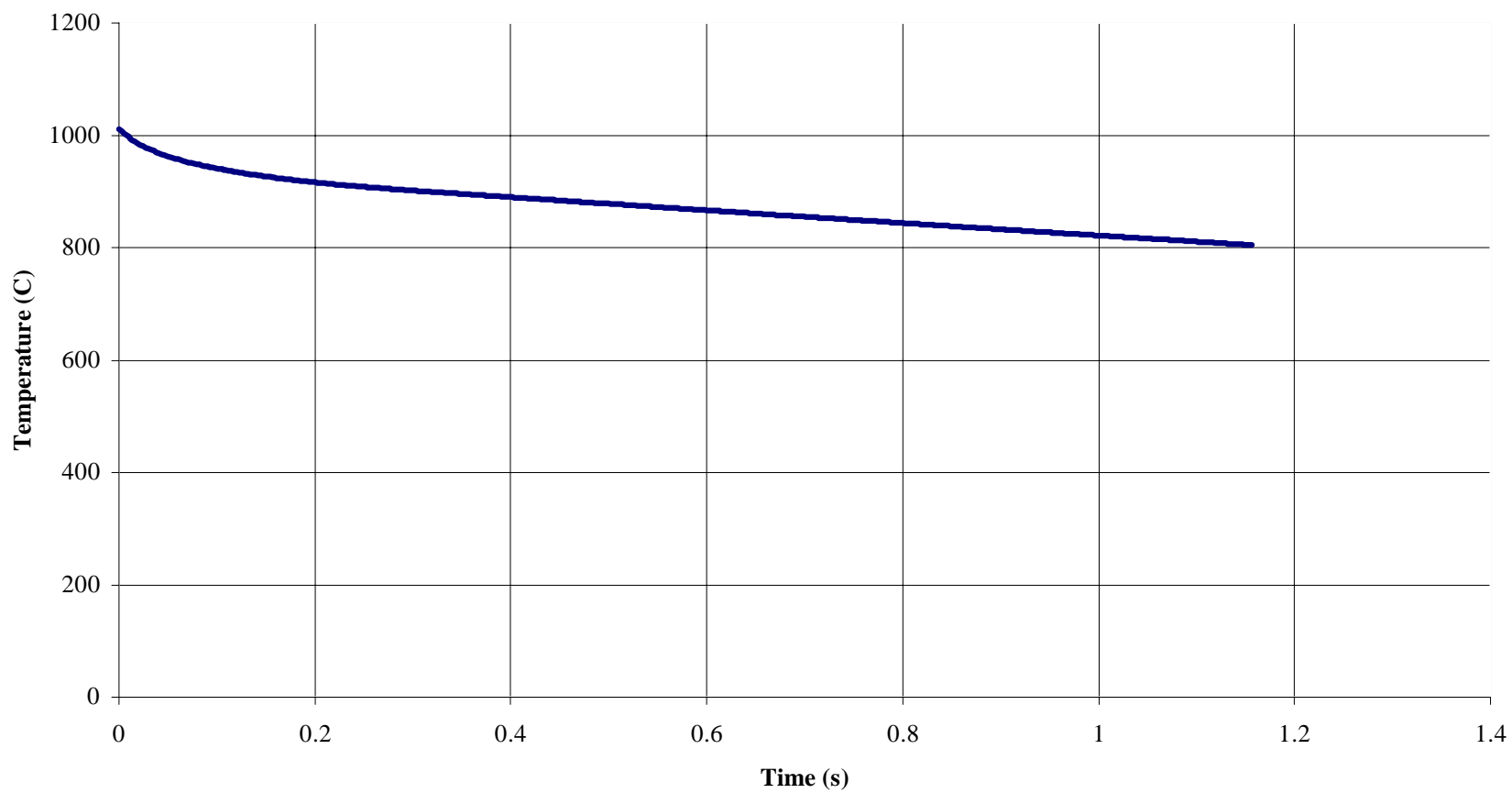

Figure 4.10 Temperature drop along outside wall of schumacher filter during regular filtration, $U=3.6$ $\mathrm{cm} / \mathrm{s}, \mathrm{M}($ pulse $)=0.27 \mathrm{~kg} / \mathrm{s}, \mathrm{T}(\mathrm{fil})=800 \mathrm{C}, \mathrm{UC}=4 \%$ 
Temperature drop along ash layer at $0.2 \mathrm{~mm}$ from outer wall of filter, during regular filter operation

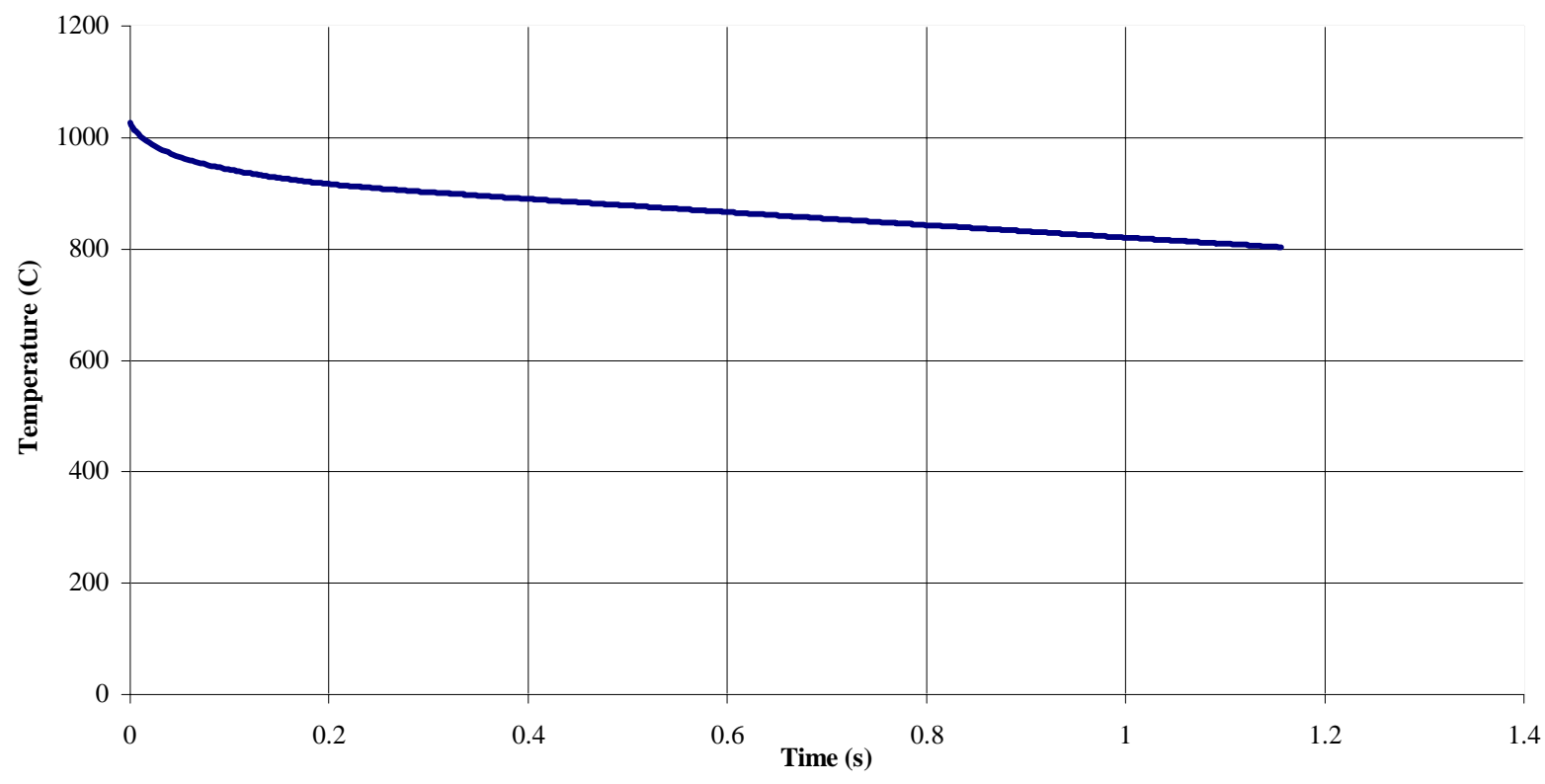

Figure 4.11 Temperature drop at the edge of a $0.2 \mathrm{~mm}$ thick residual ash layer during regular filtration, $U=3.6 \mathrm{~cm} / \mathrm{s}, \mathrm{M}($ pulse $)=0.27 \mathrm{~kg} / \mathrm{s}, \mathrm{T}(\mathrm{fil})=800 \mathrm{C}, \mathrm{UC}=4 \%$ 


\section{CHAPTER 5}

\section{DETERMINATION OF ASH DEPOSIT COMPOSITION}

\subsection{Introduction}

\section{Combustion in Fluidized Beds}

Combustion of coal in fluidized beds is becoming increasingly common. The atmospheric, fluidized bed combustion (AFBC) technology has been commercialized in the last two decades and the pressurized fluidized bed combustion (PFBC) is now following suit [15]. The fluidized bed technologies are among the most important recent development in coal combustion. Today, the fluidized bed boilers compete with the stoker boilers in commercial scale and with the pulverized coal fired boilers at the utility scale.

A fluidized bed consists of a bed of particles set in vigorous, turbulent motion by the combustion air blowing upward through the bed. The particles are mostly inert materials such as coal ash or sand, or sulfur sorbents such as limestone or dolomite. The coal particles make up only around $1 \%$ of the bed mass. At low air velocities, the air flows through the bed without moving the particles and the bed remains fixed. At velocities greater than the minimum fluidizing velocity, the bed is fluidized and the air flows through the bed in bubbles; thus the bubbling fluidized bed (BFB). At velocities approaching or greater than the free fall velocity of the particles, the particles become entrained in the air and are carried out of the furnace and externally cycled back to the bottom of the bed, thus the circulating fluidized bed. 


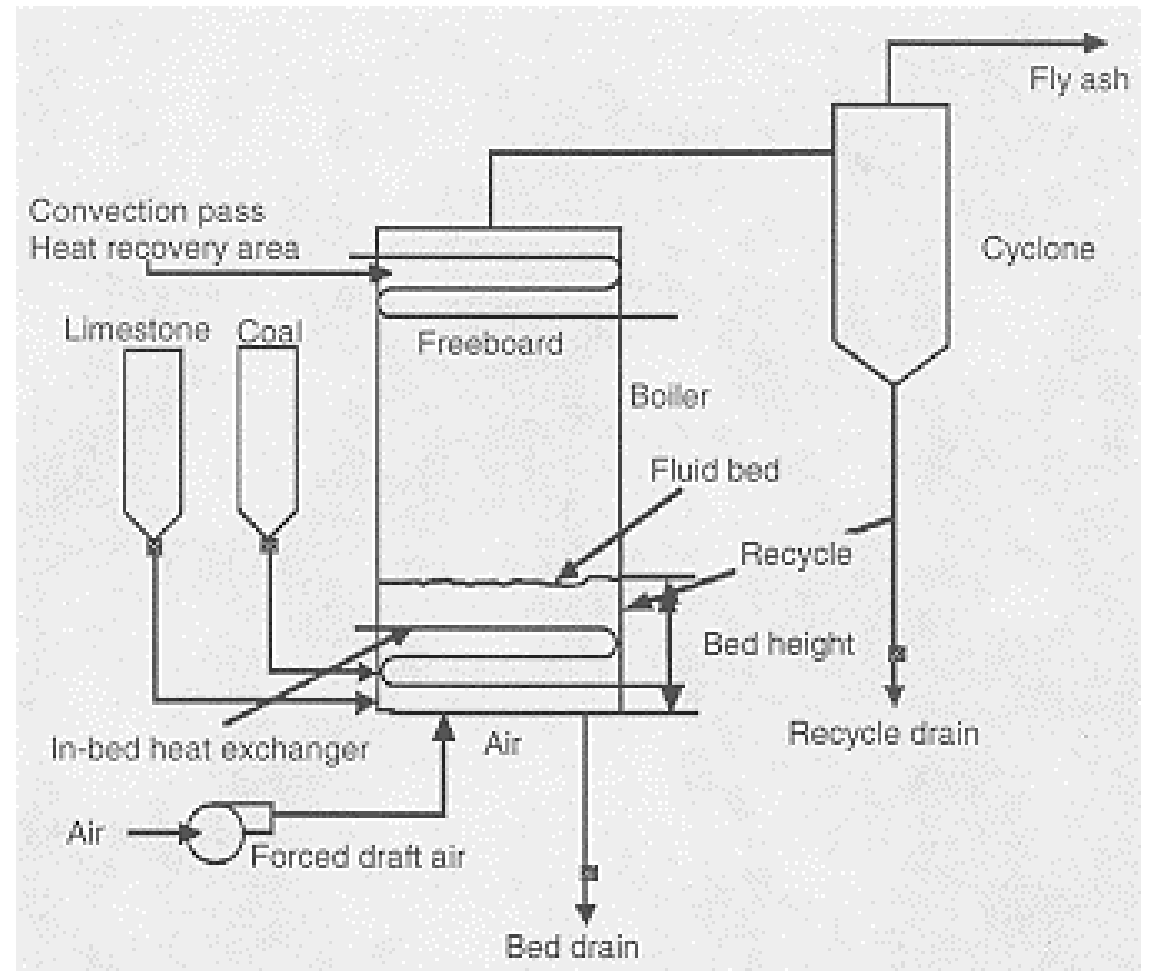

Figure 5.1 Bubbling fluidized bed schematic [16]

The basic aspects of the atmospheric, bubbling fluidized bed are illustrated in Fig 5.1. The run-of-mine coal, along with limestone is crushed to sizes of about 2.5 to $3.2 \mathrm{~cm}$, depending on whether there is an under-bed or an over-bed feed system. The crushed coal and limestone are fed to the fluidized bed of coal ash and limestone particles. To start combustion, the bed is preheated to about 800 to $1000{ }^{0} \mathrm{~F}$, depending on the particular coal properties. The coal particles, introduced in the fluidized bed are heated, dried, devolatilized, ignited, and burned, leaving ash; the residence time of the coal particles in the bed is typically around $1 \mathrm{~min}$. and usually sufficient for 80 to $90 \%$ burnout. The temperature of the bed is increased to the operating temperature, usually about $1500{ }^{0} \mathrm{~F}$ and is maintained at this relatively low level by removing enough heat, usually 40 to $45 \%$ of the heat input, with an in-bed heat exchanger. The limestone particles, introduced into 
the bed, are heated and calcined; the calcium oxide then reacts with sulfur dioxide to for calcium sulfate. Due to intensive mixing, the heat transfer rates in the bed are high and the temperature of the bed is essentially uniform. Consequently, the heat transfer rate between the bed and the in-bed heat exchanger is high in spite of the low bed temperature. The low bed temperature minimizes formation of the thermal nitric oxides and helps reduce the fuel nitric oxides. It also helps reduce slagging and fouling. [15] This is because these low temperatures are below the sintering temperature and the particles remain essentially as minerals in nature.

The atmospheric, circulating fluidized beds, developed more recently, are becoming increasingly important for the large units. The circulating fluidized bed is similar to the bubbling bed; the differences stem from smaller coal and limestone particle sizes and higher gas velocities. The bed fills the entire furnace volume although most of the mass is still in the lowest third of the bed. Thus, combustion takes place throughout the furnace.

The main process in pulverized coal combustion is the heterogeneous chemical reaction of carbon from coal with oxygen from air to produce carbon dioxide:

\section{$\mathrm{C}+\mathrm{O}_{2} \rightarrow \mathrm{CO}_{2}$}

At atmospheric pressure, limestone is the preferred sorbent. The limestone calcines to form the calcium oxide and to develop pores :

\section{$\mathrm{CaCO}_{3} \rightarrow \mathrm{CaO}+\mathrm{CO}_{2}$}


The sulfur dioxide and oxygen penetrate the pores and reacts with the calcium oxide to form calcium sulfate, a solid:

$$
\mathrm{CaO}+\mathrm{SO}_{2}+1 / 2 \mathrm{O}_{2} \rightarrow \mathrm{CaSO}_{4}
$$

which can be removed with the ash.

\subsection{Development of a combustion Model}

Fig 5.3 illustrates schematically, the combustion model that is used for the analysis.

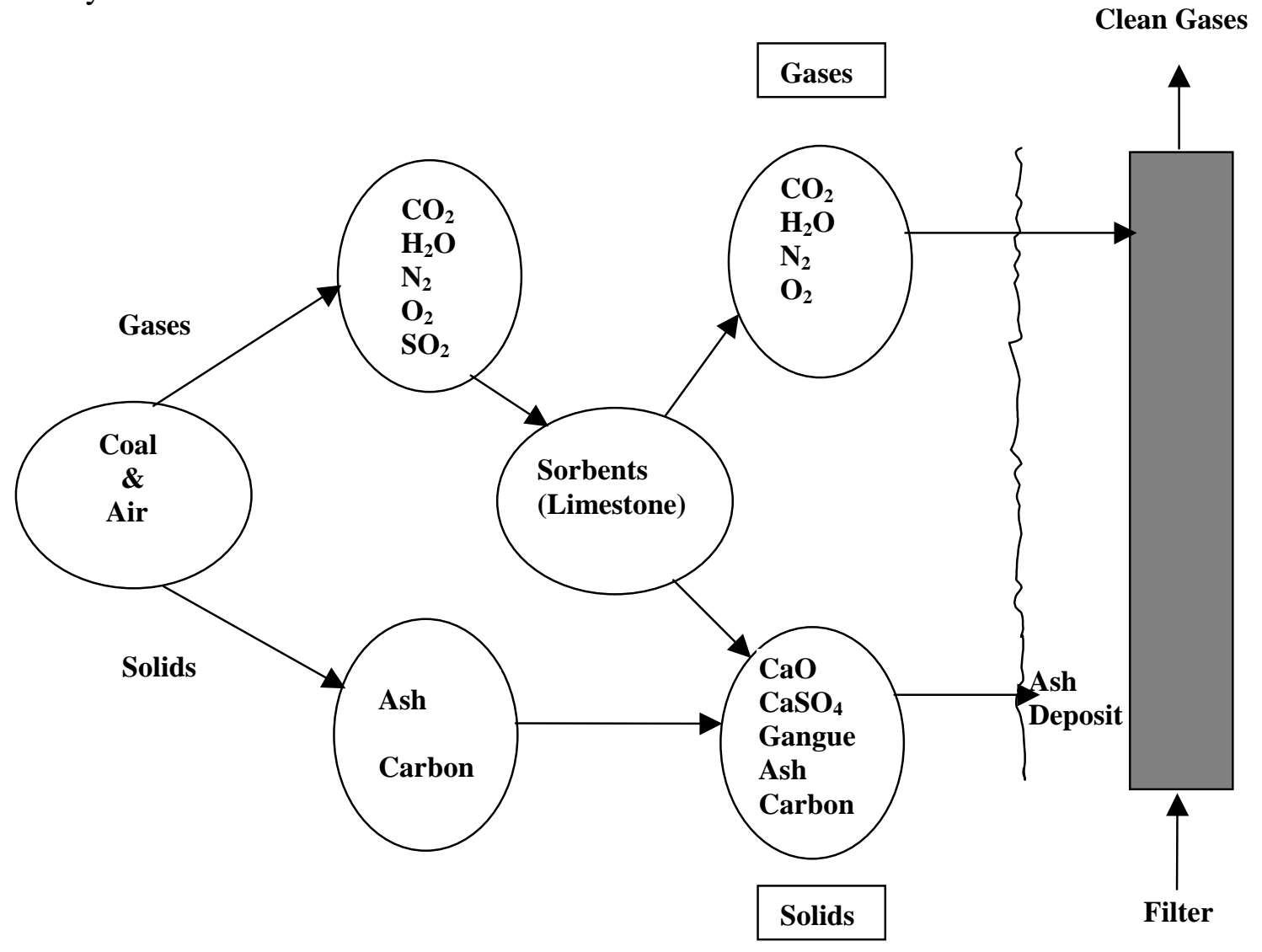

Fig 5.2 Schematic representation of the combustion process 
The products of combustion of coal were divided into two categories namely, solid products and gaseous products. The gaseous products include carbon dioxide $\left(\mathrm{CO}_{2}\right)$, oxygen $\left(\mathrm{O}_{2}\right)$, nitrogen $\left(\mathrm{N}_{2}\right)$, water-vapor $\left(\mathrm{H}_{2} \mathrm{O}\right)$ and sulfur dioxide $\left(\mathrm{SO}_{2}\right)$, while the solid products include mainly the mineral matter (ash) and carbon from coal that remains unburned. Limestone $\left(\mathrm{CaCO}_{3}\right)$ has been considered as the sorbent, which eliminates the $\mathrm{SO}_{2}$. Commercially available limestone usually contains a certain percentage of gangue, which is also considered as part of the ash deposit.

The gaseous products enter the candle filter radially leaving the solids behind on the filter surface and they pass out of the filter from the top. The solid products, are carried along with the flow of the gases and form a deposit on the filter wall, which is initially soft. In order to clean the deposit, generally a back pulse jet of air is used. During the back-pulse cleaning operation, the oxygen concentration is at least two orders of magnitude higher than that during the actual combustion process. As a result, carbon that remained unburned and in the ash deposit does undergo combustion during the backpulse event, resulting in heat generation and a local increase in temperature in the ash deposit [22].

\subsection{Development of a computer program for estimation of heat generation}

In order to estimate the heat generated, a computer program has been developed. The program essentially uses stoichiometry to estimate the concentration of unburned carbon in the deposit. In the program, all essential parameters such as coal-composition, excess-air percentage, calcium : sulfur ratio and percentage unburned carbon are treated as variables. The basic stoichiometric calculations used in the program are described below : 
5.3.1 Estimation of the products of combustion

Step 1. Calculation of the air-fuel stoichiometric co-efficient

$$
\begin{aligned}
{\left[\mathrm{C}_{\mathrm{x} 1} \mathrm{H}_{\mathrm{x} 2} \mathrm{~N}_{\mathrm{x} 3} \mathrm{O}_{\mathrm{x} 4} \mathrm{~S}_{\mathrm{x} 5} \mathrm{Ash}_{\mathrm{x} 6}\right]+\mathrm{X}\left[\mathrm{O}_{2}+3.76 \mathrm{~N}_{2}\right] \rightarrow } \\
{[\mathrm{v} 1] \mathrm{CO}_{2}+[\mathrm{v} 2] \mathrm{H}_{2} \mathrm{O}+[\mathrm{v} 3] \mathrm{N}_{2}+[\mathrm{v} 4] \mathrm{SO}_{2}+[\mathrm{v} 5](\mathrm{Ash}) }
\end{aligned}
$$

Knowing the coal composition, a chemical balance of equation (5.1) is performed in order to calculate the stoichiometric air:fuel ratio as ;

$$
X=\frac{2 \mathrm{v}_{1}+\mathrm{v}_{2}+2 \mathrm{v}_{4}-\mathrm{x}_{4}}{2}
$$

where ;

$$
\begin{aligned}
& \mathrm{v}_{1}=\mathrm{x}_{1} \\
& \mathrm{v}_{2}=\mathrm{x}_{2} \\
& \mathrm{v}_{4}=\mathrm{x}_{5} / 2
\end{aligned}
$$

\section{Step 2. Setup actual combustion equation}

Knowing the stoichiometric coefficient from equation (5.2) and other input parameters such as $\mathrm{Ca}: \mathrm{S}$ ratio (R), excess-air co-efficient (EA), percentage of carbon 
that remains unburned and percentage of gangue in limestone, the actual combustion equation may now be setup as ;

$\left[\mathrm{C}_{\mathrm{x} 1} \mathrm{H}_{\mathrm{x} 2} \mathrm{~N}_{\mathrm{x} 3} \mathrm{O}_{\mathrm{x} 4} \mathrm{~S}_{\mathrm{x} 5} \mathrm{Ash}_{\mathrm{x} 6}\right]+(1+\mathrm{EA}) \mathrm{X}\left[\mathrm{O}_{2}+3.76 \mathrm{~N}_{2}\right]+\left(\mathrm{Rx}_{5}\right)\left[\mathrm{CaCO}_{3}\right]+[\mathrm{Gangue}]$

$\rightarrow$

$\mathrm{v}_{1}\left[\mathrm{CO}_{2}\right]+\mathrm{v}_{2}\left[\mathrm{H}_{2} \mathrm{O}\right]+\mathrm{v}_{3}\left[\mathrm{CaSO}_{4}\right]+\mathrm{v}_{4}\left[\mathrm{~N}_{2}\right]+\mathrm{x}_{7}[\mathrm{C}]+\mathrm{v}_{5}\left[\mathrm{O}_{2}\right]+\mathrm{v}_{6}[\mathrm{CaO}]+[\mathrm{Ash}]+$ [Gangue]

As before, a chemical balance of equation (5.3) was performed in order to estimate the various products formed as:

1.Moles of $\mathrm{CO}_{2}$ formed, $\mathrm{v}_{1}=\mathrm{x}_{1}+\mathrm{Rx}_{5}-\mathrm{x}_{7}$

and weight of $\mathrm{CO}_{2}$ formed $=(44) \mathrm{v}_{1}$

2.Moles of $\mathrm{H}_{2} \mathrm{O}$ formed, $\mathrm{v}_{2}=\mathrm{x}_{2} / 2$

and weight of $\mathrm{H}_{2} \mathrm{O}$ formed $=(18) \mathrm{v}_{2}$

3.Moles of $\mathrm{CaSO}_{4}$ formed, $\mathrm{v}_{3}=\mathrm{x}_{5}$

and weight of $\mathrm{CaSO}_{4}$ formed $=(136) \mathrm{v}_{3}$

4.Moles of $\mathrm{N}_{2}$ formed, $\mathrm{v}_{4}=\left\{\mathrm{x}_{3}+2(1+\mathrm{EA}) \mathrm{X}(3.76)\right\} / 2$ 


$$
\text { and weight of } \mathrm{N}_{2} \text { formed }=(28) \mathrm{v}_{4}
$$

5.Moles of $\mathrm{O}_{2}$ formed, $\mathrm{v}_{5}=\left\{\mathrm{x}_{4}+2(1+\mathrm{EA}) \mathrm{X}+3 \mathrm{Rx} \mathrm{x}_{5}-2 \mathrm{v}_{1}-\mathrm{v}_{2}-4 \mathrm{v}_{3}-\mathrm{v}_{6}\right\} / 2$

$$
\text { and weight of } \mathrm{O}_{2} \text { formed }=(32) \mathrm{v}_{5}
$$

From the above equations, the total weight of the solid products (the deposit) may be calculated and used to estimate the percentage of unburned carbon in the solid matter that actually gets deposited on the filter wall.

\subsubsection{Calculation of initial hard ash thickness}

The thickness of deposit required for complete consumption of oxygen in the back-pulse air was calculated by knowing the mass-flow of air $(m)$ during the backpulse cleaning operation and the total duration $(\mathrm{t}=0.3 \mathrm{~s})$, as described below:

Assuming a mass fraction of $29 \%$ oxygen in air, the actual quantity of oxygen available for combustion,

$$
m_{o_{2}}=(0.29)\left(\dot{m}_{\text {air }} t\right)
$$

and mass of carbon required for oxygen consumption is,

$$
\mathrm{m}_{\text {carbon }}=\left(\frac{12}{32}\right) \mathrm{m}_{\mathrm{O}_{2}}
$$


and the actual mass of deposit needed for oxygen consumption,

$$
\mathrm{m}_{\text {deposit }}=\left(\frac{\text { Mass of deposit }}{\text { Mass of unburned Carbon }}\right) \mathrm{m}_{\text {carbon }}
$$

and the volume of deposit needed for oxygen consumption,

$$
V_{\text {deposit }}=\frac{\text { Mass of deposit }}{\text { Deposit Density }}
$$

The deposit density has to be determined independently and in the current study, the value used was selected based on measurements already made [refer section 4.3.2]. Therefore,

thickness of deposit needed for oxygen consumption,

$$
\Delta \mathrm{r}=\frac{\mathrm{V}_{\text {deposit }}}{(\text { Outer Filter Area)(Filter Length })}
$$

\subsubsection{Calculation of Heat generation rate}

The enthalpy of combustion is essentially the enthalpy of combustion for the conversion of carbon to carbon dioxide i.e.:

$$
\mathrm{C}+\mathrm{O}_{2} \rightarrow \mathrm{CO}_{2} \quad \Delta \mathrm{H}=-393.5 \mathrm{~kJ} / \mathrm{mole}
$$


Knowing the enthalpy of combustion $(\Delta \mathrm{H})$, the mass-flow of Oxygen $\left(\left(\mathrm{mo}_{2}\right)\right)$ and the thickness of the deposit ( $\Delta \mathrm{r}$ from equation 5.18), the heat generation rate in the deposit was calculated as;

$$
\dot{Q}^{\prime \prime \prime}=\Delta H\left(\frac{12}{32} \dot{m}_{O_{2}}\right) \frac{1}{2 \Pi r \Delta r L}
$$




\section{CHAPTER 6}

\section{POTENTIAL FOR SINTERING IN ASH DEPOSITS}

\subsection{Review of reaction rates for sintering}

Fluidized bed combustion processes are used for cleaner and more efficient energy generation from feedstocks such as coals, lignites, straws, peats and waste liquors. The processes which are operated at high temperatures involve systems which are multiphase and have complex chemical reactions.

The development of strength in ash deposits is due primarily to sintering or densification of the deposit [16].

Kingery et al [17] have identified the different mechanisms for sintering as;

1. By evaporation and condensation

2. By viscous flow

3. By surface diffusion

4. By grain-boundary or lattice diffusion

5. By plastic deformation

However, Benson et al [16] have suggested that liquid phase or viscous flow sintering is the dominant mechanism by which ash deposits sinter. They have also suggested that other mechanisms may also be involved, but to a very less extent. Hence, viscous flow sintering is the primary focus in the current research.

Viscous flow is illustrated in Figure 6.1, [16] where two particles are beginning to sinter. The sintering potential depends on both the amount and the physical properties (e.g viscosity) of the liquid phase. In addition, the liquid phase can be either reactive or 
non-reactive with respect to solid components in the melt. Viscous flow sintering with a reactive liquid phase results in the formation of large amounts of liquid. There is an appreciable solubility of the solid phases in the liquid and good wetting of the solid by the liquid. Slagging deposits often sinter by viscous flow with a reactive liquid phase. On the other hand, viscous flow sintering with a non-reactive liquid phase does not lead to dissolution of the solid components. This type of sintering generally plays a role in the strengthening of low-temperature fouling deposits where sulfates bond silicate particles

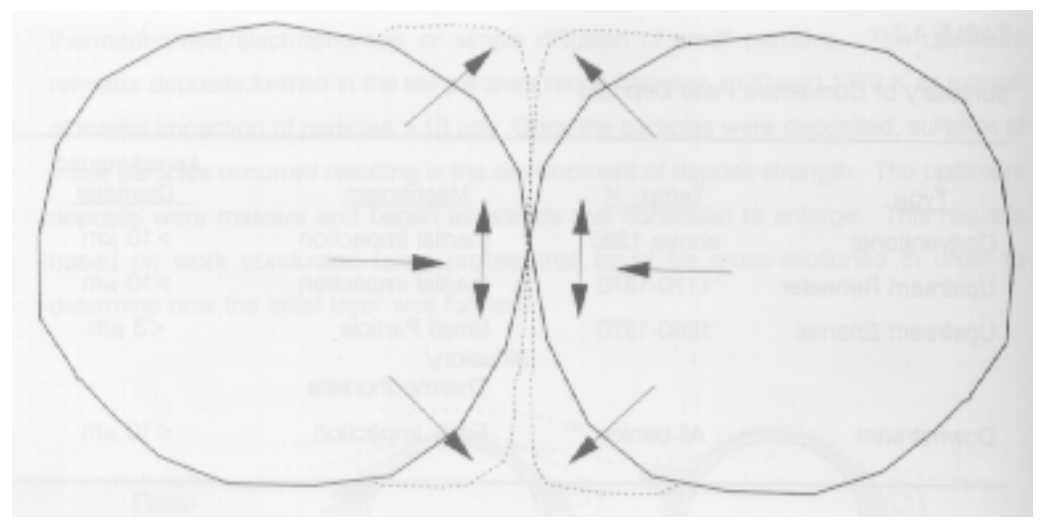

Figure 6.1 Viscous flow sintering of two particles (direction of arrows indicate the flow of mass) [16]

together with little or no reaction between the silicate and the sulfate phases. Sintering of these deposits by viscous flow of a non-reactive liquid takes significantly longer than the time required for the sintering of slagging deposits since the liquid must first accumulate as a result of sulfation reactions and/or condensation. Solid state sintering may also play a role in the densification of low-temperature fouling deposits. 
The driving force for densification is derived from the capillary pressure of the liquid phase between particles. When two particles that are coated with a liquid phase are in contact with each other, the inter-particle space becomes a capillary in which substantial capillary pressure can develop. The capillary pressure increases densification by;

1. Re-arranging the particles to increase packing effectiveness

2. Increasing the number of contact points between particles

3. Promoting the dissolution of smaller particles to produce larger particles (Ostwald ripening)

4. Transferring material away from particle contact points and causing particle centers to move closer together.

The reactivity and liquid forming propensity of the deposited ash particles can be approximated from the base-to-acid ratio distribution of the particles. Basic components include network modifiers such as calcium or sodium. Acidic components include species such as silica which are network formers. A mixture of acidic and basic components tends to react to form low melting point species. Therefore, a deposit which contains both acidic and basic particles has a high potential for liquid phase formation. In contrast, a deposit consisting of particles which are either all basic or all acidic has less potential for liquid phase formation. Particles which contain both acidic and basic components may also melt at low temperatures and contribute to liquid phase sintering.

Crystallization is another factor which may affect the densification process. The formation of crystals from a liquid phase reduces the amount of liquid. The composition of the residual liquid, and hence its physical properties, may also change as components 
are selectively removed by crystallization. The formation of the crystals or solid grains themselves may also affect the local density and strength of the deposit. In general, crystallization tends to slow the densification process and weaken the deposit.

Relationships are currently being developed between the chemical composition and physical properties of coal ash slags [16]. Two key physical properties for viscous flow sintering are the viscosity $(\eta)$ and the surface tension $(\gamma)$. Nowak and Benson [16] have performed experiments with homogenous slags in order to relate the base-to-acid ratio (chemical composition) to the surface tension-to-viscosity ratio $(\gamma / \eta)$. Figure 6.2 [16] is a plot of the measured $\gamma / \eta$ as a function of the base-to-acid ratio, which indicates that $\gamma / \eta$ is clearly dependent on the chemistry of the system. A linear relationship was obtained from experiments performed in air, while an exponential increase was observed for experiments performed in $\mathrm{CO} / \mathrm{CO}_{2}$ environment. The rapid

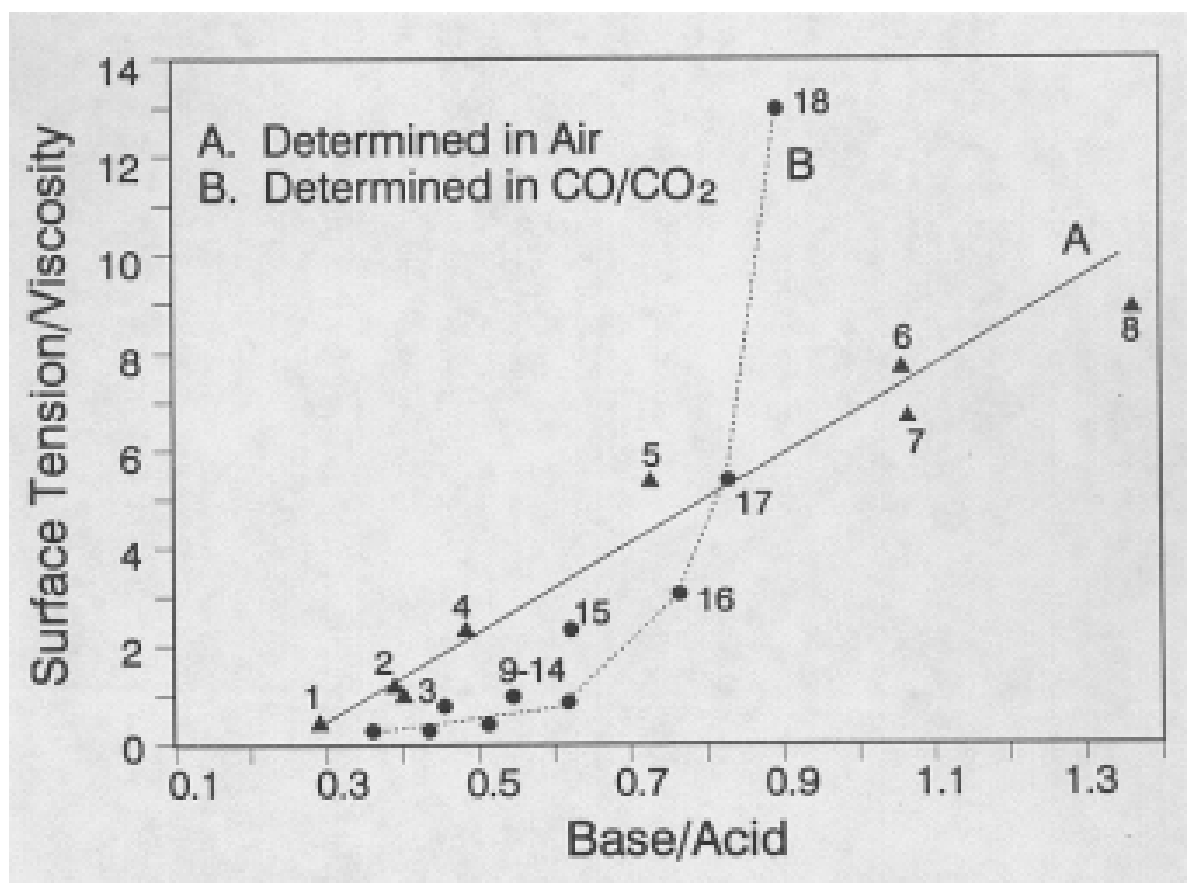

Figure 6.2 Measured surface tension/viscosity ratio versus base-to-acid ratio, determined in air and a $\mathrm{CO} / \mathrm{CO}_{2}$ atmosphere [16] 
change for the $\mathrm{CO} / \mathrm{CO}_{2}$ experiments was due to a change in the oxidation state of the iron which decreased the viscosity of the liquid. Compressive strengths were also determined for selected homogeneous slag pellets that were sintered in air at $1370{ }^{0} \mathrm{~K}$ as shown in Figure 6.3. The pellet strength increased with increasing $\gamma / \eta$, as expected for viscous flow sintering.

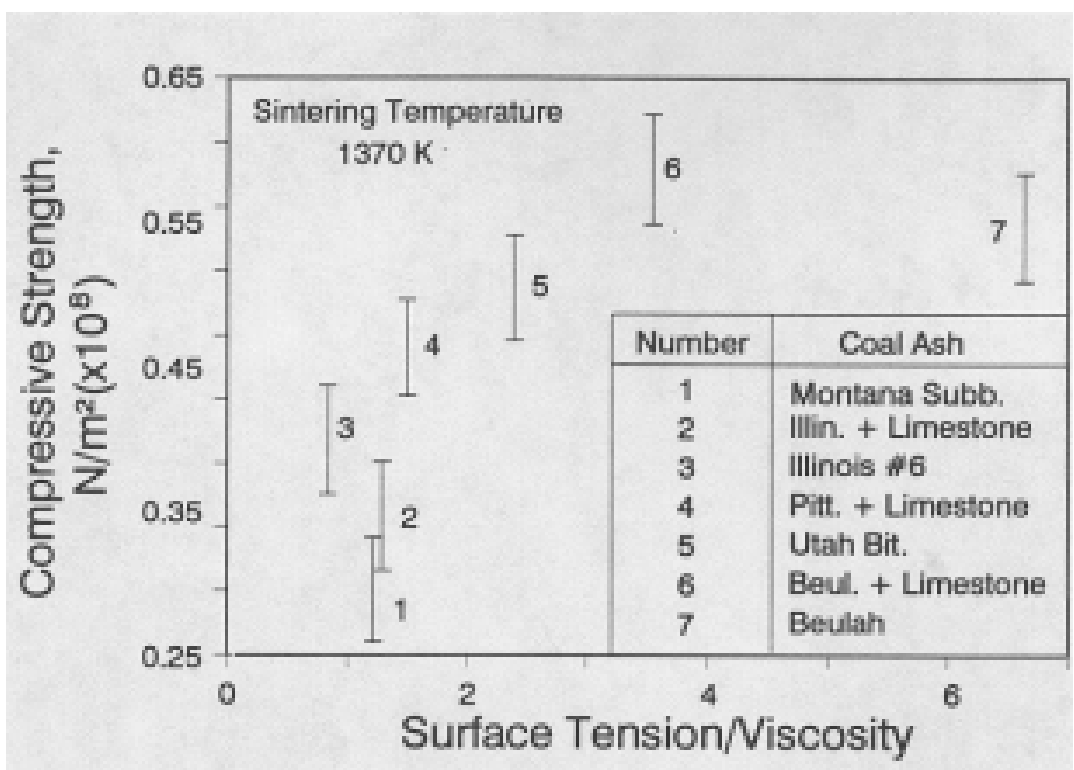

Figure 6.3 Compressive strengths of pellets sintered at $1370 \mathrm{~K}$ in air, versus the surface tension/viscosity ratio for selected homogeneous coal ashes [16]

\subsection{A model for sintering in fluidized bed combustion processes}

Prediction of deposit strength is essential to the development of a feasible ash management strategy and the performance evaluation of new fuels in existing boilers. As discussed earlier, viscous flow sintering is the dominant process in deposit strength development. 
Frenkel [18] developed a relationship that defines the sintering or coalescence of particles in terms of measurable parameters such as particle size, viscosity and surface tension. Here, the sintering of two particles has been modeled by representing the particles as smooth spheres and considering the viscous flow of material at the contact surface under surface tension or applied forces. For two such particles in contact, the initial deformation of the particles is the result of surface tension forces pulling the particles together. This results in a viscous flow and the diffusion of the material.

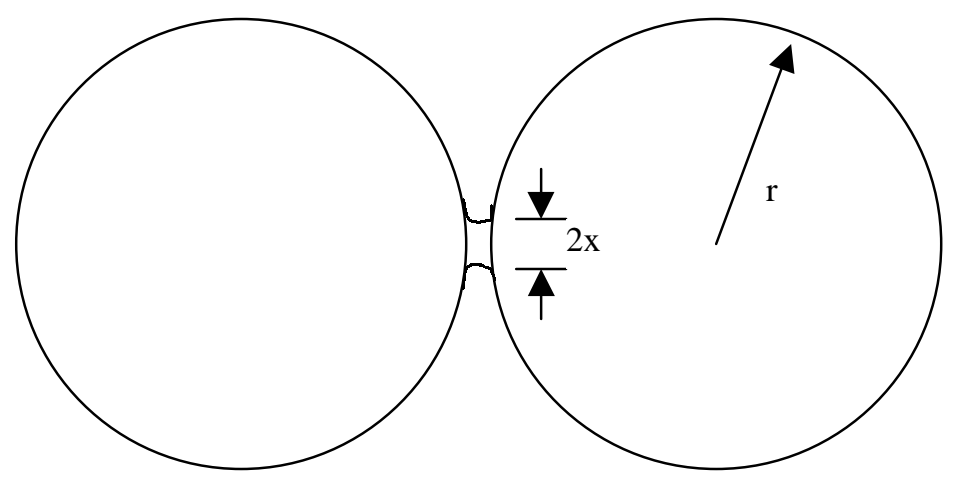

Figure 6.4 Viscous flow sintering of two spheres

The rate of neck growth, at the interface between the two particles is represented by an equation of the form :

$$
\left(\frac{x}{r}\right)^{2}=k t
$$

where,

$\mathrm{x}$ is the neck radius

$\mathrm{t}$ is the time

$r$ is the radius of the particle 
In the Frenkel equation [18],

$$
k=\frac{3 \gamma}{2 r \eta}
$$

where;

$\gamma$ is the surface tension and

$\eta$ is the viscosity

However, in real systems, the particles are neither perfectly smooth spheres nor are they mono-disperse. Furthermore, in glassy systems, the rheology is unlikely to be Newtonian in character. An Arrhenius dependence of viscosity on temperature is often taken as [18];

$$
\eta=\eta_{0} e^{\left(\frac{E}{R T}\right)}
$$

In simple model of a fluidized bed, particles may be considered to remain in close proximity, in quiescent zones with little relative motion, until they are disturbed by the movement of a bubble. Bubbles affect particles in two ways:

1. By producing flow and hence displacement of particles relative to each other

2. By inducing convective movement of particles upwards through the bed, as a result of which re-circulation of particles occurs, with particles in the dense phase moving downwards. Although the downward movement can, 
theoretically, be uniform across a horizontal section of the bed, in practice, and particularly in large beds, it may be concentrated into certain zones, for example near to the wall.

However, if it is assumed that the residence time in the quiescent zones is sufficiently long for sinter necks to reach a critical size such that the agglomerates formed are sufficiently strong not be fractured by the bubble motion, then the critical time, $\mathrm{t}_{\mathrm{s}}$ for sintering is given from the Frenkel equation as [10];

$$
t_{s}=\left(\frac{x}{r}\right)^{2} \frac{2 r \eta}{3 \gamma}
$$

This equation is applicable when $\mathrm{x} / \mathrm{r}<0.3$.

The rate of deposit strength development can be expressed as follows:

$$
\frac{d s}{d t}=\frac{3 k \gamma}{2 \eta \mathrm{r}}
$$

where;

$\mathrm{s}$ is the strength

$\mathrm{k}$ is a constant 
Figure 6.5 illustrates the relationship between the viscosity, surface tension and rate of sintering as a function of temperature.

The Frenkel model does not accurately describe the final stages of sintering where extensive neck growth has occurred. Instead, a model of Mackenzie and Shuttleworth [16] can be used to describe the shrinkage of isolated closed pores and densification kinetics in the later stages of sintering.

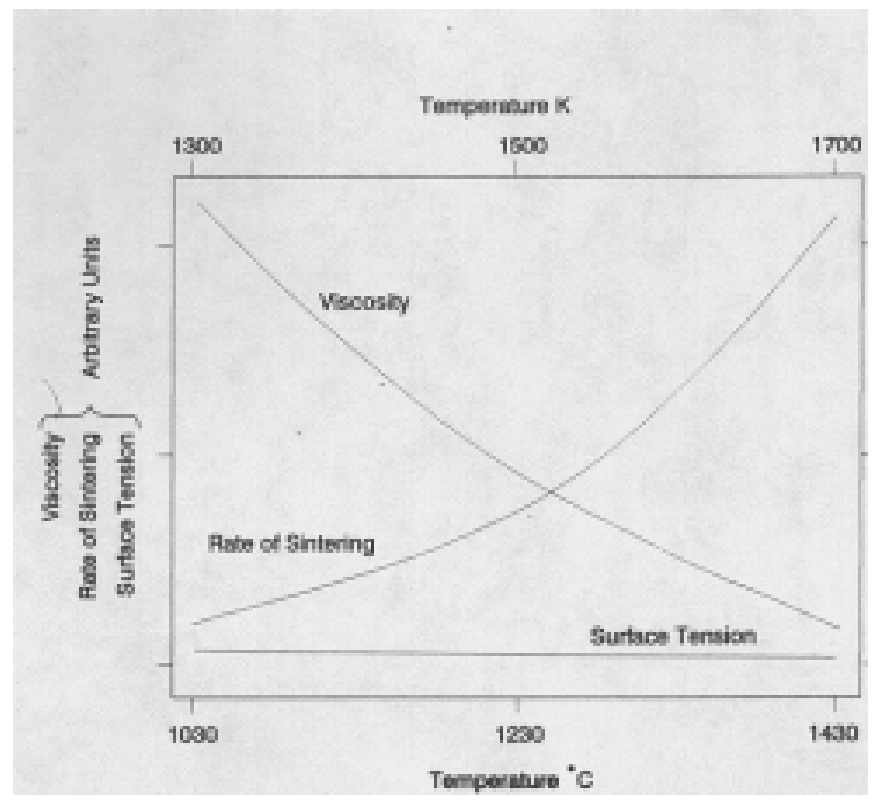

Figure 6.5 Effect of temperature on ash-sintering parameters [10] 


\subsection{Selected parameters for the sintering model}

\section{Viscosity of the ash}

In this study, the Frenkel model has been made use of, for calculating the times required for a strongly sintered bond to form. Further, an Arrhenius dependence of viscosity on temperature has been assumed as;

$$
\eta=\eta_{0} \mathrm{e}^{\mathrm{E} / \mathrm{RT}}
$$

Hence, it is needed to first evaluate the constants $\eta_{0}$ and the ratio, $\mathrm{E} / \mathrm{R}$.

Barrick and Moore [19] have presented a paper on the empirical correlation of coal ash viscosity with ash chemical composition. In this paper, a stepwise regression analysis has been used to correlate the coal ash viscosity versus temperature relationship with the ash chemical composition. In the current research, an Eastern US type coal in an oxidizing atmosphere has been selected. Barrick and Moore have presented the viscositytemperature relationship for such a coal in their paper. From these results, the constants $\eta_{0}$ and $E / R$ are calculated and are used in equation (6.4).

\section{Surface tension}

It is seen from the Frenkel equation that Surface tension is one of the factors influencing the sintering process. As is evident from Figure (6.4), the value of surface tension decreases slightly with increase in temperature.

Raask [10] has conducted a number of surface-tension tests at temperatures of upto $1750^{0} \mathrm{~K}$. The results varied from 0.25 to $0.4 \mathrm{~N} / \mathrm{m}$ and an average value of $0.32 \mathrm{~N} / \mathrm{m}$ has been proposed. This value has been chosen in the current research and has been assumed to remain constant. 


\section{Particle radius and $x / r$ ratio}

A uniform particle radius of $5 \mu \mathrm{m}$ has been selected for this research. For particles of this size, Raask [10] has suggested four arbitrary stages of sintering of ash deposit on boiler tubes, leading from the initial contact between the particles to the formation of fused slag where the shape of initial constituent particles is no longer distinguishable. These four stages of sintering are summarized in table, 6.1. In this research, analysis is being made for the possibility of a strongly sintered deposit forming on the candle filter and hence an $\mathrm{x} / \mathrm{r}$ ratio of 0.1 has been chosen. 


\begin{tabular}{|c|c|c|}
\hline Value of $x / r$ & Degree of sintering & Comment \\
\hline 0.001 & Onset of sintering & $\begin{array}{l}\text { The deposit of this degree } \\
\text { of sintering on boiler tubes } \\
\text { has no significant cohesive } \\
\text { strength and would } \\
\text { probably fall off under the } \\
\text { action of gravity and boiler } \\
\text { vibration. }\end{array}$ \\
\hline 0.01 & Slightly sintered matrix & $\begin{array}{l}\text { The deposit on boiler tubes } \\
\text { would probably be removed } \\
\text { by soot blowing. }\end{array}$ \\
\hline 0.1 & \begin{tabular}{|l} 
Strongly sintered deposit \\
\end{tabular} & $\begin{array}{l}\text { The deposit on boiler tubes } \\
\text { would be difficult to } \\
\text { remove by soot blowing. }\end{array}$ \\
\hline$>0.3$ & Slagging & $\begin{array}{l}\text { The ash particles lose their } \\
\text { original identity and the } \\
\text { deposit on boiler tubes } \\
\text { cannot be removed by soot } \\
\text { blowing. }\end{array}$ \\
\hline
\end{tabular}

Table 6.1 Degree of sintering based on the ratio of neck bond radius to particle $\operatorname{radius}(\mathrm{x} / \mathrm{r})[10]$ 


\section{CHAPTER 7}

\section{RESULTS \& CONCLUSIONS}

\subsection{Results from the combustion model}

\subsubsection{Introduction}

Composition of the coal and combustion conditions influence to a large extent, the amount of unburned carbon that is part of the ash deposited on boiler tubes. In the current research, it is being assumed that this unburned carbon in the deposit undergoes combustion during the surface regeneration operation, leading to heat generation and a local rise in deposit temperature. Since the amount of heat generated is dependent on the amount of unburned carbon undergoing combustion, it is required to estimate the amount of carbon in the deposit.

Taking into account the coal-composition and combustion conditions, the combustion model estimated the heat generated during the surface regeneration operation. The heat transfer model then calculated the temperature distribution during each surface regeneration event. The growth of the residual ash deposit was then estimated from a rather simple model for sintering. There were a very large number of parameters in this study. Therefore, a specific coal composition was selected to form the combustion products and a specific limestone composition was selected for the absorption of sulfur dioxide. The candle filter selected for this study is the Schumacher (\# S2097/352C [20]). The operating conditions selected were not very different from those employed at the Tidd power plant in Ohio, USA [13]. 
The basic study was concerned with the specific case of $4 \%$ unburned carbon and a product temperature of $800^{\circ} \mathrm{C}$. Therefore, the discussion is directed towards these conditions. Two other cases were considered, to obtain an indication of the significance of a change in unburned carbon or temperature. These conditions are shown in Table 7.1.

\begin{tabular}{|l|l|l|l|}
\hline & $\begin{array}{l}\text { Case I } \\
\text { (Reference) }\end{array}$ & Case II & Case III \\
\hline$\%$ unburned carbon & $4 \%$ & $2 \%$ & $4 \%$ \\
\hline Product temperature $\left({ }^{\circ} \mathrm{C}\right)$ & 800 & 800 & 700 \\
\hline
\end{tabular}

Table 7.1 Parameters employed in this study

\subsubsection{Selection of Coal}

In the present research, an Eastern US type coal burning in an oxidizing atmosphere has been selected. Table 7.2 lists the composition of such a coal:

\begin{tabular}{|l|l|}
\hline Element & \% Composition \\
\hline Carbon & 74 \\
\hline Hydrogen & 8 \\
\hline Oxygen & 3 \\
\hline Nitrogen & 4 \\
\hline Sulfur & 1 \\
\hline Ash & 10 \\
\hline
\end{tabular}

Table 7.2 Composition of Coal Used in This Study 


\subsubsection{Selection of combustion parameters}

Parameters that influence the combustion of coal are;

1. Amount of excess air available for combustion

2. Percentage of carbon in the coal that does not undergo combustion and remains unburned

3. Calcium to Sulfur ratio

4. Percentage of gangue in limestone being added

Table 7.3 lists the values of these parameters that have been selected in this research.

\begin{tabular}{|l|l|l|}
\hline Parameter & Case I & Case II \\
\hline Excess air (\%) & 30 & 30 \\
\hline Unburned carbon (\%) & 4 & 2 \\
\hline Calcium : Sulfur & 3 & 3 \\
\hline Gangue percentage in limestone (\%) & 4 & 4 \\
\hline
\end{tabular}

Table 7.3 Values of combustion parameters used in this research

\subsubsection{Results from the calculation of combustion products}

Basic stoichiometry, developed in chapter 5 was used to estimate the composition of the products of the combustion system. The stoichiometric Air/Fuel ratio was calculated and a value of 8.08 was obtained. Based on the data in Table 7.3, composition 
of the products of combustion formed, is shown in Table 7.4. These quantities are based on $100 \mathrm{~kg}$ of the selected coal.

\begin{tabular}{|c|c|c|c|c|}
\hline & Case I & Case I & Case II & Case II \\
\hline Product & Moles" & $\begin{array}{c}\text { Weight } \\
\text { (kg) }\end{array}$ & $\begin{array}{c}\text { Moles }{ }^{*} \\
(\mathrm{~kg})\end{array}$ & $\begin{array}{c}\text { Weight } \\
(\mathrm{kg})\end{array}$ \\
\hline $\mathrm{CO}_{2}$ & 6 & 264 & 6 & 264 \\
\hline $\mathrm{H}_{2} \mathrm{O}$ & 4 & 72 & 4 & 72 \\
\hline $\mathrm{CaSO}_{4}$ & 0.03 & 4.08 & 0.03 & 4.08 \\
\hline $\mathrm{N}_{2}$ & 39.65 & 1110.2 & 39.65 & 1110.2 \\
\hline $\mathrm{O}_{2}$ & 2.51 & 84.66 & 2.51 & 84.66 \\
\hline $\mathrm{C}$ & 0.25 & 2.96 & 0.12 & 1.48 \\
\hline $\mathrm{CaO}$ & 0.06 & 3.36 & 0.06 & 3.36 \\
\hline Ash & & 10 & & 10 \\
\hline Gangue & & 0.38 & & 0.38 \\
\hline
\end{tabular}

Based on $100 \mathrm{~kg}$ of coal

Table 7.4 Calculated Composition of Combustion Products

From the above results, when the unburned carbon \% was 4 , weight of unburned carbon is $2.96 \mathrm{~kg} / 100 \mathrm{~kg}$ of coal burned, and the total weight of solid products (referred to as 'ash') was calculated to be $20.78 \mathrm{~kg} / 100 \mathrm{~kg}$ of coal burned. The unburned carbon percentage in the deposit by weight is thus $2.96 / 20.78=14.24 \%$. 
When the unburned carbon \% was 2, weight of unburned carbon is $1.48 \mathrm{~kg} / 100 \mathrm{~kg}$ of coal burned, and the total weight of solid products was calculated to be $19.62 \mathrm{~kg} / 100$ $\mathrm{kg}$ of coal burned. The unburned carbon percentage in the deposit by weight is thus $1.48 / 19.62=7.54 \%$.

\subsubsection{Estimation of hard ash thickness}

The initial temperature history was calculated in the deposit using equations (4.5) through (4.15). The surface regeneration mass flow rate was $0.27 \mathrm{~kg} / \mathrm{s}$, which was assumed constant during the process. Flow rates were calculated using equation (4.31). Initially, the addition of residual ash was assumed to be that volume with unburned carbon that would consume all the oxygen in the surface regeneration flow. With every cycle of surface regeneration, the residual ash thickness was assumed to grow, resulting in an increased surface area for subsequent deposition. Hence, an iterative computer program was used to calculate the growth of deposit thickness with every cycle of operation. For these calculations, an oxygen fraction in air of $29 \%$ was used for the surface regeneration flow.

After the temperature cycles have been determined, the sintering model was employed to determine a more realistic growth for the residual ash.

Table 7.5(a) presents the results of this program and the growth of deposit thickness corresponding to the number of cycles of operation for an unburned carbon $\%$ of $4 \%$, while Table 7.5 (b) presents the results for an unburned carbon $\%$ of $2 \%$. 


\begin{tabular}{|l|l|l|}
\hline No. Of Cycles & $\begin{array}{c}\text { Thickness of ash deposited } \\
(\mathbf{m m})\end{array}$ & $\begin{array}{l}\text { Cumulative thickness } \\
(\mathbf{m m})\end{array}$ \\
\hline 1 & 0.21 & 0.21 \\
\hline 5 & 0.196 & 0.99 \\
\hline 10 & 0.190 & 1.8 \\
\hline 15 & 0.185 & 2.6 \\
\hline 20 & 0.180 & 3.6 \\
\hline 25 & 0.175 & 4.4 \\
\hline 30 & 0.171 & 5.2 \\
\hline
\end{tabular}

Table 7.5(a) Growth of residual ash thickness with cycles of operation with $4 \%$ unburned carbon

\begin{tabular}{|l|l|l|}
\hline No. Of Cycles & Thickness of ash deposited & Cumulative thickness \\
\hline 1 & 0.38 & 0.38 \\
\hline 5 & 0.358 & 1.83 \\
\hline 10 & 0.340 & 3.56 \\
\hline 15 & 0.330 & 5.21 \\
\hline 20 & 0.310 & 6.78 \\
\hline 25 & 0.290 & 8.28 \\
\hline 30 & 0.285 & 9.73 \\
\hline
\end{tabular}

Table 7.5(b) Growth of residual ash thickness with cycles of operation with $2 \%$ unburned carbon 


\subsection{Results from the heat transfer model}

\subsubsection{Description of model}

The heat transfer model developed in Chapter 4 was used to calculate the temperature profiles in the filter and the ash, both during the surface regeneration event as well as during the regular filtration operation.

The filter used in the analysis was a Schumacher SiC filter, which is made of silicon carbide grains bonded together with a clay binder. Since the surface re-generation is carried out at high temperatures (around $800^{\circ} \mathrm{C}$ ), both mechanical and thermal properties of the filter at higher temperatures were used. However, these properties were assumed to remain constant with temperature. Material and physical properties of the Schumacher filter used, are listed in Table 7.6 [21].

The number of nodes and intervals being made use of was calculated based on satisfying the stability criterion, which takes into consideration characteristics of the Schumacher filter and gas properties. This stability criterion is discussed in section 4.3 of Chapter 4. 


\begin{tabular}{|l|c|c|}
\hline Material or physical & Value & Units \\
property & & $/^{0} \mathrm{C}$ or $l^{0} \mathrm{~K}$ \\
\hline Co-efficient of thermal & $4.6 \mathrm{E}-6$ & $\mathrm{Kg} / \mathrm{m}^{3}$ \\
\hline Density & 1885 & \\
\hline Porosity & 0.31 & $\mathrm{~J} / \mathrm{kg}{ }^{0} \mathrm{C}$ or ${ }^{0} \mathrm{~K}$ \\
\hline Specific Heat & 690 & $\mathrm{~W} / \mathrm{m}^{0} \mathrm{C}$ or ${ }^{0} \mathrm{~K}$ \\
\hline Thermal conductivity & 5.84 & $\mathrm{~m}$. \\
\hline Permeability & & $\mathrm{m}$. \\
\hline Length & 1.5 & $\mathrm{~m}$. \\
\hline Inner radius & & $\mathrm{m}$. \\
\hline
\end{tabular}

Table 7.6 Material and physical properties of Schumacher filter [21]

Thermal and physical properties of the gases considered in this analysis are presented in Table (7.7) 


\begin{tabular}{|l|c|c|}
\hline \multicolumn{1}{|c|}{ Property } & Value ${ }^{*}$ & Units \\
\hline Density & 3.366 & $\mathrm{~kg} / \mathrm{m}^{3}$ \\
\hline Specific Heat & 1140.512 & $\mathrm{~J} / \mathrm{kg}{ }^{0} \mathrm{C}$ or ${ }^{0} \mathrm{~K}$ \\
\hline Thermal Conductivity & 0.0709 & $\mathrm{~W} / \mathrm{m}^{0} \mathrm{C}$ or ${ }^{0} \mathrm{~K}$ \\
& & $\mathrm{~kg} / \mathrm{m}-\mathrm{s}$ \\
\hline Viscosity & $4.44 \mathrm{E}-5$ & \\
\hline
\end{tabular}

$*$ at $800^{\circ} \mathrm{C}$ and 10 bar

\section{Table 7.7 Physical properties of gases at $800^{\circ} \mathrm{C}[11]$}

A program in 'Visual Basic' was written to solve the numerical equations described earlier. Flow chart depicting the program logic was shown in Chapter 4. Since the explicit finite difference method was used, the program calculates the temperatures of a node at an instant based on the temperatures of that node, the previous node and the next node, all at the previous instant. In order to store the generated results, a static array was declared in the program. The number of rows in this array corresponds to the number of time intervals used and the number of columns corresponds to the number of nodes used. Hence the size of the array is represented as;

[No. of intervals X No. of nodes] 
Each element (or cell) in the array was defined to be of the 'Double' data type supported by Visual Basic, that can store numbers with a precision of 16 digits and with a range of $-4.9 \times 10^{-34}$ to $+4.9 \times 10^{+34}$. Since such a data type occupies 8 bytes of memory, the total Random Access Memory (RAM) needed on the computer was calculated as;

$$
\begin{aligned}
\text { RAM needed } & =8 \text { bytes X No. of intervals X No. of nodes } \\
& =8 \text { X } 11000 \text { X } 650 \\
& \sim 58 \text { Mega Bytes }
\end{aligned}
$$

Hence, for this analysis, a 64 MB Pentium computer was used.

\subsubsection{Temperature profiles generated by the heat-transfer model}

Figures 7.1 through 7.5 show the various temperature profiles generated by the model during surface regeneration and regular operation of the filter. 
Temperature distribution in an ash layer $0.2 \mathrm{~mm}$ from outer wall of filter, after one cycle of operation

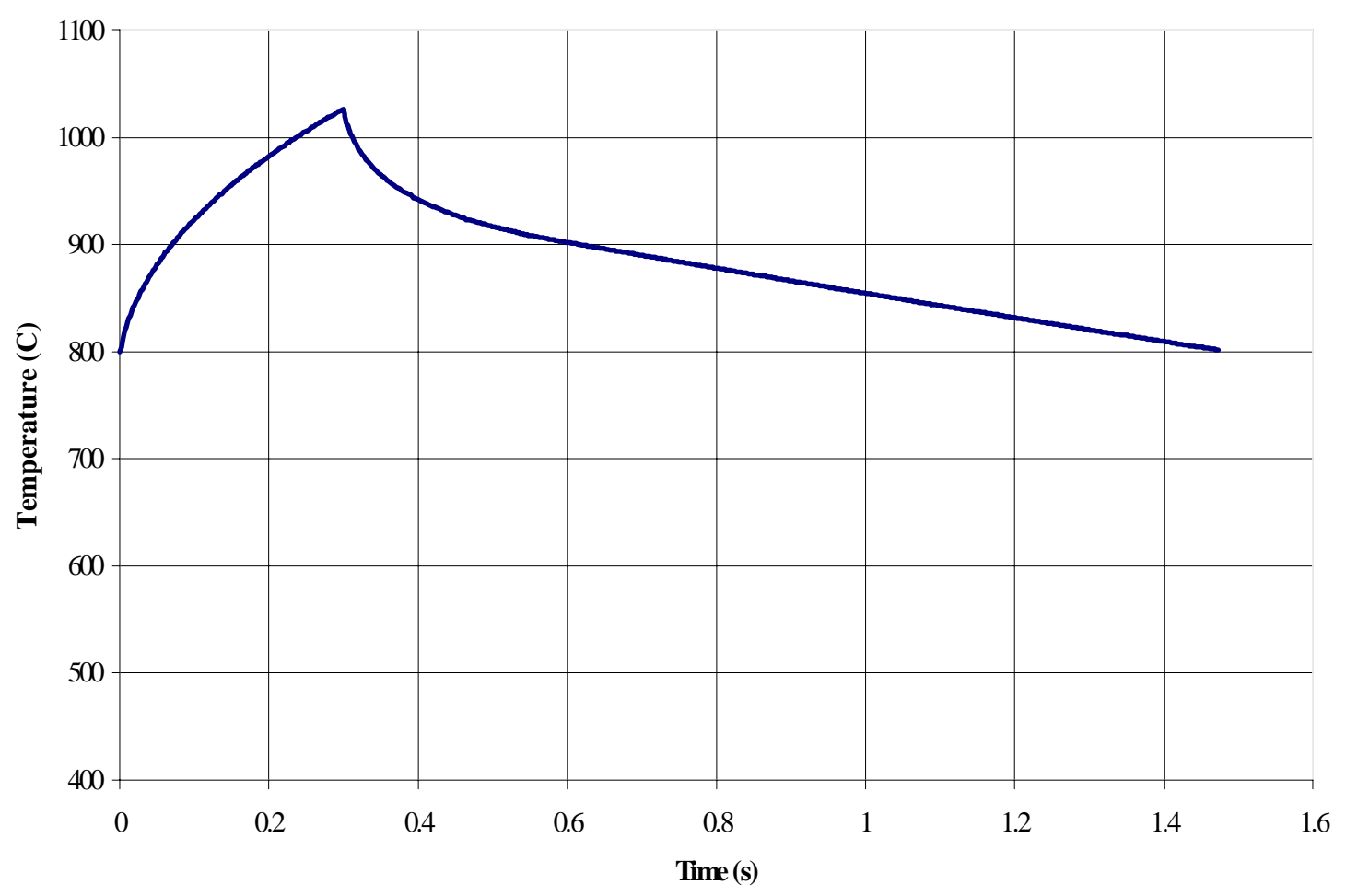

Figure 7.1 Temperature distribution in a layer of ash. Unburned carbon $=4 \%, T(f i l)=800 \mathrm{C}, \mathrm{U}=3.6 \mathrm{~cm} / \mathrm{s}$, M(pulse) $=0.27 \mathrm{~kg} / \mathrm{s}$ 
Temperature distribution along ash layer, $0.2 \mathrm{~mm}$ from outer wall of filter

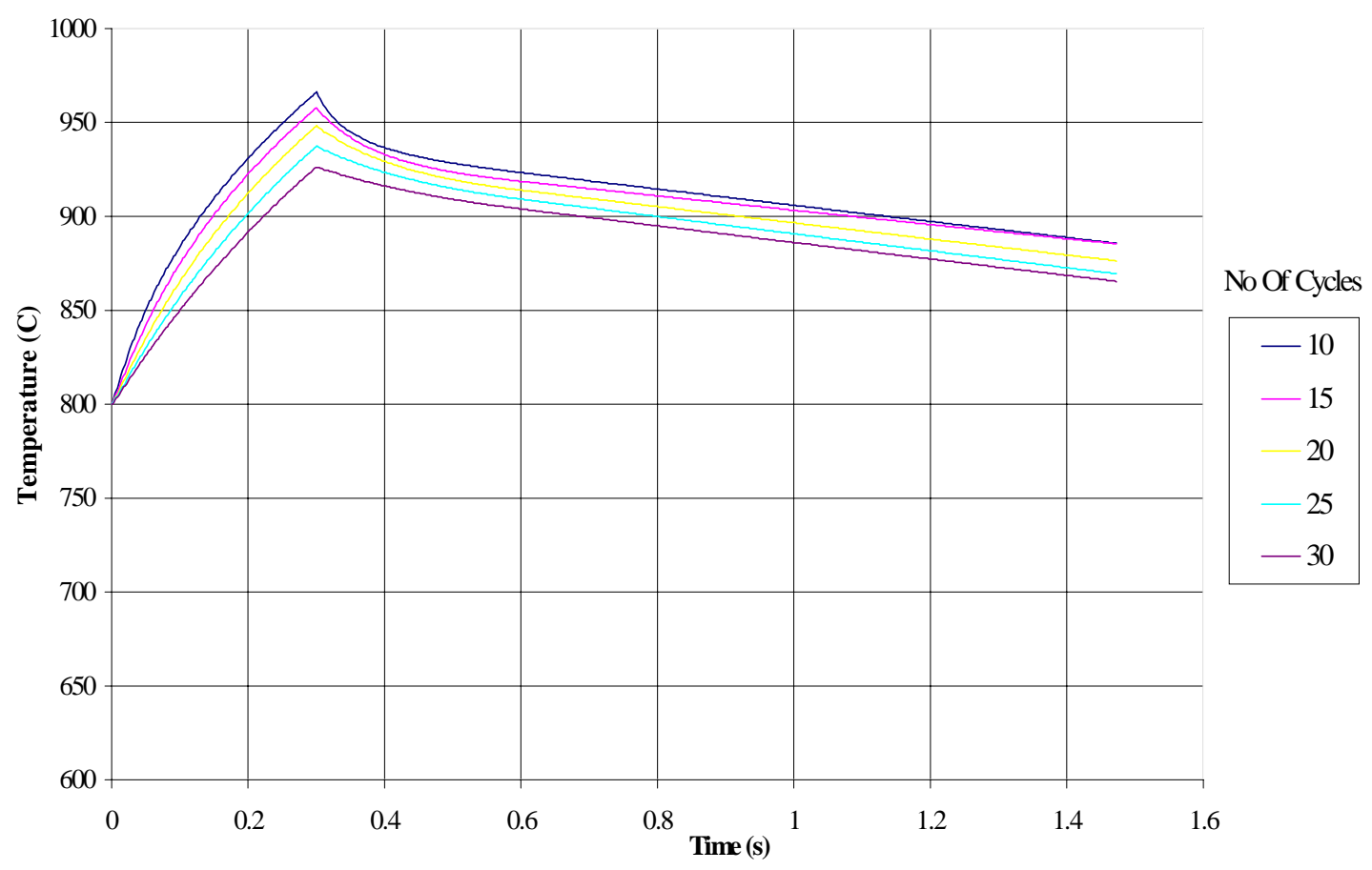

Figure 7.2 Temperature distributions in a layer of ash, after different number of cycles of operation. UC $=4 \%$, $\mathrm{T}($ fil $)=800 \mathrm{C}, \mathrm{U}=3.6 \mathrm{~cm} / \mathrm{s}, \mathrm{M}($ pulse $)=0.27 \mathrm{~kg} / \mathrm{s}$ 
Two additional heat-transfer analyses were carried out to examine the temperature distributions in the ash for an unburned carbon $\%$ of $2 \%$ and when the filtration temperature was $700^{\circ} \mathrm{C}$.

The temperature distribution curves for these two analyses are presented in Figures 7.3 and 7.4. In Figure 7.5, the temperature distribution in the outer edge of the residual ash layer formed after one cycle of operation, is shown for the 3 different operating conditions considered in this research. 


\section{Temperature distribution at the outer edge of a residual ash layer after one cycle of operation}

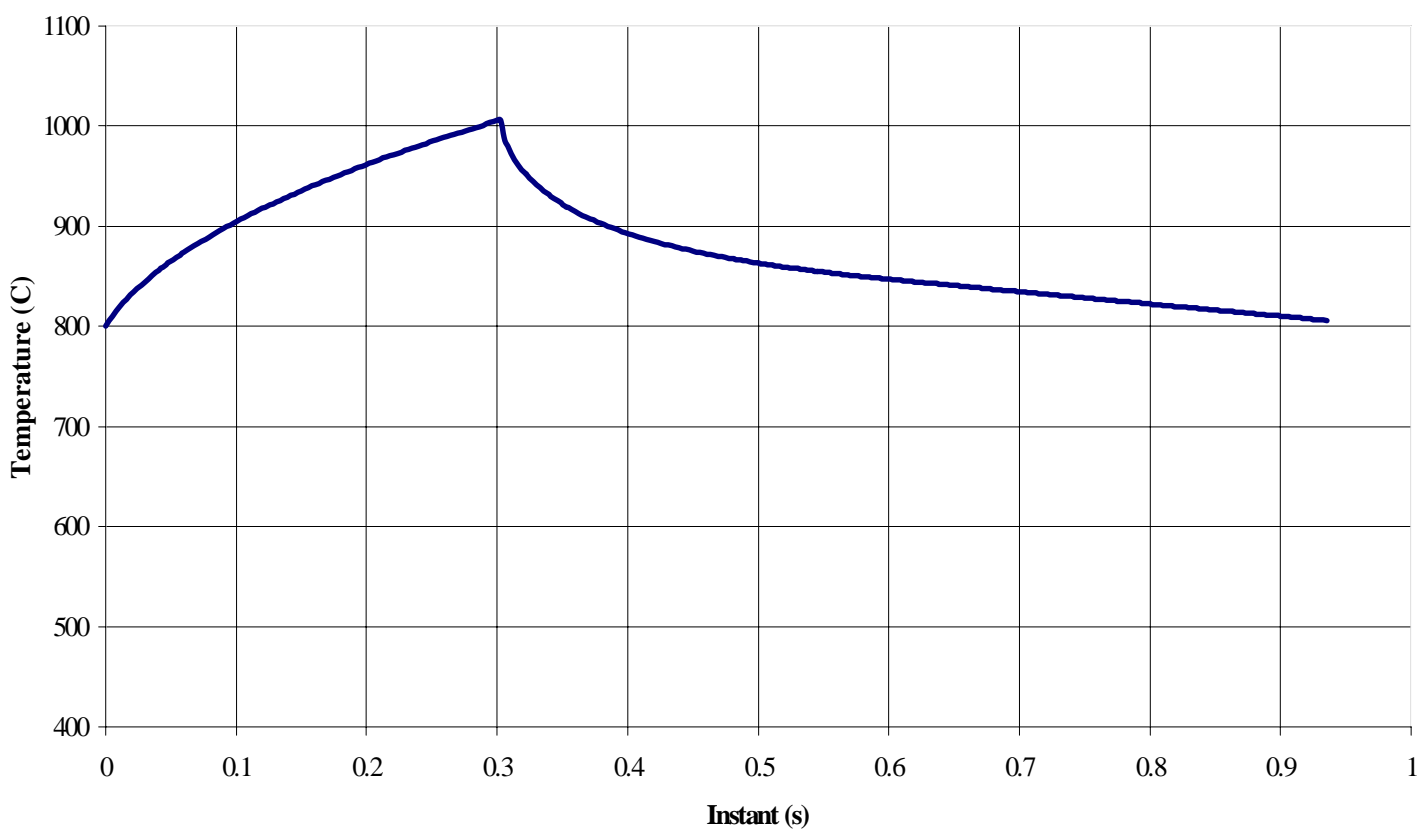

Figure 7.3 Temperature distribution at the edge of a $0.2 \mathrm{~mm}$ thick residual ash layer, during pulse-cleaning and regular operation, $\mathrm{UC}=2 \%, \mathrm{~T}(\mathrm{fil})=800 \mathrm{C}, \mathrm{U}=3.6 \mathrm{~cm} / \mathrm{s} \mathrm{M}(\mathrm{pulse})=0.27 \mathrm{~kg} / \mathrm{s}$ 
Temperature distribution in an ash layer $0.2 \mathrm{~mm}$ from outer wall of filter, after one cycle of operation, with filtration temperature of $700 \mathrm{C}$

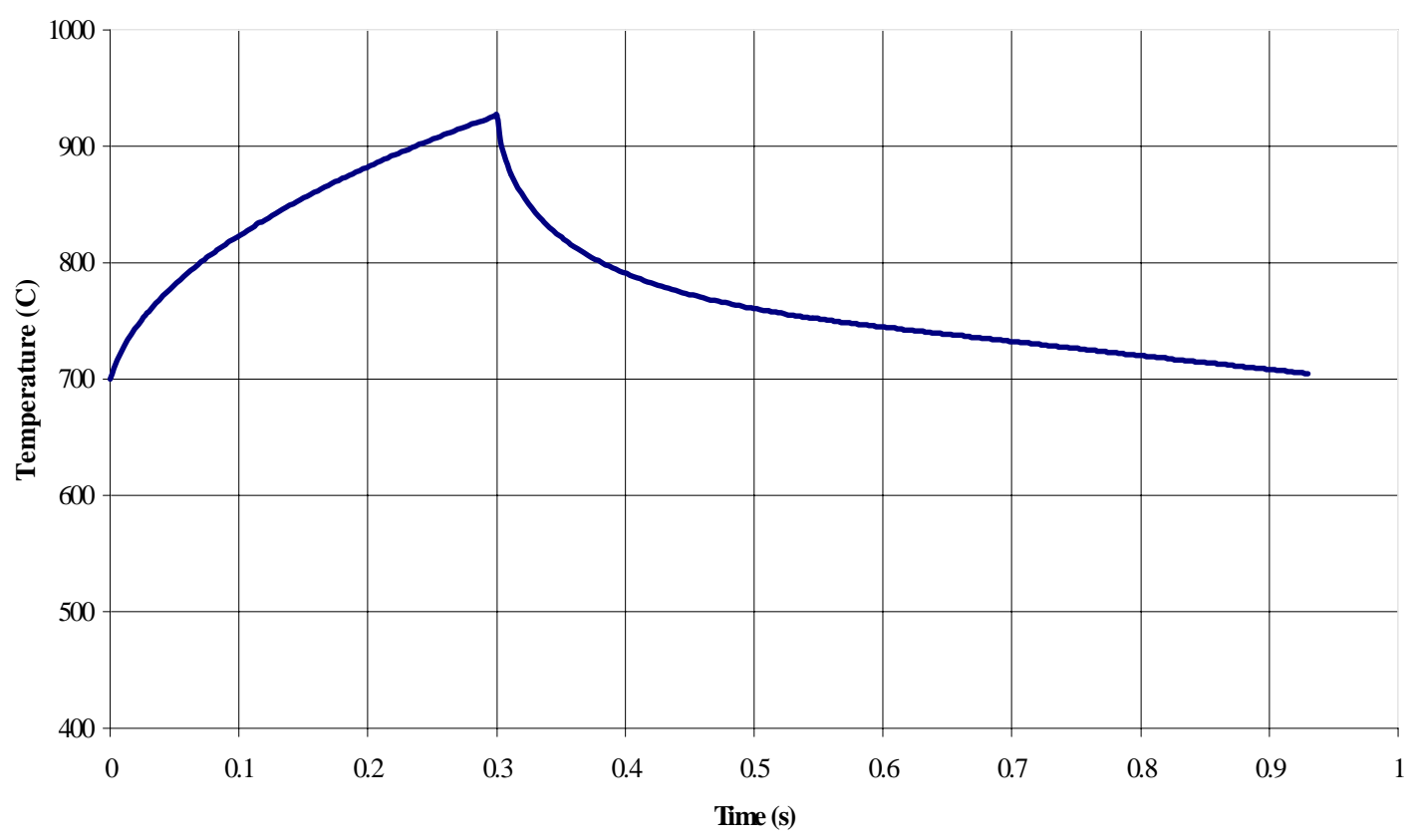

Figure 7.4 Temperature distribution in an ash layer, after one cycle of operation. $\mathrm{UC}=4 \%$, $\mathrm{T}($ fil $)=700 \mathrm{C}, \mathrm{U}=3.6 \mathrm{~cm} / \mathrm{s}, \mathrm{M}($ pulse $)=0.27 \mathrm{~kg} / \mathrm{s}$, 
Temperature distributions at edge of residual ash after one cycle of operation

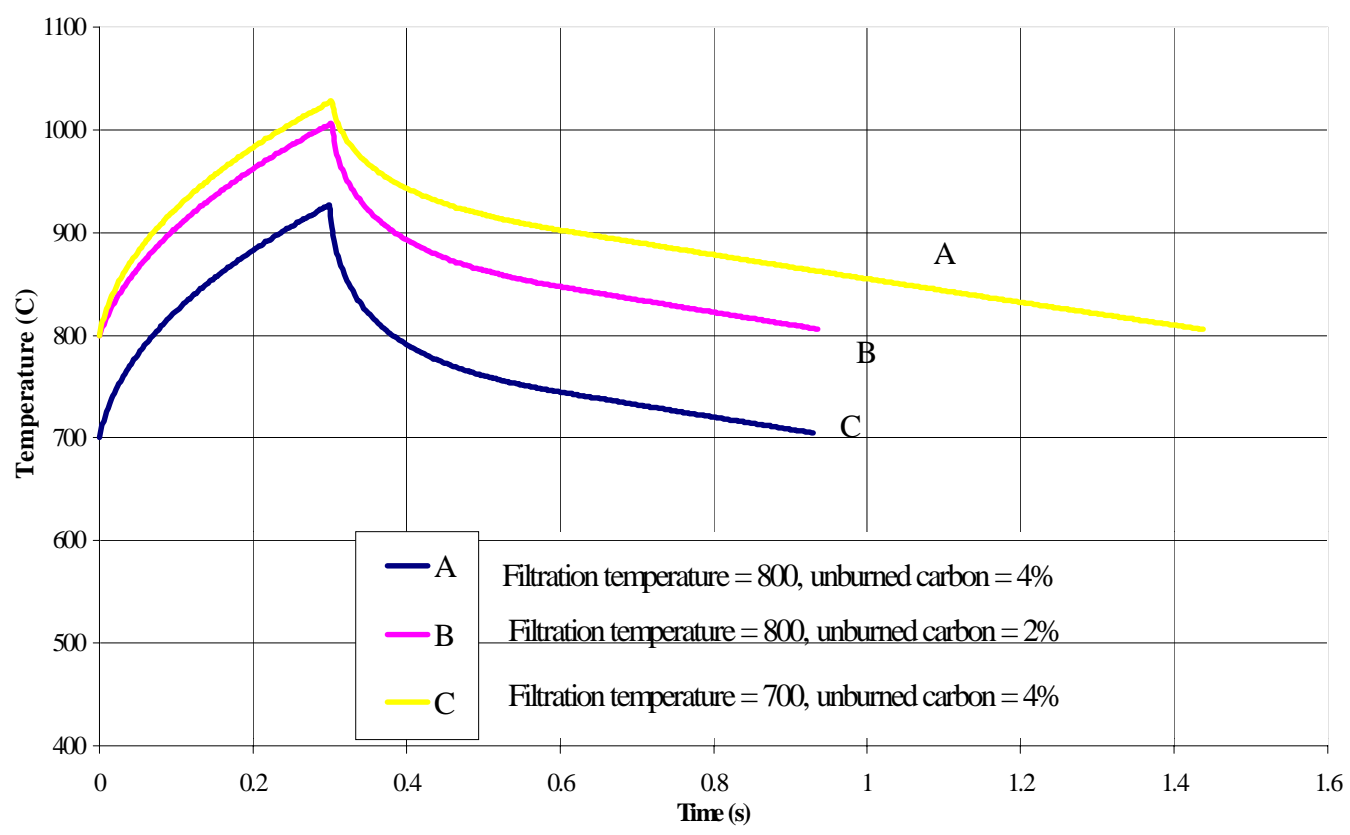

Figure 7.5 Effect of unburned carbon $\%$ and filtration temperature on temperature distribution in an ash layer, $\mathrm{U}=3.6 \mathrm{~cm} / \mathrm{s}, \mathrm{M}($ pulse $)=0.27 \mathrm{~kg} / \mathrm{s}$ 


\subsection{Results from the sintering model}

In the present research, sintering of ash deposits has been modeled using the Frenkel model [18]. This model has been described in section 6.2 of chapter 6 . The basic equation used for determining the sintering times as a function of temperature is equation (6.4).

The ash viscosity is assumed to have an Arrhenius dependence on temperature as described in section 6.2. Equation 6.3 is used to calculate ash viscosity as a function of temperature. The values of the constants $\mu_{0}$ and $E / R$ are determined for the type of ash chosen in this research, by empirical correlation of viscosity with ash chemical composition, as described in section (6.3).

Table 7.8 lists the relevant properties of the ash particles used in the present research.

\begin{tabular}{|l|c|c|}
\hline \multicolumn{1}{|c|}{ Property } & Value & Units \\
\hline Particle radius & $5 \mathrm{E}-6$ & $\mathrm{~m}$ \\
\hline Surface Tension & 0.32 & $\mathrm{~N} / \mathrm{m}$ \\
\hline Viscosity co-efficient & $1.13 \mathrm{E}-11$ & $\mathrm{~Pa} \mathrm{~s}$ \\
\hline E/R & $4.707 \mathrm{E}+04$ & $\left({ }^{0} \mathrm{~K}\right)^{-1}$ \\
\hline
\end{tabular}

Table 7.8 Properties of ash particles used in the sintering model 
Figure 7.6 shows the temperature dependence of viscosity, plotted using equation (6.3).

\section{Temperature dependence of viscosity}

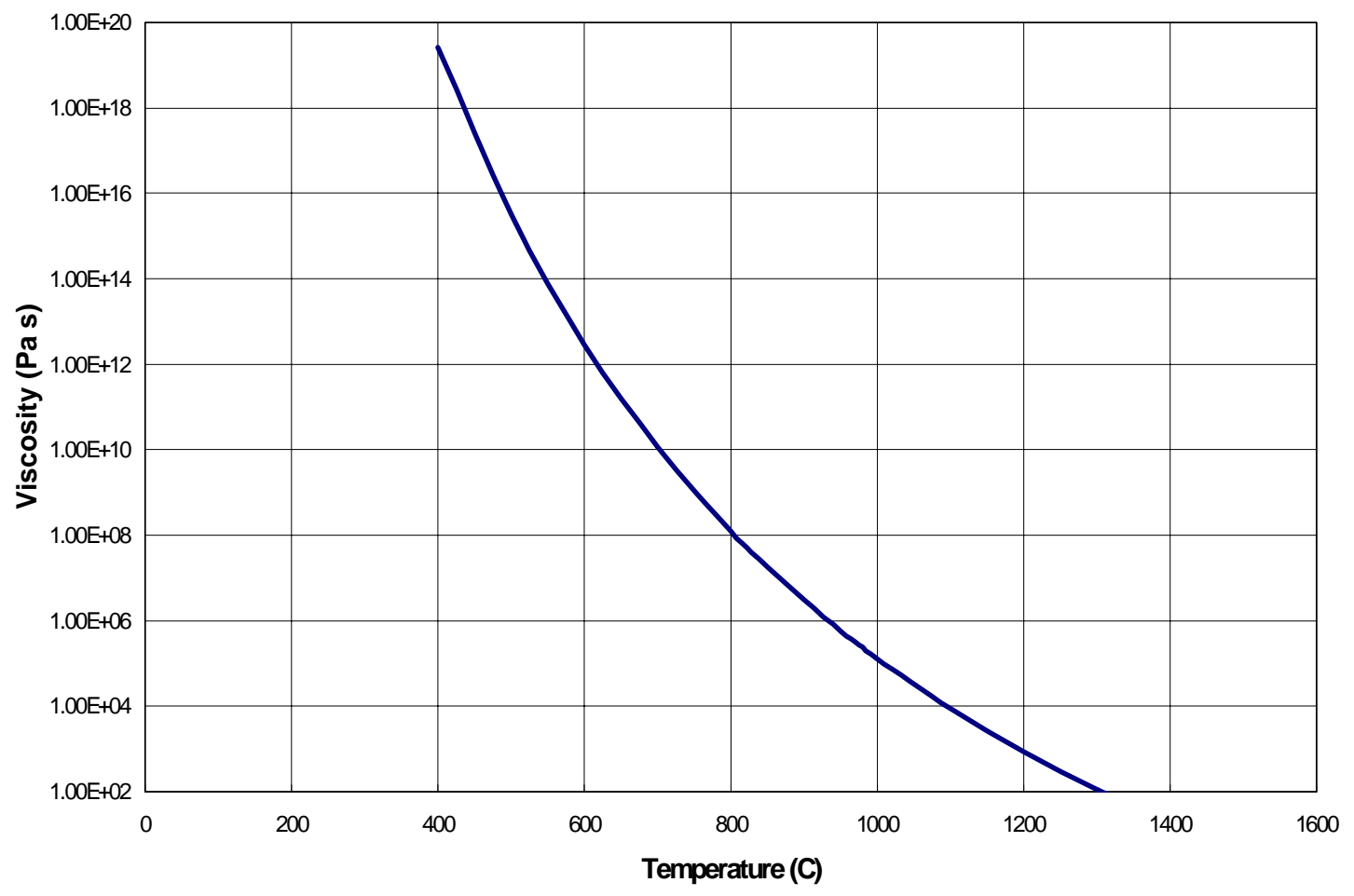

Figure 7.6 Temperature dependence of viscosity 
The times required for different degrees of sintering to occur, as a function of temperature are calculated using equation (6.4) and are plotted in Figure (7.7). It is observed that as the degree of sintering (characterized by the $\mathrm{x} / \mathrm{r}$ ratio) increases, the corresponding times required also increase.

\section{Sintering time v/s temperature of deposit}

Particle radius $=5$ micro meter, Surface tension $=0.32 \mathrm{Nm}$

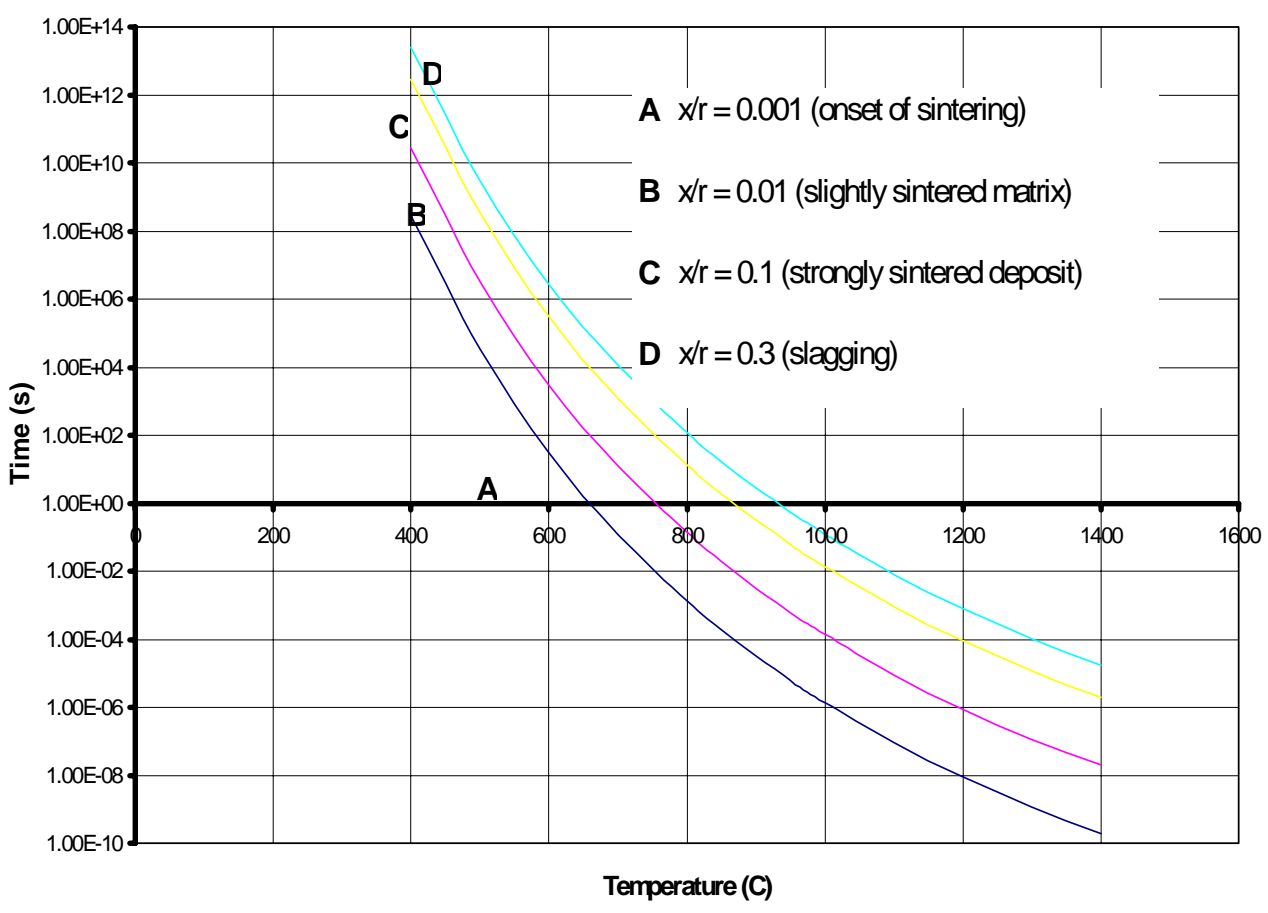

Figure 7.7 Times needed for different degrees of sintering, as a function of temprature, for 5 micron particles with a surface tension of $0.32 \mathrm{~N} / \mathrm{m}$ 
Figure 7.8 shows the effect of particle size on sintering times. An $\mathrm{x} / \mathrm{r}$ ratio of 0.1 has been used here, which corresponds to a strongly sintered bond. It is seen that as the particle size increases, the sintering times also increase.

Effect of particle size on sintering time

For a strongly sintered deposit $(\mathrm{x} / \mathrm{r}=0.1)$

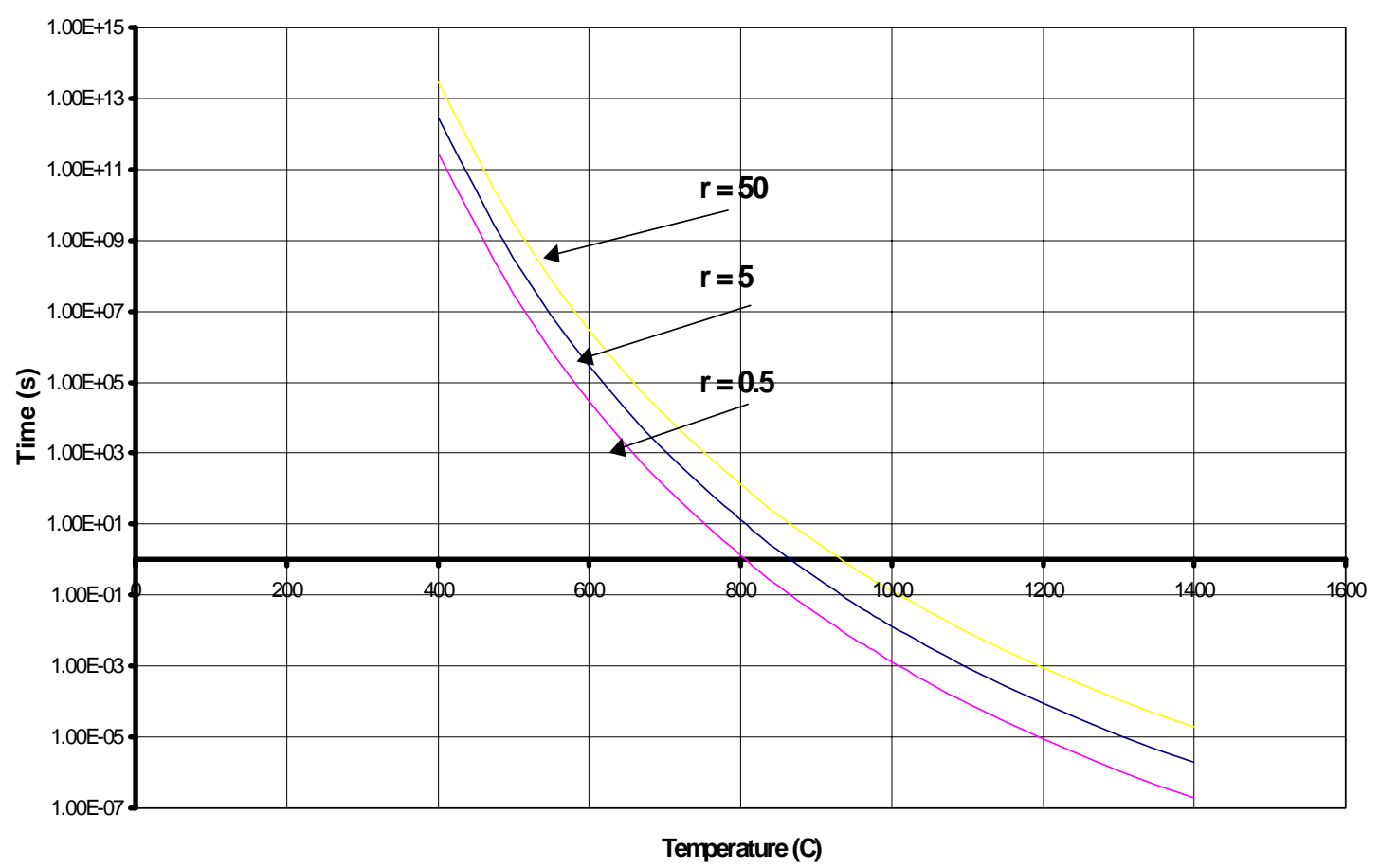

Figure 7.8 Effect of particle size on sintering times. Particle sizes are in microns, $\mathrm{x} / \mathrm{r}=0.1$, surface tension $=032 \mathrm{~N} / \mathrm{m}$ 


\subsection{Combine results from 7.1, 7.2 and 7.3}

Analysis of the current problem was done by setting up three models namely;

1. The combustion model

2. The heat transfer model

3. The sintering model

The analysis of these models is individually explained in chapters 4, 5 and 6 respectively. Individual results from their analyses have been outlined in sections 7.1, 7.2 and 7.3 respectively. The current section combines the results obtained from these models in order to examine the possibility of sintering in residual ash deposits on candle filters.

Based on the composition of the coal selected and other combustion parameters such as the excess-air ratio, $\mathrm{Ca} / \mathrm{S}$ ratio and $\%$ of gangue in limestone, the thickness of the deposit that builds up on the candle filter in every cycle of operation was estimated by analysis of the combustion model. Further, based on the constant mass-flow rate during surface regeneration and the amount of unburned carbon present in the deposit, the thickness of the deposit which undergoes combustion due to this unburned carbon, and an estimate of the amount of heat generated, was obtained.

The thickness of the heat generating layer and the heat generation rate as estimated by the combustion model, were used as inputs to the heat transfer model. A temperature profile was developed, both in the filter and in the ash, during the surface regeneration event and also during regular filtration. Temperatures experienced in the ash layer, and the durations for which these temperatures were experienced, were estimated.

By analysis of the sintering model, the lengths of time for which the ash particles need to remain, at various temperatures were estimated. This estimate was made for 
different degrees of sintering to form, and was based on ash chemistry. A timetemperature curve for sintering was then generated.

Examination of the results obtained from the analysis of the heat transfer model indicates that a temperature gradient exists within the residual ash layer itself. Hence, different layers of ash will experience different degrees of sintering. However, in the present research, investigation of the extent of sintering has been confined to only one layer of the deposit. This layer represents the outer edge of the residual ash deposit formed after the first surface regeneration.

In order to examine the possibility of a strongly sintered bond forming in this layer, the sintering curve generated by the sintering model was super-imposed on the temperature profile curves generated by the heat transfer model. These super-imposed curves are presented in Figures 7.9 through 7.15.

For the temperature distribution curve, the scale of the ' $x$ ' axis corresponds to the instance after the surface regeneration operation was initiated. However, since the sintering curve is drawn in terms of absolute time, this value is added to the corresponding value of instance and then plotted. 


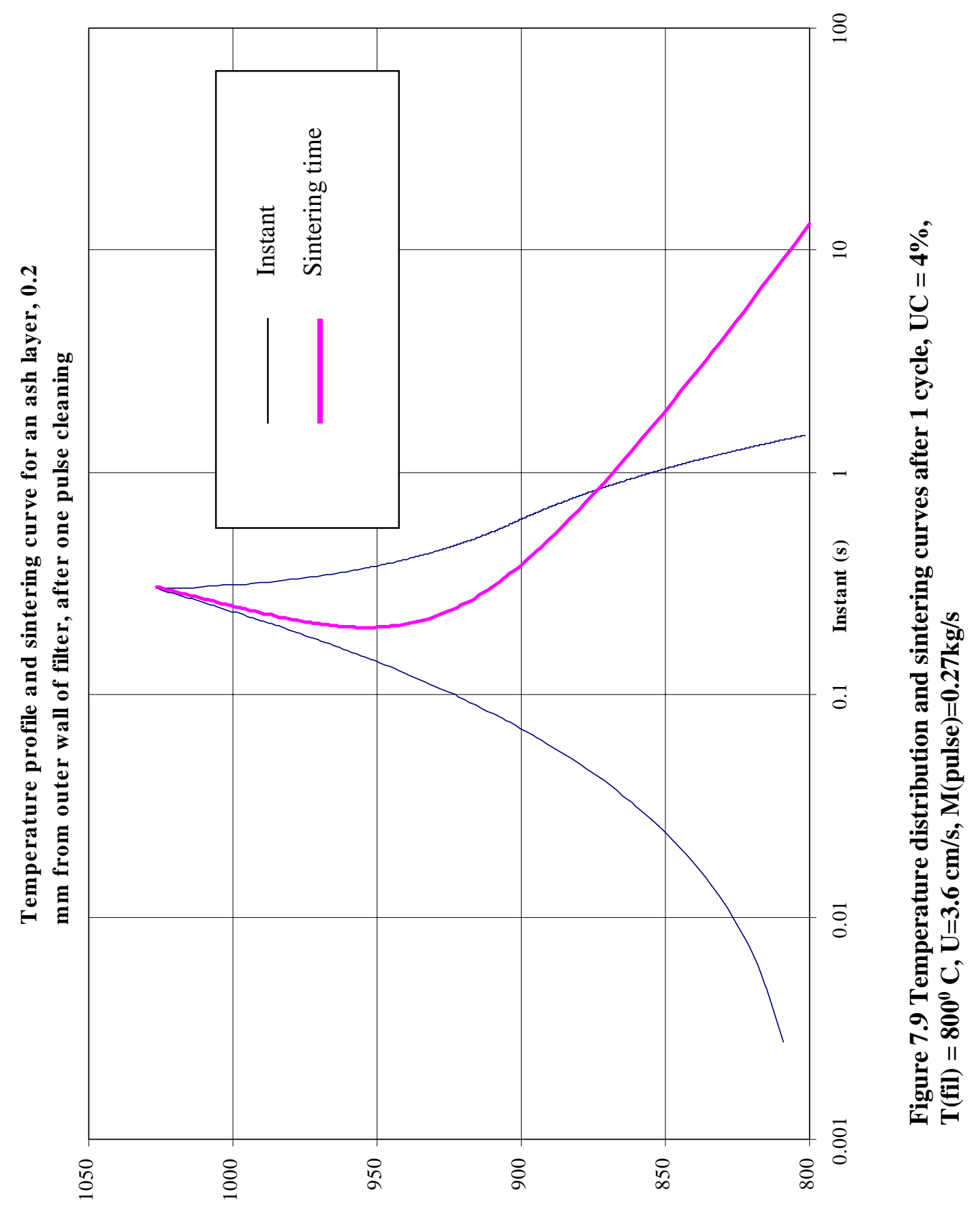

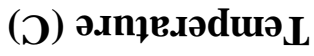




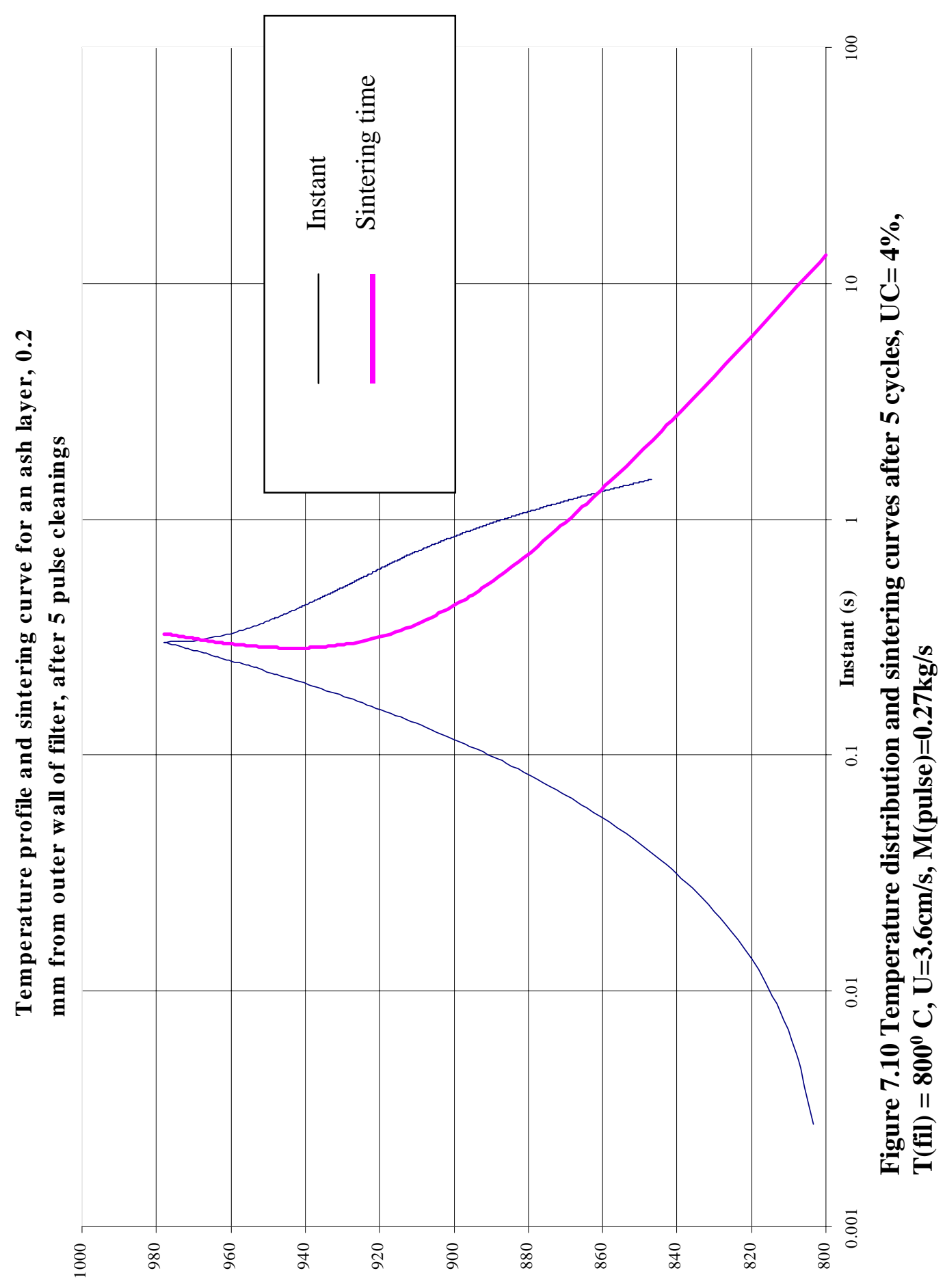

(ग) ә.Iṇฺ..əduә $\mathbf{L}$ 


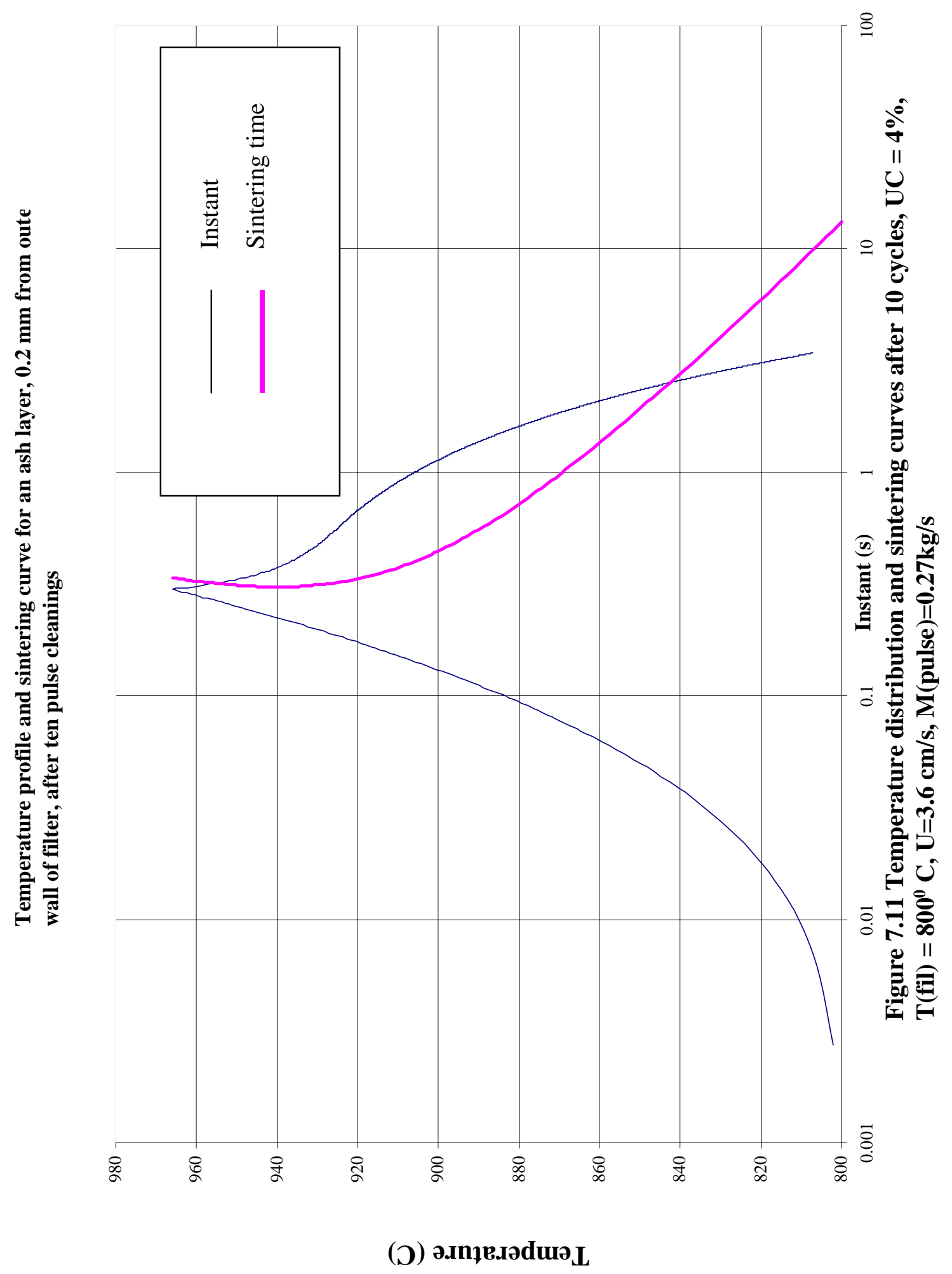




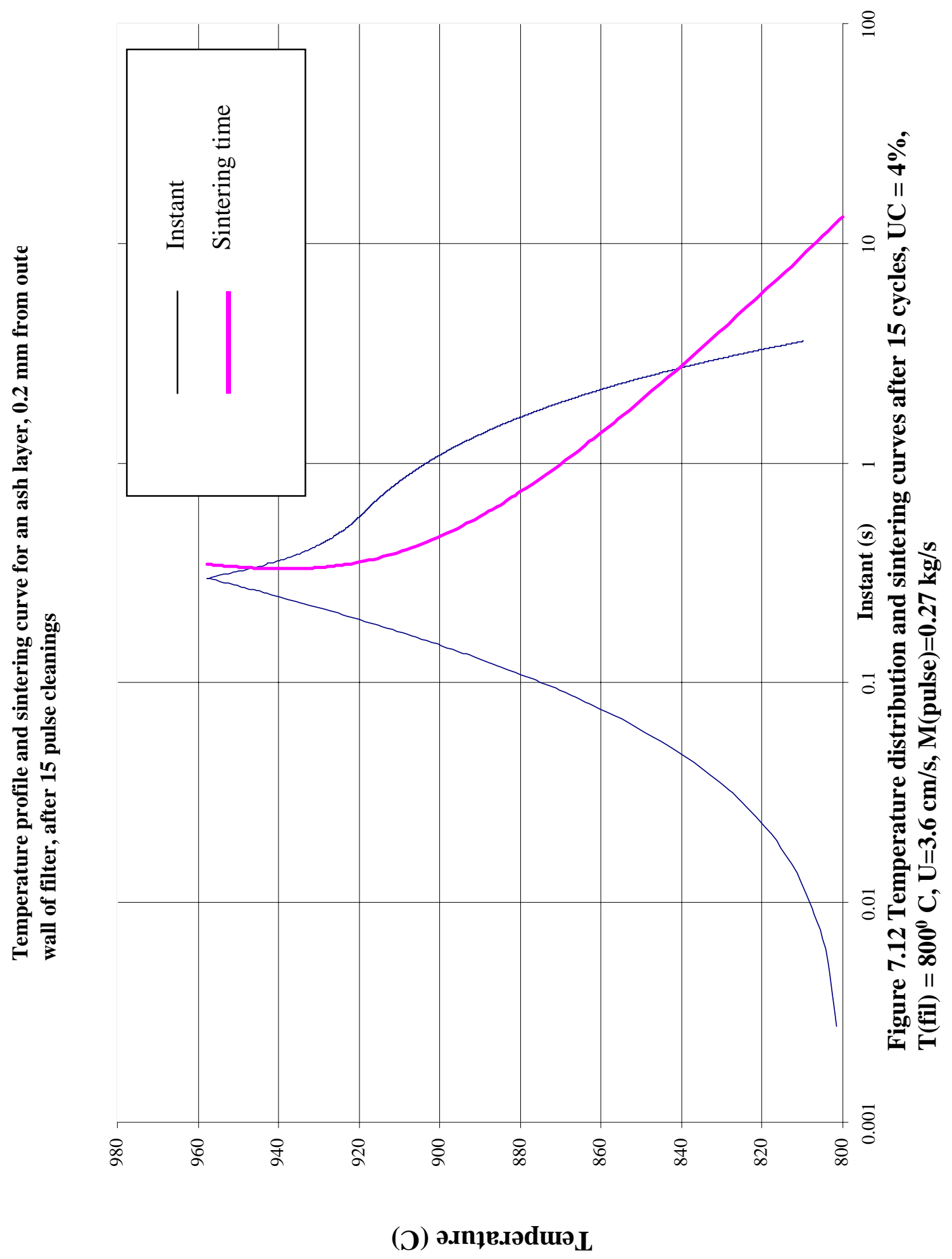




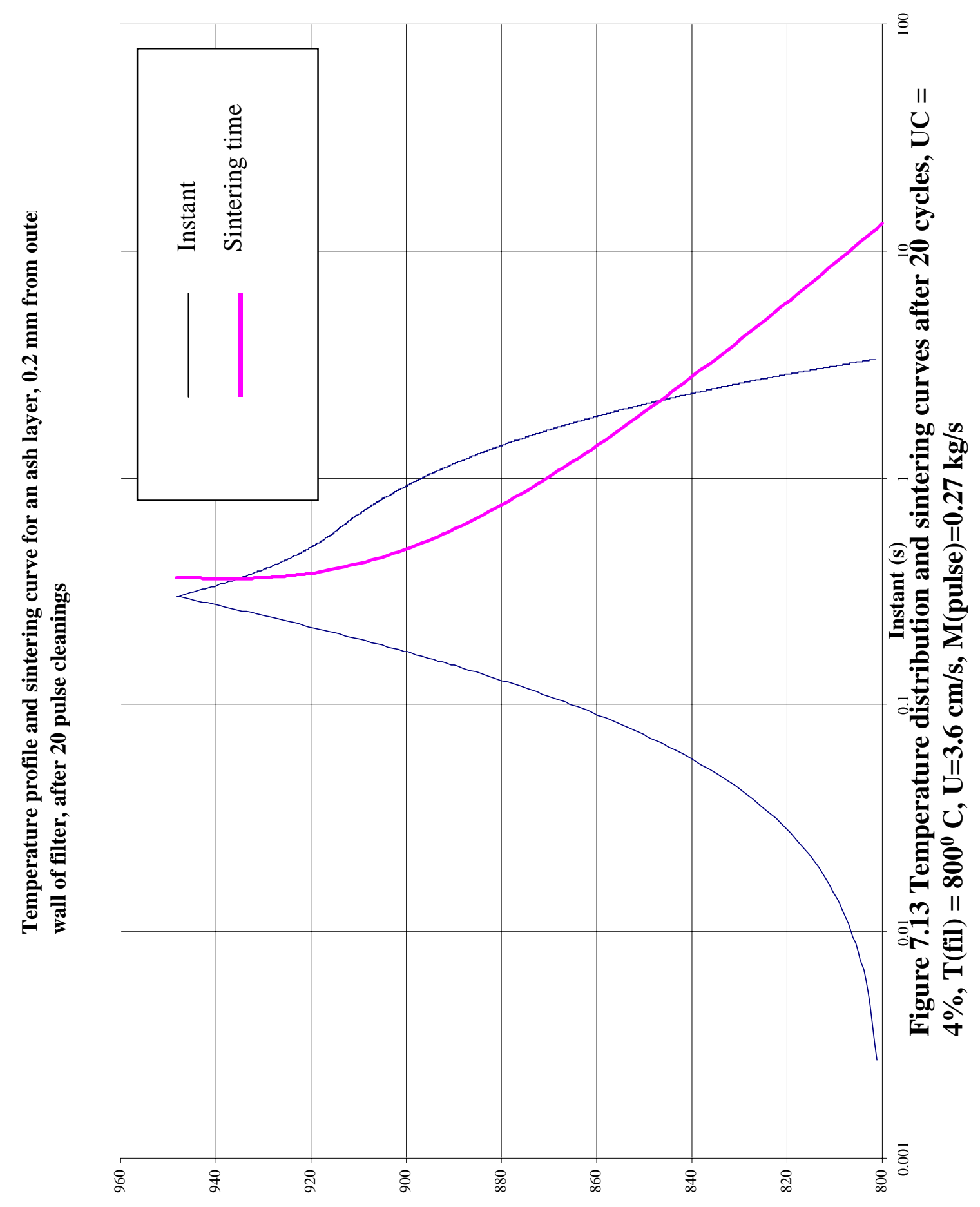

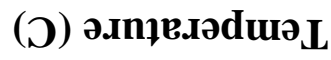




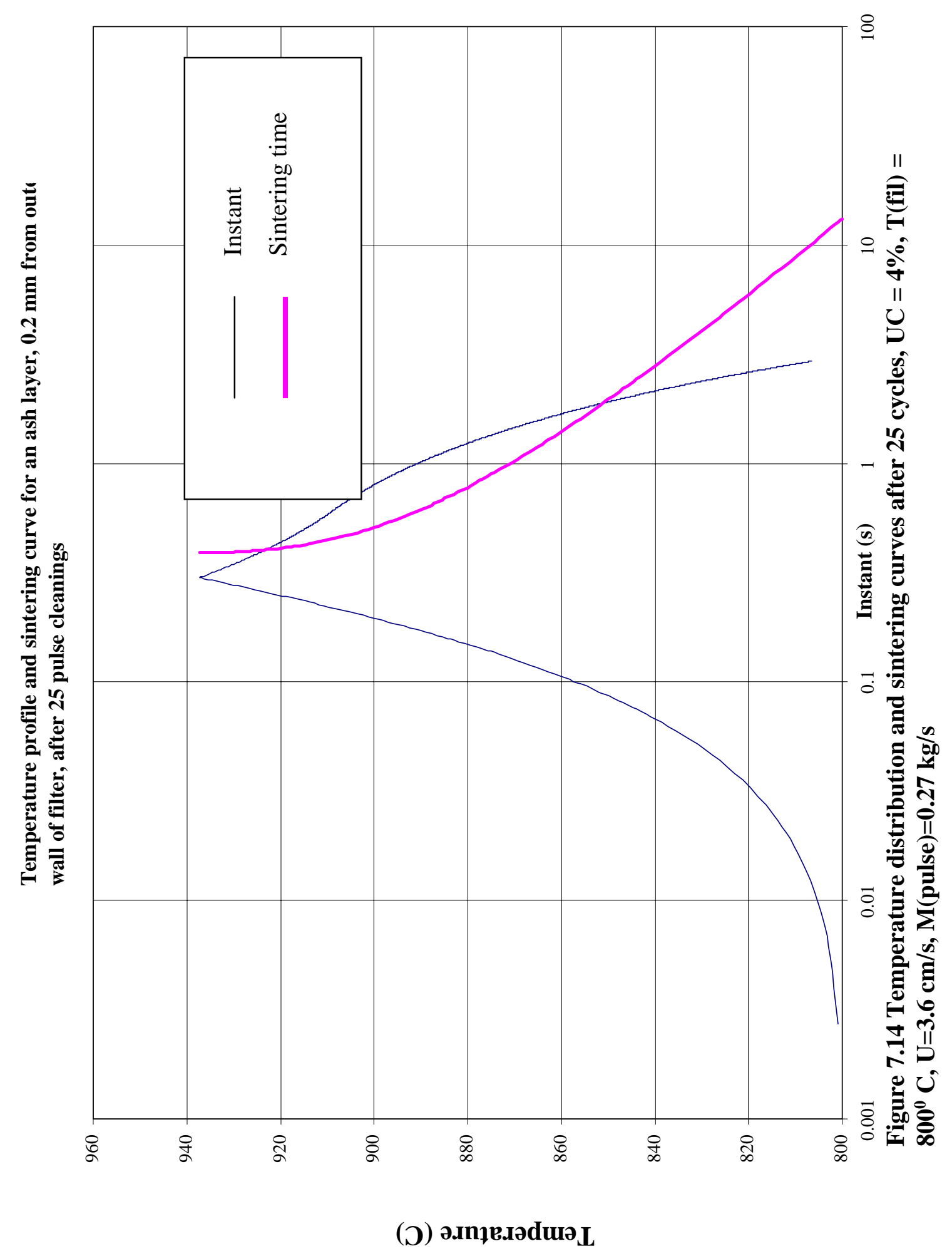




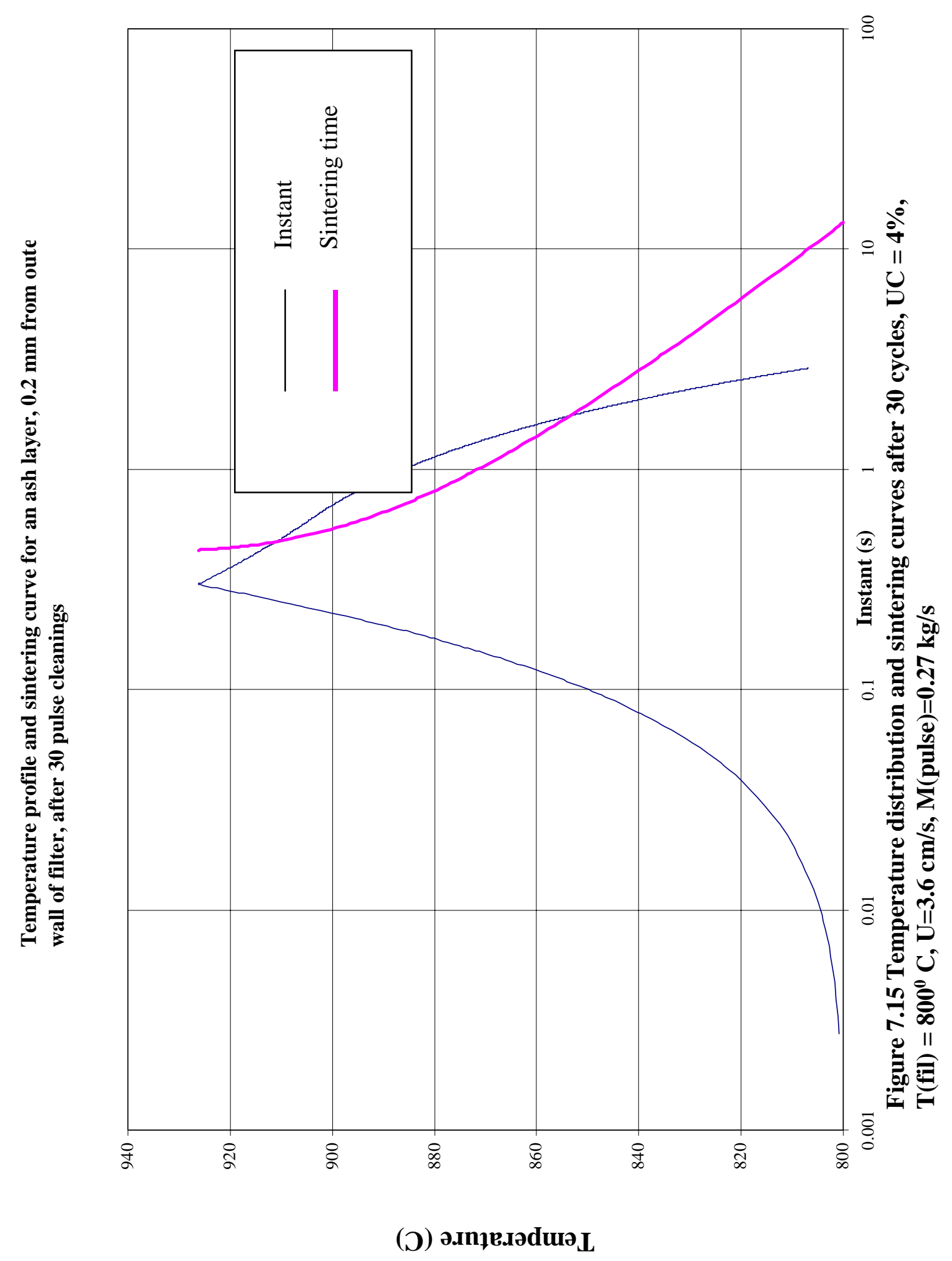


In order to examine the influence of the percentage of unburned carbon in the deposit and the effect of filtration temperature, two additional analyses were carried out.

In the first analysis, the percentage of unburned carbon was decreased to $2 \%$. In the second analysis, the temperature of the filtration gases was reduced from $800^{\circ} \mathrm{C}$ to $700^{0} \mathrm{C}$.

The temperature distribution and sintering curves were super-imposed for the same ash layer as before, to examine the possibility of the formation of a strongly sintered bond with these new conditions. These curves are presented in Figures 7.16 and 7.17 . 


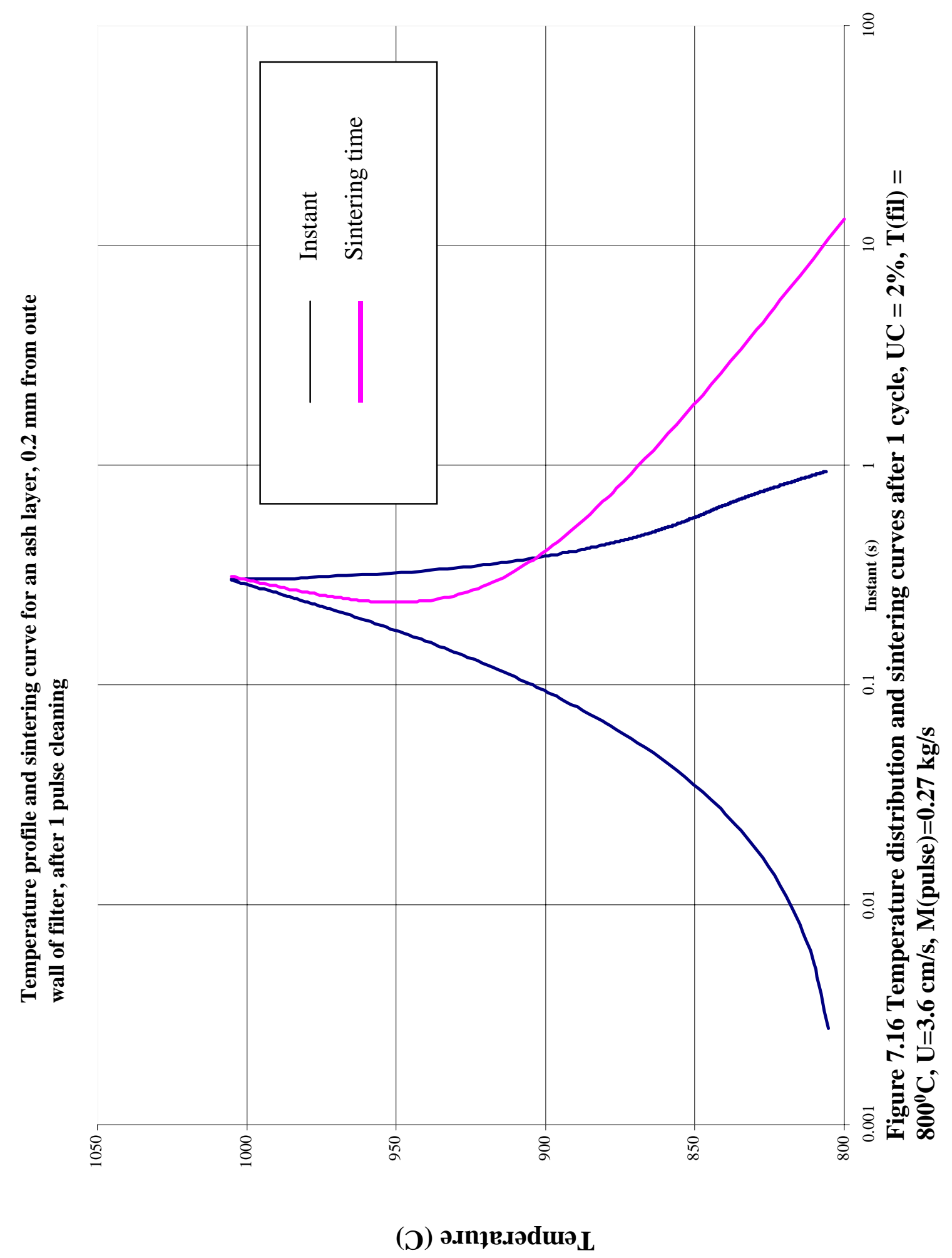




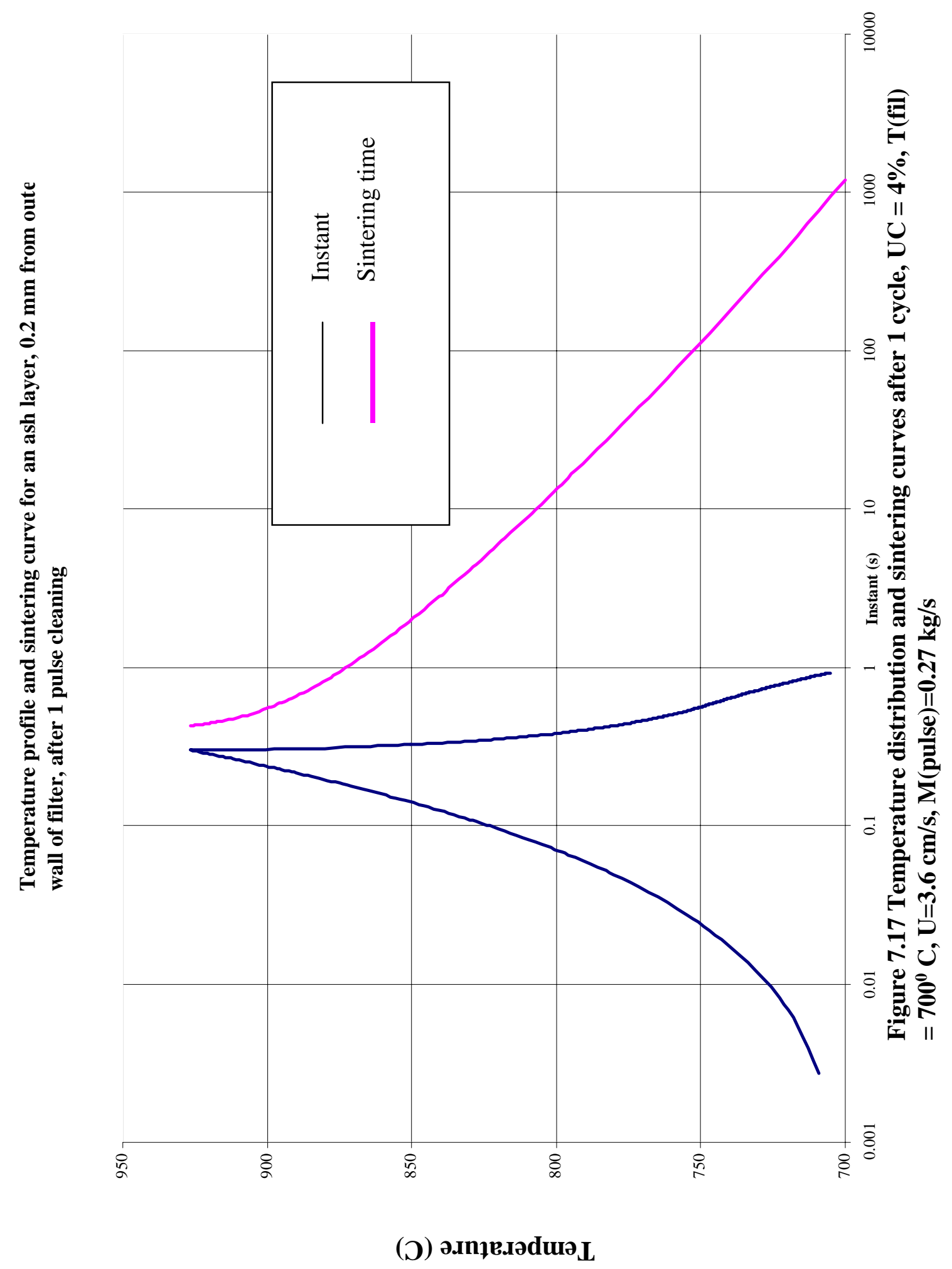




\subsection{Discussion of results}

The current section is a discussion of the results that have been presented thus far in this chapter. Tables 7.5(a) and 7.5(b) outline the growth in residual ash thickness, for unburned carbon amounts of $4 \%$ and $2 \%$. It is seen that with $2 \%$ unburned carbon, the growth of residual ash layer is faster than with $4 \%$ unburned carbon. This is because of the fact that as the unburned carbon \% reduces, a greater thickness of the deposit is needed to consume all of the oxygen in the pulse-cleaning air. Figure 7.1 shows the temperature distribution at the edge of the residual ash, after one cycle of operation, which includes a surface regeneration operation and a regular filtration operation. Once the surface regeneration is stopped and regular filtration is resumed, temperature of the ash layer starts dropping. However, it is observed that the rate of cooling is not as rapid as the rate of temperature rise. This is due to the reduced mass-flow rates encountered during filtration.

Figure 7.2 shows the temperature profiles in the layer of ash after 5, 10, 15, 20, 25 and 30 cycles of operation. It is observed that the maximum temperatures experienced by the layer during surface regeneration keeps falling. This is due to:

1. There is no heat generation in this layer after the first surface regeneration

2. As more residual ash builds up, the reaction zone is shifted further and further away from this layer of ash.

The rate of temperature drop during regular filtration decreases. As the number of cycles of operation increases, more residual ash is formed. Hence the incoming filtration gases are at a higher temperature with every completed cycle. 
Figure 7.5 is a comparison of the temperature profiles for a coal with a reduced percentage of unburned carbon $(2 \%)$ and for a case when the filtration temperature is reduced from $800^{\circ} \mathrm{C}$ to $700^{\circ} \mathrm{C}$. For both these curves, the maximum temperatures reached are less. Maximum temperature reached for curve 'B' (with $2 \%$ unburned carbon) is less than that for curve 'A' (with $4 \%$ unburned carbon) since less carbon undergoes combustion, resulting in a reduced heat generation rate. For curve ' $\mathrm{C}$ ', a significant amount of heat generated is transferred to the filter, since it is at a lower temperature (700 ${ }^{0} \mathrm{C}$ ) and hence maximum temperature reached in the layer of ash is less.

Figure 7.7 illustrates the times needed at different temperatures for various degrees of sintering to take place. It is observed that for a given temperature, the times needed are about an order of magnitude higher for each increment in the degree of sintering.

Figure 7.8 illustrates the effect of particle size on sintering times. It is seen that smaller particles sinter faster than bigger particles. Particle-size is thus an important parameter that influences sintering ability.

Figure 7.9 shows the temperature profile and the sintering curve being superimposed, for a layer that represents the edge of the residual ash formed after one surface regeneration. The sintering curve has been drawn for an $\mathrm{x} / \mathrm{r}$ ratio of 0.1 , which corresponds to a strongly sintered bond. The time needed for sintering to occur at a particular temperature has been measured from the instant this particular temperature is first seen by the ash layer. Hence, if the sintering curve lies inside the temperature-profile curve, then it means that the ash layer 'sees' (or experiences) this temperature or higher, for lengths of time more than that actually needed for sintering to occur to the chosen 
degree. However, if the sintering curve just 'touches' the temperature-profile curve, then it means that the ash layer experiences this temperature or higher, for a length of time that is just sufficient for sintering to take place.

It can be seen from this figure that the sintering curve lies inside the temperatureprofile curve when the ash experiences temperatures of about $870^{\circ} \mathrm{C}$ or higher. This temperature is referred to here as the 'cross-over' temperature, i.e. the temperature at which the two curves cross or cut each other.

Figures 7.10 through 7.15 show the super-imposed sintering and temperatureprofile curves for the same ash layer, after 5, 10, 15, 20, 25 and 30 cycles of operation respectively. It is observed that as the number of operating cycles increases, the "crossover' temperature (described above) reduces. It is also observed that as the number of cycles of operation increases, the sintering curve for this layer moves closer to the temperature profile curve. As the number of cycles increases, temperatures experienced by the layer decrease, as evident from Figure 7.2. Hence at these reduced temperatures, the corresponding sintering times needed are more, thereby causing the sintering curve to move closer to the temperature profile curve.

Figure 7.16 shows the sintering/temperature-profile curve for the ash layer, when the unburned carbon $\%$ in the coal is reduced to $2 \%$. It is observed that the cross-over temperature has increased (to about $900{ }^{\circ} \mathrm{C}$ ) and the sintering curve has moved closer to the temperature profile curve. This suggests that combustion conditions that result in a lesser percentage of unburned carbon in the ash deposit are likely to lead to a lesser degree of sintering occurring in the deposit. 
Figure 7.17 shows the sintering/temperature-profile curve for the ash layer, when the filtration is carried out at temperatures of $700^{\circ} \mathrm{C}$. It is observed that in this case, the sintering curve lies outside the temperature-profile curve, thereby implying that a strongly sintered bond is not likely to form under these conditions. This can be explained because of the faster cooling rate that the layer experiences due to the reduced filtering temperatures. Moreover, at these reduced temperatures, the corresponding sintering times required for a strongly sintered bond to form, increase exponentially. Hence, it can be implied that reduced filtration temperatures would lead to a lesser of degree of sintering occurring in the deposit. 


\section{CHAPTER 8}

\section{CONCLUSIONS AND RECOMMENDATIONS}

\subsection{Conclusion}

Filtration of hot gases at high temperatures is a key feature in the development of advanced power generation systems, like pressurized fluidized bed combustion. When coal undergoes combustion, not all the carbon may be consumed. During filtration of the hot gases, this unburned carbon is carried along with the flow of gases and is part of the ash that is deposited on the candle filter. Formation of this deposit increases the pressure drop across the filter and reduces the filtration efficiency. Pulse cleaning techniques which employ a high pressure jet of air are generally used to blow away these deposits. Because of the relatively high mass-flow rates prevalent during pulse-cleaning, unburned carbon in the deposit now starts burning (if surface regeneration is carried out with air) and leads to a local rise in deposit temperature. If these temperatures last for long enough periods of time, then a high degree of 'sintering' takes place in the deposits, leading to development of strength in the deposits.

In this research, a model was developed to predict the possibility of sintering occurring in the ash deposits, as a function of the various combustion parameters and ash chemistry. The following conclusions have been arrived at:

1. Analyses with two different percentages of unburned carbon, while keeping all other conditions the same, have indicated that increase in the amount of unburned carbon will cause sintering to a higher degree. Hence, type of coal and combustion conditions play an important part in influencing the likelihood of sintering. 
2. Analyses with two different filtration temperatures $\left(800^{\circ} \mathrm{C}\right.$ and $\left.700^{\circ} \mathrm{C}\right)$, while keeping all other combustion conditions the same, has indicated that a much higher degree of sintering is likely with the higher filtration temperature (800 $\left.{ }^{0} \mathrm{C}\right)$, than with the lower filtration temperature $\left(700{ }^{0} \mathrm{C}\right)$.

3. It is thus recommended that filtration temperatures be kept as low as possible and unburned carbon percentages be reduced, in order to minimize the formation of strongly sintered deposits on candle filters.

\subsection{Recommendations for future work}

The sintering model used in this study estimates the degree of sintering and the sintering times for a layer of ash, by generating a sintering-time curve. In order to locate the points on this curve, sintering times are estimated by assuming the ash particles to sinter at constant temperatures. However in reality, the degree of sintering is characterized by the cumulative effect of the continuously varying temperatures, and the times for which these temperatures are experienced by the layer of ash under consideration. Hence, future work should try to incorporate this cumulative effect, in their work.

It has also been assumed in this research that thermal properties of the filter and ash remain constant at all temperatures. However in reality, the thermal properties of both filter and ash change with temperature. Future work should consider in their analyses, these properties as a function of temperature. 


\section{REFERENCES}

1) Cicero Daniel C., Dennis Richard A., Geiling Donald W. and Schmidt Dale K., "Hotgas cleanup for coal-based gas turbines", Mechanical Engineering, September, 1994, pp. $70-75$

2) Whige L.R., Tompkins T.L., Hsieh K.C., Johnson D.D., "Ceramic filters for Hot Gas Cleanup”, Journal of Engineering for Gas Turbines and Power, July 1993, Vol. 115, pp. 665-669

3) Lippert T.E., Newby R.A., Alvin M.A., Bachovchin D.M., Bruck G.J., Smeltzer E.E., "Development of Hot Gas Cleaning Systems for Advanced Coal-Based Gas Turbine Cycles", Transactions of the ASME, Vol. 115, July 1993, pp. 658-664

4) Stringer J., Leitch A.J., "Ceramic Candle Filter Performance at the Grimithorpe (UK) Pressurized Fluidized Bed Combustor", Journal of Engineering for Gas Turbines and Power

5) Jones Michael and Rogers Paul, "The Evaluation of Low-Density Ceramic Filters In a Boiler Flue Gas Cleanup System”, Gas Cleaning at High Temperatures, Chapman \& Hall, 1993, pp. 190-202

6) Quimby Jay M. and Sam Kumar K., "Hot Gas Cleanup for Advanced Power Generation System", Gas Cleaning at High Temperatures, Chapman \& Hall, 1993, pp. 66-85

7) Koch D., Schulz K., Seville J.P.K. and Clift R., "Regeneration of Rigid Ceramic Filters", Gas Cleaning at High Temperatures, Chapman \& Hall, 1993, pp. 244-265

8) Schneider P.J., "Conduction Heat Transfer", Addison-Wesley Publishing Company, Inc., 2'nd edition, 1957

9) "Fuel-ash effects on boiler design and operation in Steam", Babcock \& Wilcox, $38^{\text {th }}$ edition, Anon, 1972 pp. 15-1 to 15-19

10) Raask Erich, "Mineral Impurities in Coal Combustion", Hemisphere Publishing Corporation, 1985

11) Thomas Linden C., "Heat Transfer", Pretence Hall Inc., 1992 
12) Laux S., Giernoth B., Bulak H., Renz U., “Aspects of Pulse-Jet Cleaning of Ceramic Filter Elements", Gas Cleaning at High Temperatures, Chapman \& Hall, 1993, pp. 203-223

13) Mudd M.J., Hoffman J. D., "Operating Experience From the TIDD PFBC Hot Gas Clean Up Program", Transactions of the ASME, Fluidized Bed Combustion-Volume 1, ASME 1995

14) Anderson D.W., Viskanta R., Incropera F.P., "Effective Thermal Conductivity of Coal Ash Deposits at Moderate to High Temperatures, Journal of Engineering for Gas Turbines and Power, April 1997, Vol. 109, pp. 215-221

15) Radulovic Predrag T. and Smoot L. Douglas, "Coal Processes and Tehcnologies", Fundamentals of Coal Combustion, Elsevier Science Publishers B.V. 1993, pp. 1-78

16) Benson Steven A., Jones Michael L. and Harb John N., "Ash Formation and Deposition", Fundamentals of Coal Combustion, Elsevier Science Publishers B.V. 1993, pp. 299-373

17) Kingery W. D., Bowen H. K., Uhlmann D.R., "Introduction to Ceramics", John Wiley \& Sons, second edition, 1976

18) Seville J.P.K., Pflug H. Silomon, Knight P. C., Skrifvars B-J. and Hupa M., “A New Model for Sintering in Fluidized Bed Combustion Processes", International Conference on Ash Behavior Control in Energy Conversion, pp. 150-157

19) Barrick S.M., Moore G. F., "Empirical Correlation of Coal Ash Viscosity With Ash Chemical Composition", presented at the Winter Annual Meeting, New York, N.Y., December 5, 1976 by the Fuels Division of the ASME, pp. 1-9

20) Alvin Mary Anne, Lippert Thomas E., Diaz Edward S., Smeltzer Eugene E., "Thermal and Chemical Stability of Ceramic Candle Filters", pp. 485-509

21) Mallela Rajeev, "Numerical Simulation of Strength Characteristics of Ash Deposits", Masters Thesis, College of Engineering, West Virginia University, 1997

22) Johnson Eric K., Department of Mechanical \& Aerospace Engineering, West Virginia University, 1998, Oral Communication

23) Weinbaum S. and Wheller H. L. Jr., "Heat Transfer in Sweat-Cooled Metals", Journal of Applied Physics, Volume 20, No. 1, Jan., 1949, pp. 113-122 


\section{Appendix A}

\section{Verification of results from numerical heat transfer analysis}

Temperature distribution near inner wall of filter, after $0.3 \mathrm{~s}$

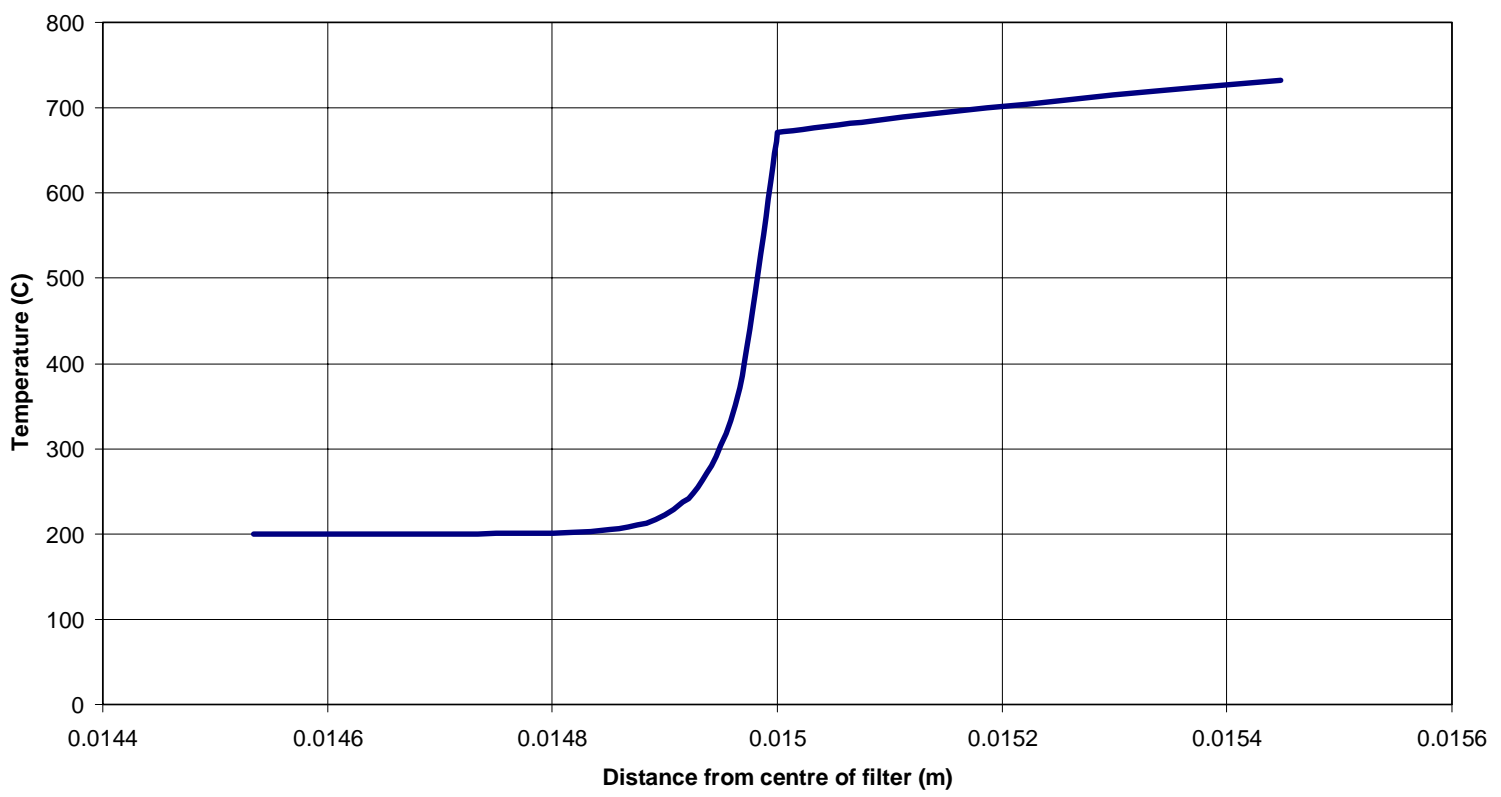

Figure A-1.1 Temperature distribution in the vicinity of the inside wall of filter at the end of surface regeneration, $U=3.6 \mathrm{~cm} / \mathrm{s}, M(P u l s e)=0.27 \mathrm{~kg} / \mathrm{s}, \mathrm{T}(\mathrm{fil})=800 \mathrm{C}, \mathrm{UC}=4 \%$

Figure A-1.1 shows the temperature distribution in the vicinity of the filter, at the end of the surface regeneration operation.

Here,

Initial temperature of the pulse cleaning gases $=200{ }^{\circ} \mathrm{C}$,

Filtration Temperature $=800{ }^{0} \mathrm{C}$,

Duration of surface regeneration $=0.3$ seconds

During surface regeneration, heat is gained by the pulse cleaning gas. This heat comes from the portion of the filter whose temperature drops below $800{ }^{0} \mathrm{C}$ at the end of the 
surface regeneration event. At the end of the surface regeneration, all of the gas reaches the filtration temperature (of $800{ }^{\circ} \mathrm{C}$ ). Hence, if the numerical heat transfer analysis is accurate,

Heat gained by the pulse-cleaning gas $=$ Heat lost by the region of the filter below $800{ }^{\circ} \mathrm{C}$ If $\mathrm{Q}_{1}$ is the heat gained by the gas,

$$
Q_{1}=\dot{m} c_{g} \tau(800-200)
$$

If $\mathrm{Q}_{2}$ is the heat lost by the filter,

$$
Q_{2}=\sum_{m=1}^{N} \rho_{f} c_{f}(\Delta V)\left[800-T_{m}^{0.3}\right]
$$

where ' $\mathrm{N}$ ' corresponds to the last node in the filter whose temperature drops below $800{ }^{\circ} \mathrm{C}$, at the end of surface regeneration.

$\mathrm{Q}_{1}$ and $\mathrm{Q}_{2}$ were calculated and the ratio $\mathrm{Q}_{1} / \mathrm{Q}_{2}$ was then calculated to be 0.98 , which is close to 1 , thereby establishing the accuracy of the numerical heat transfer analysis. 


\section{Appendix B}

\section{Source code of the integrated 'Microsoft Visual Basic' program}

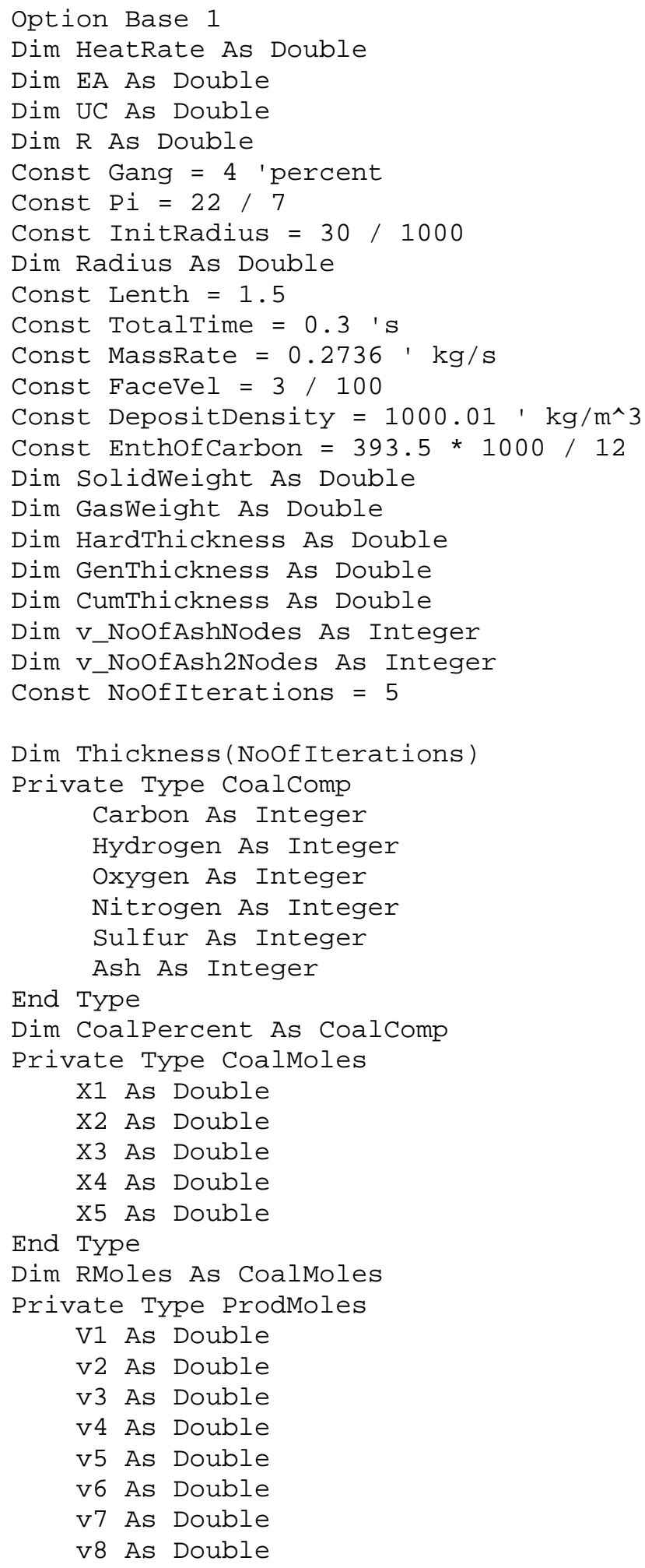




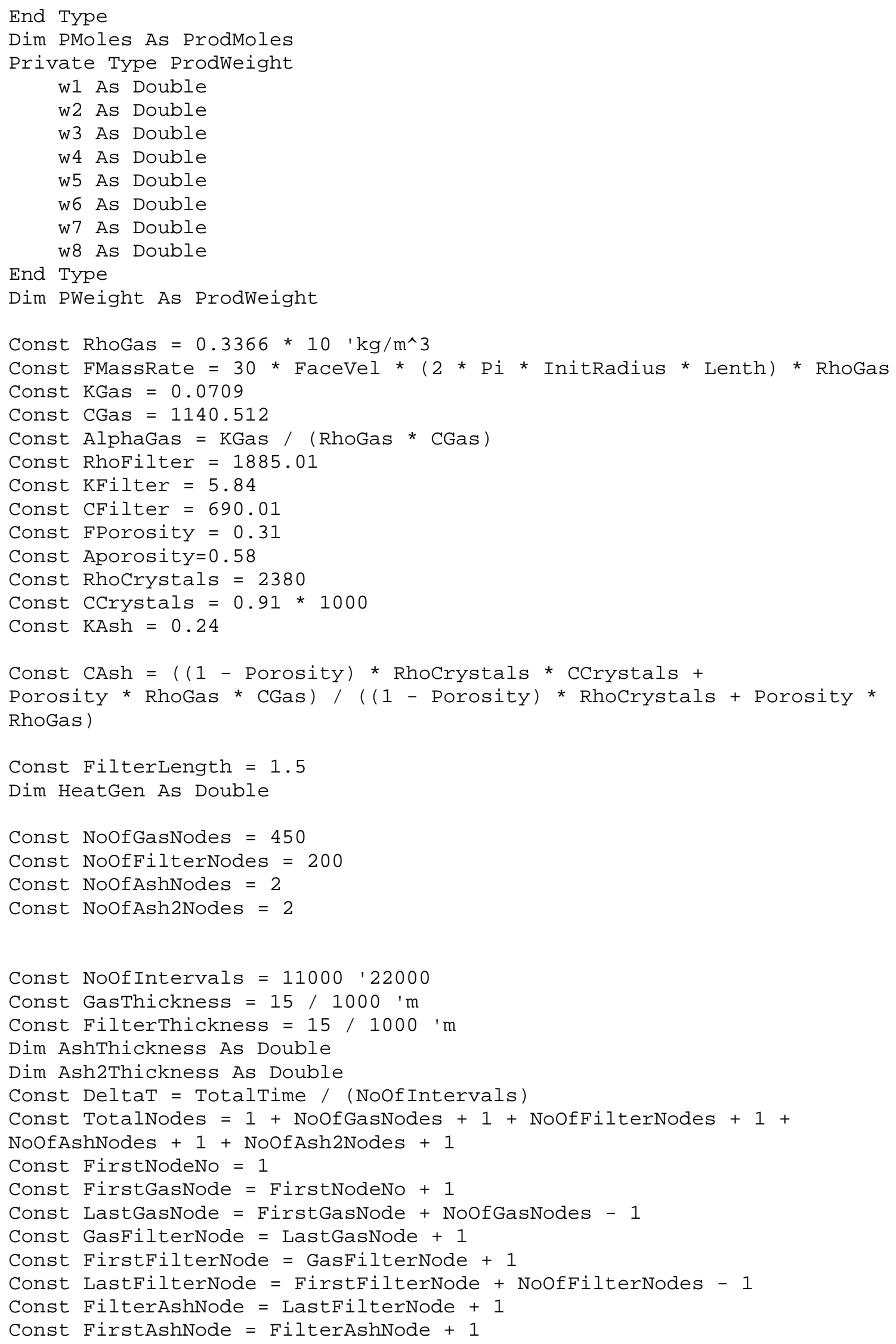




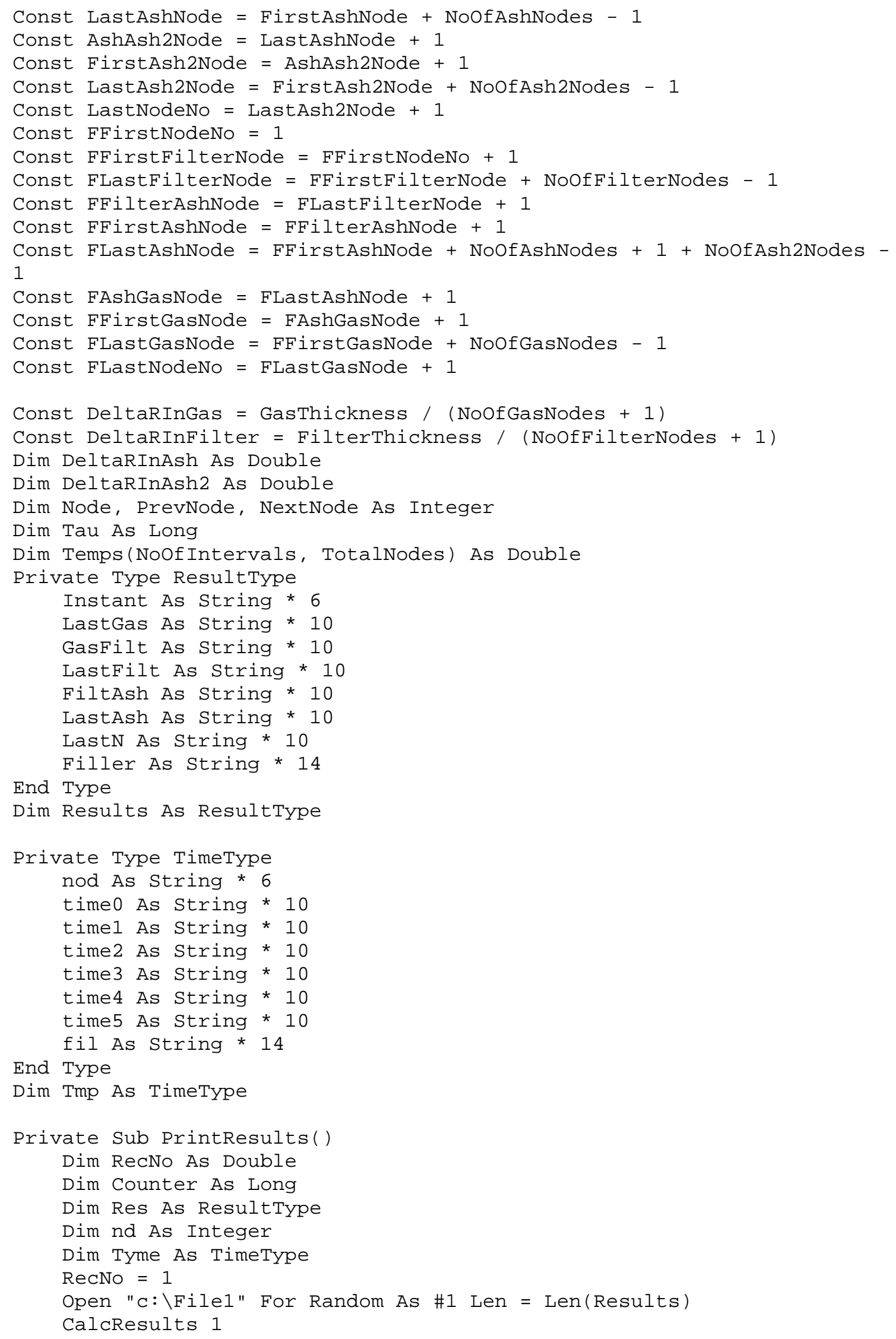




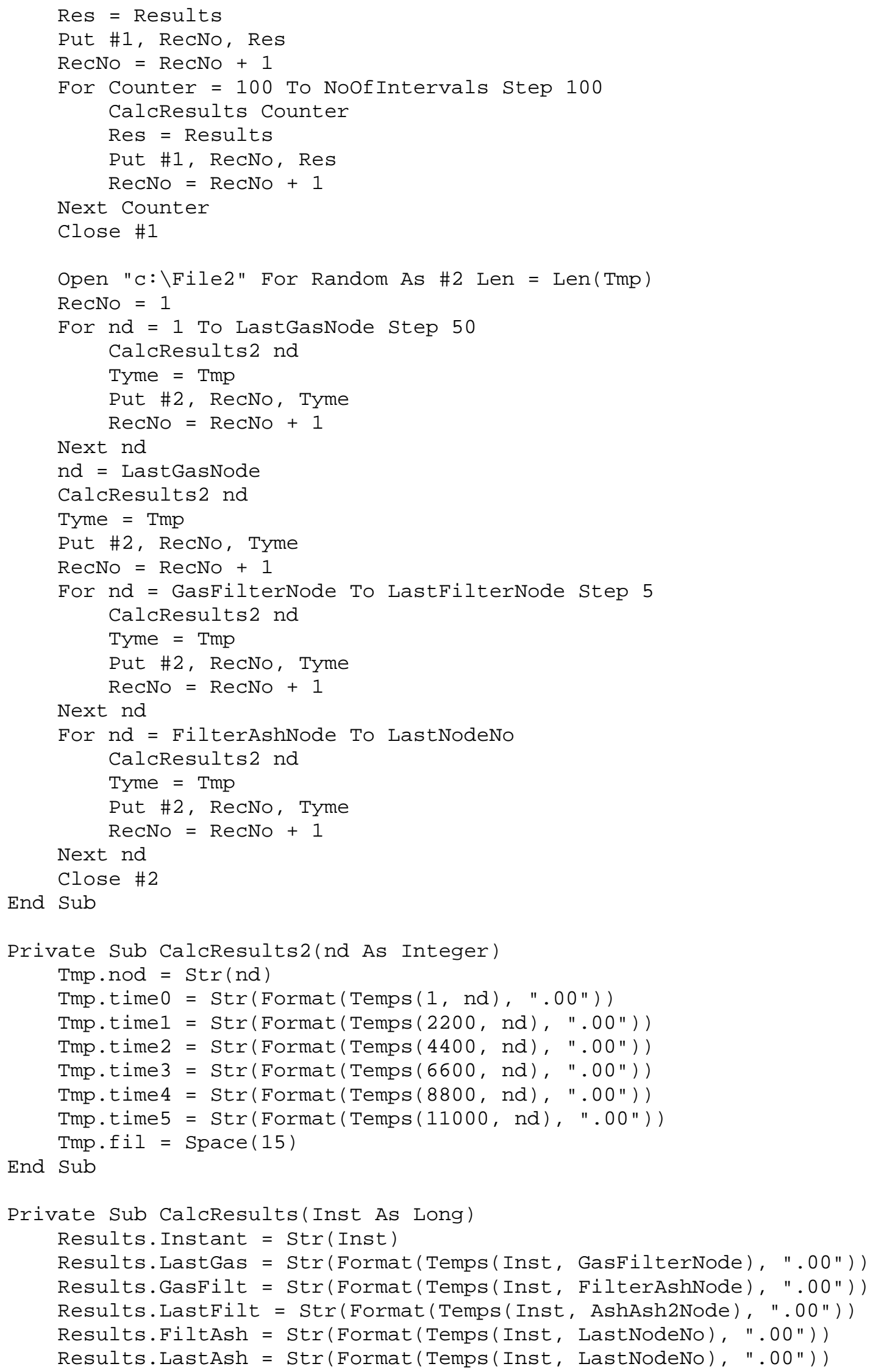




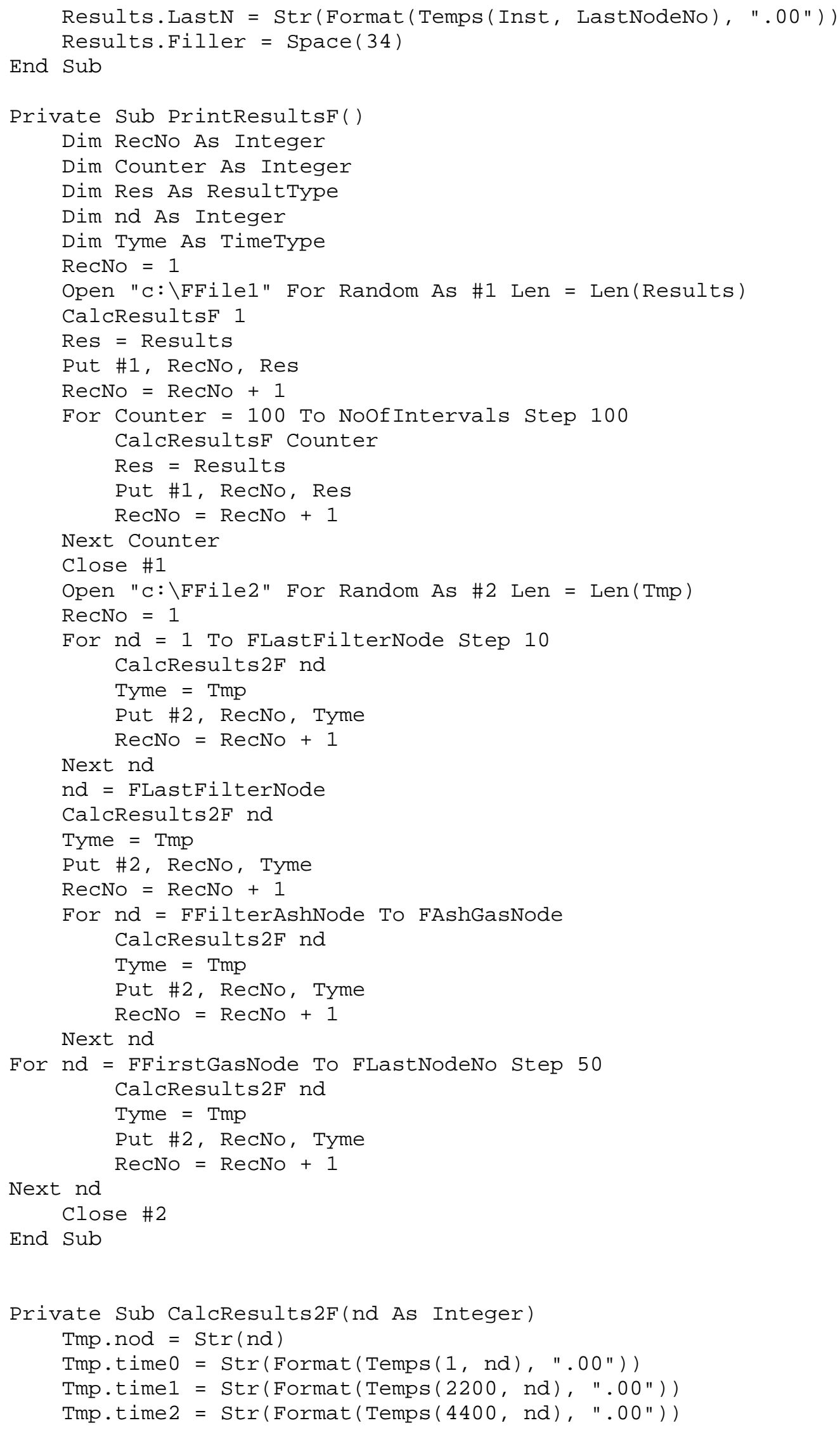




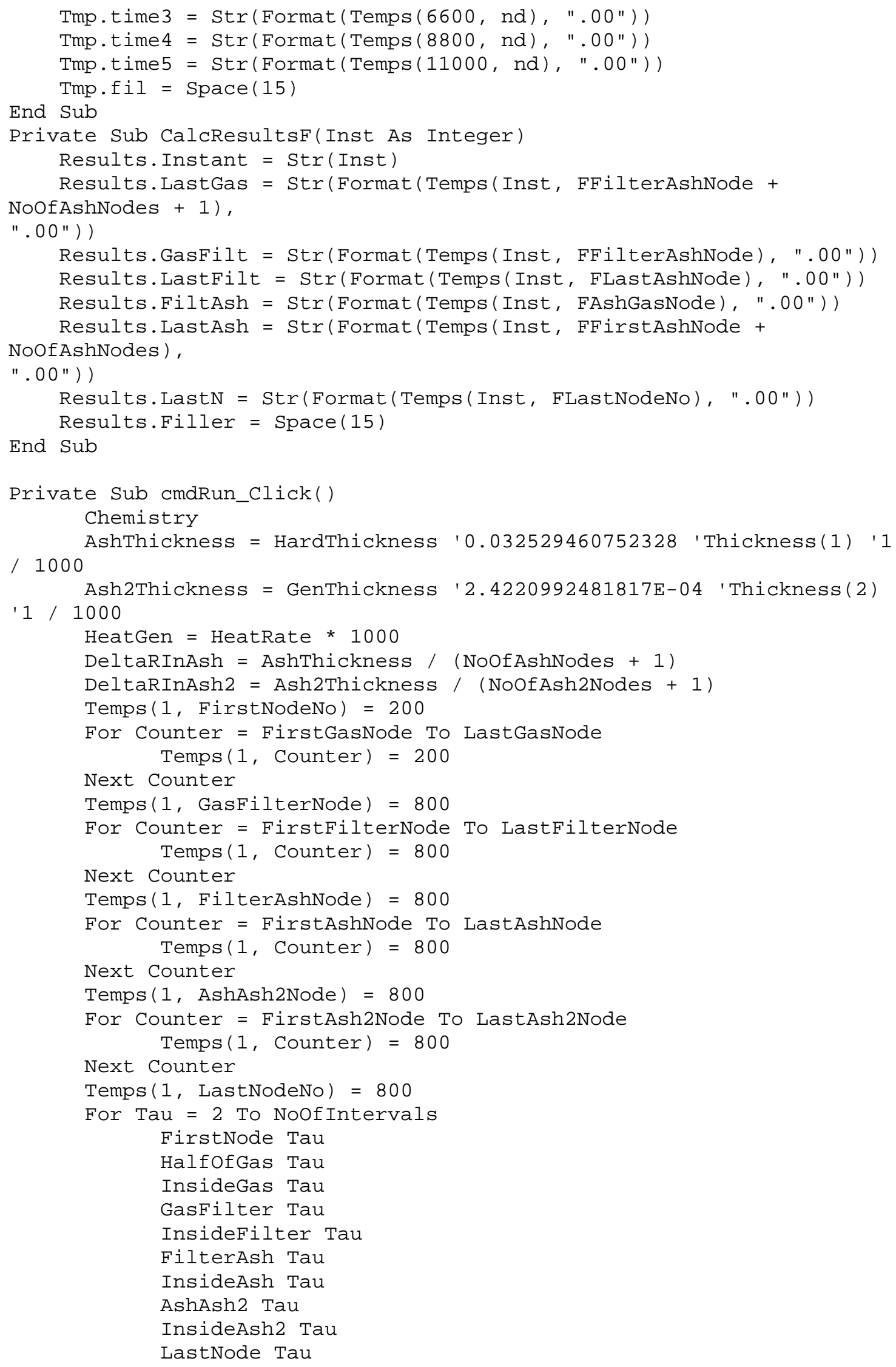




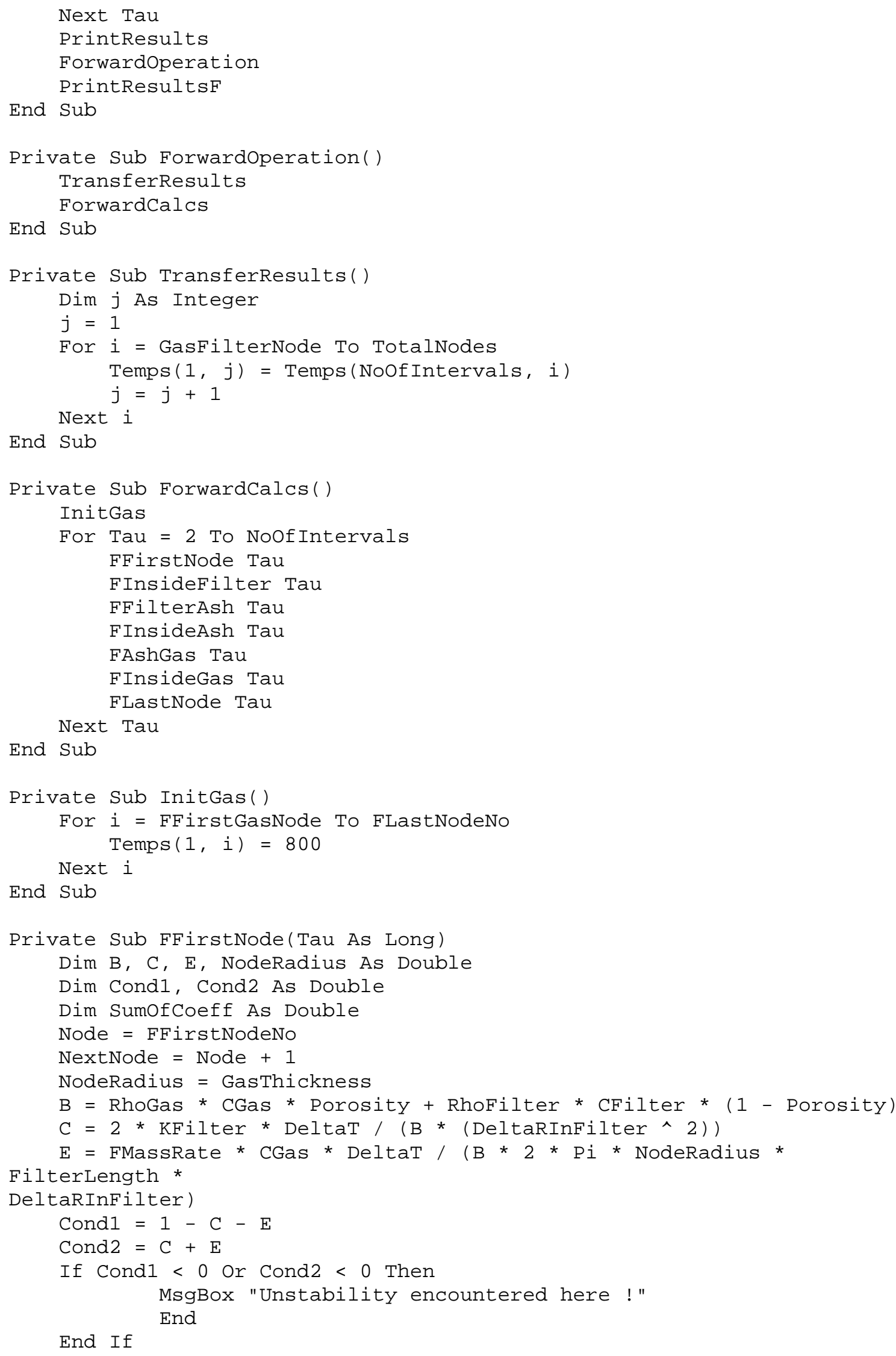




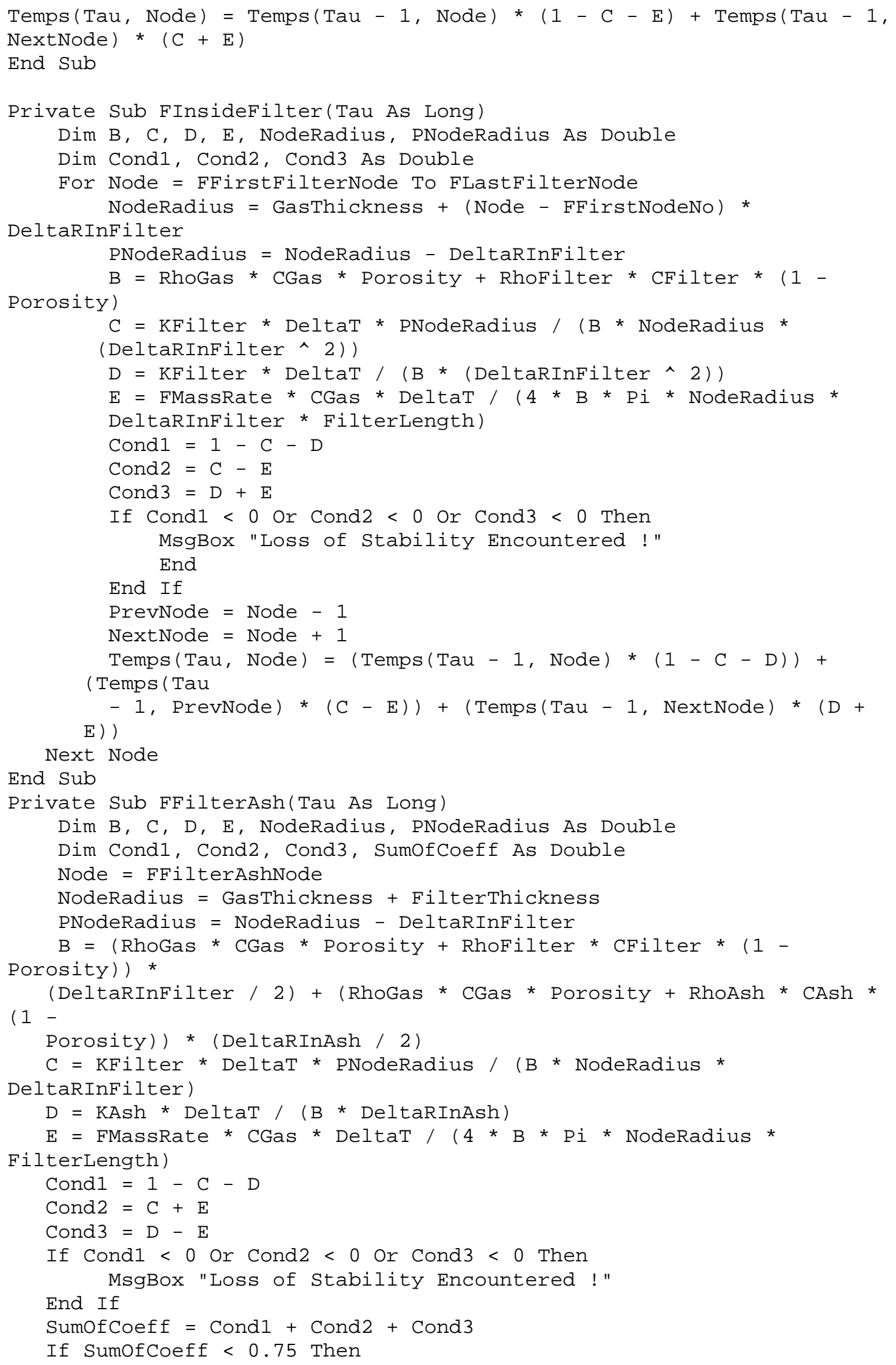




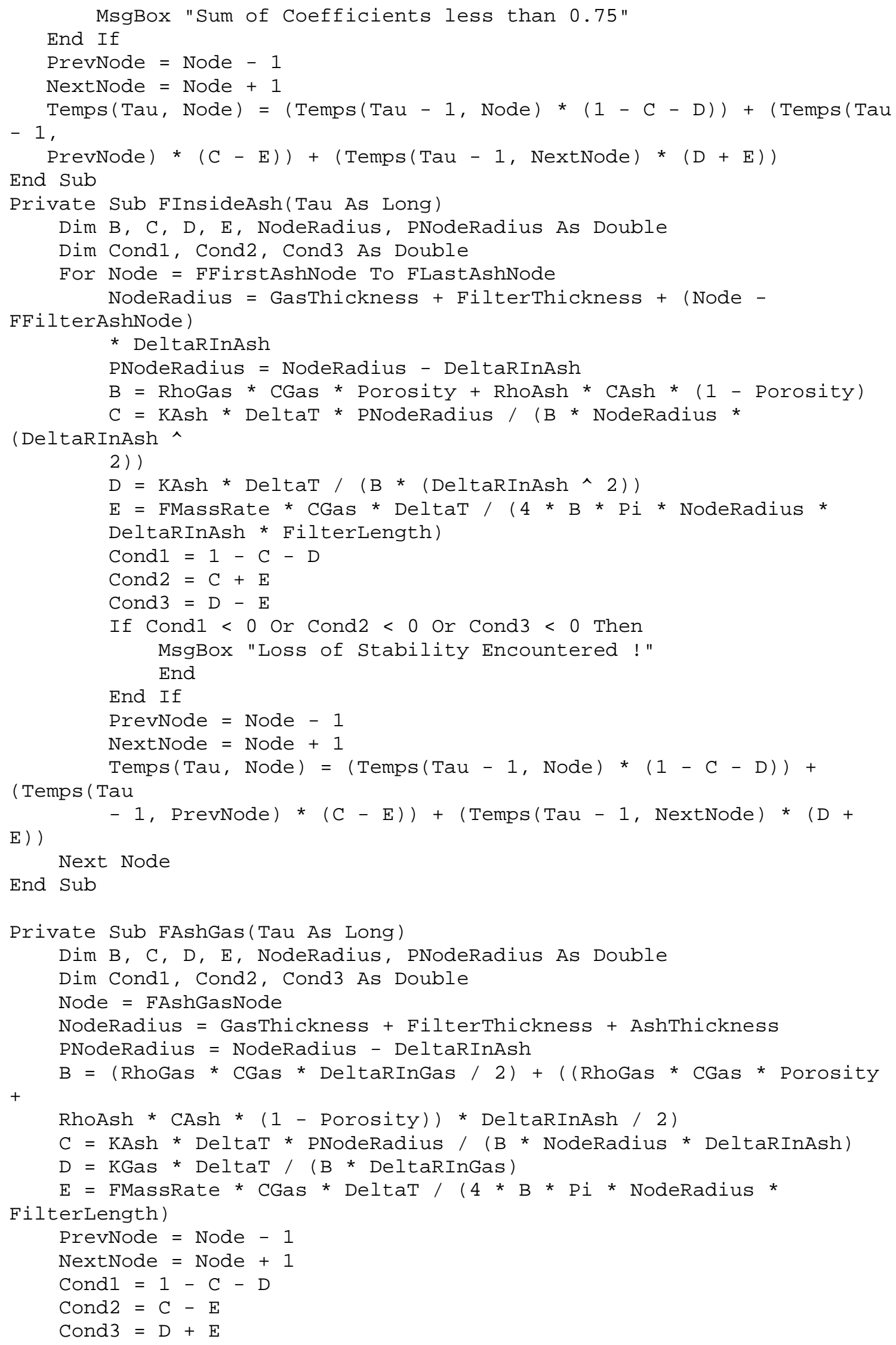




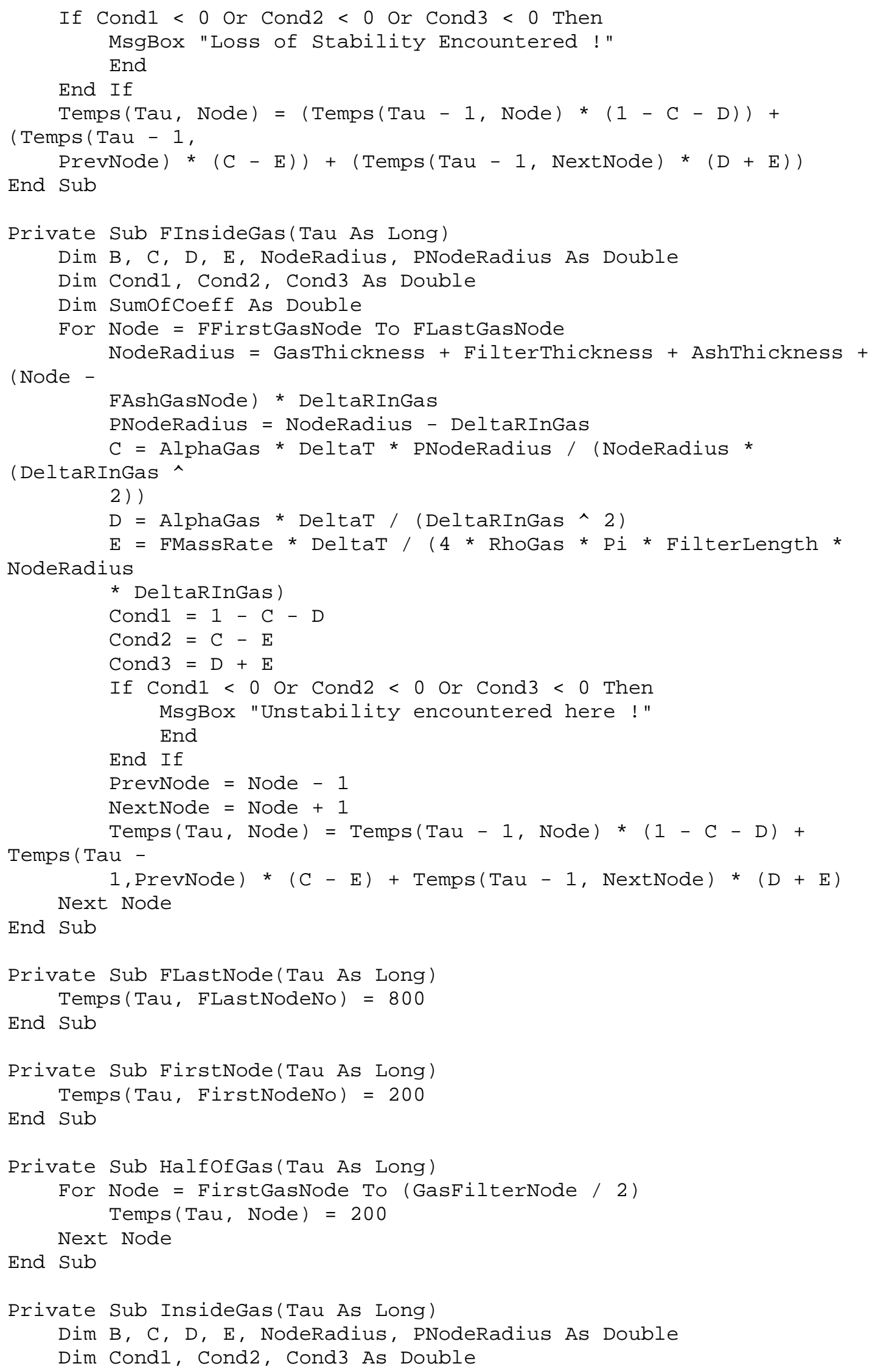




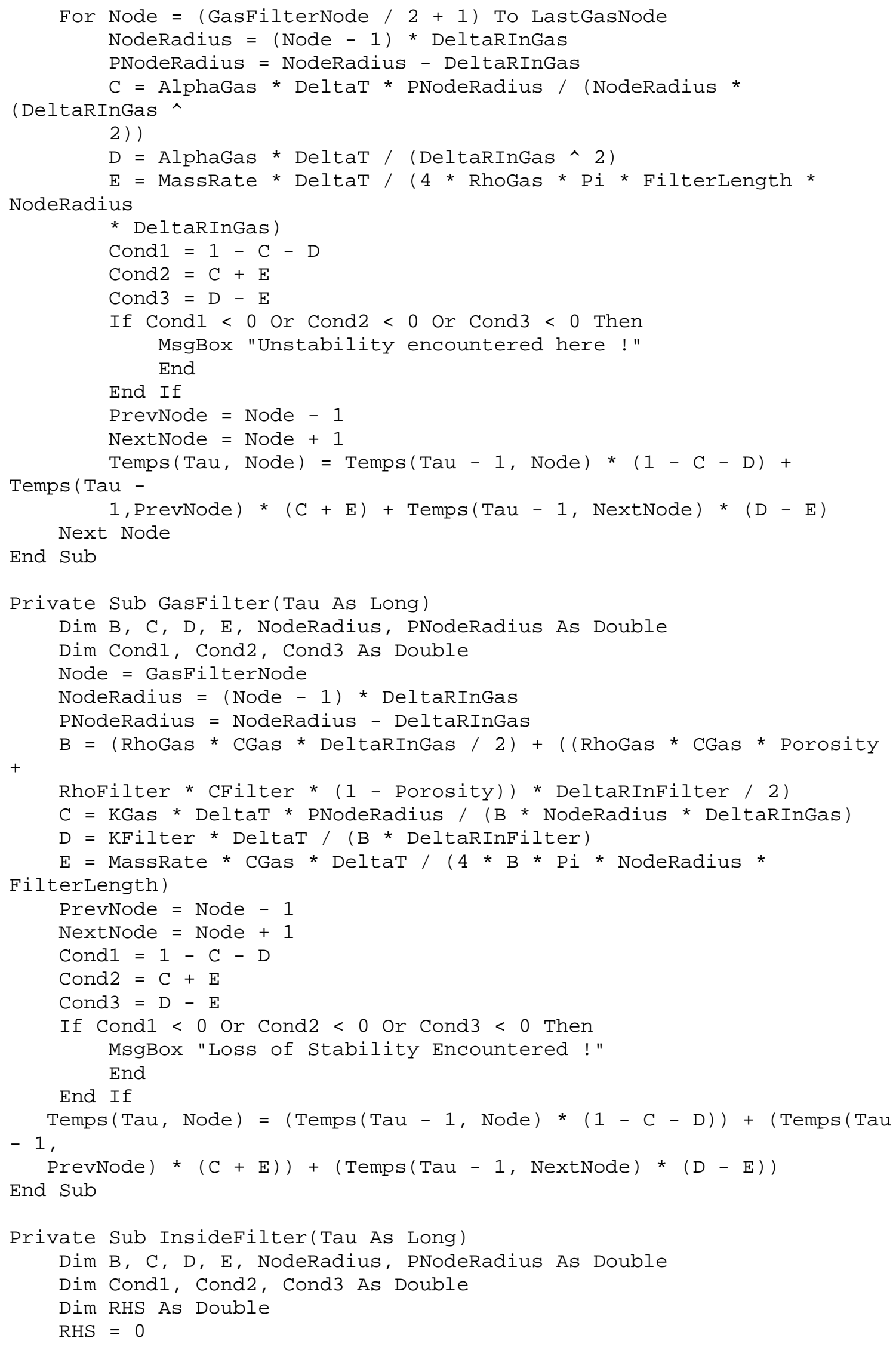




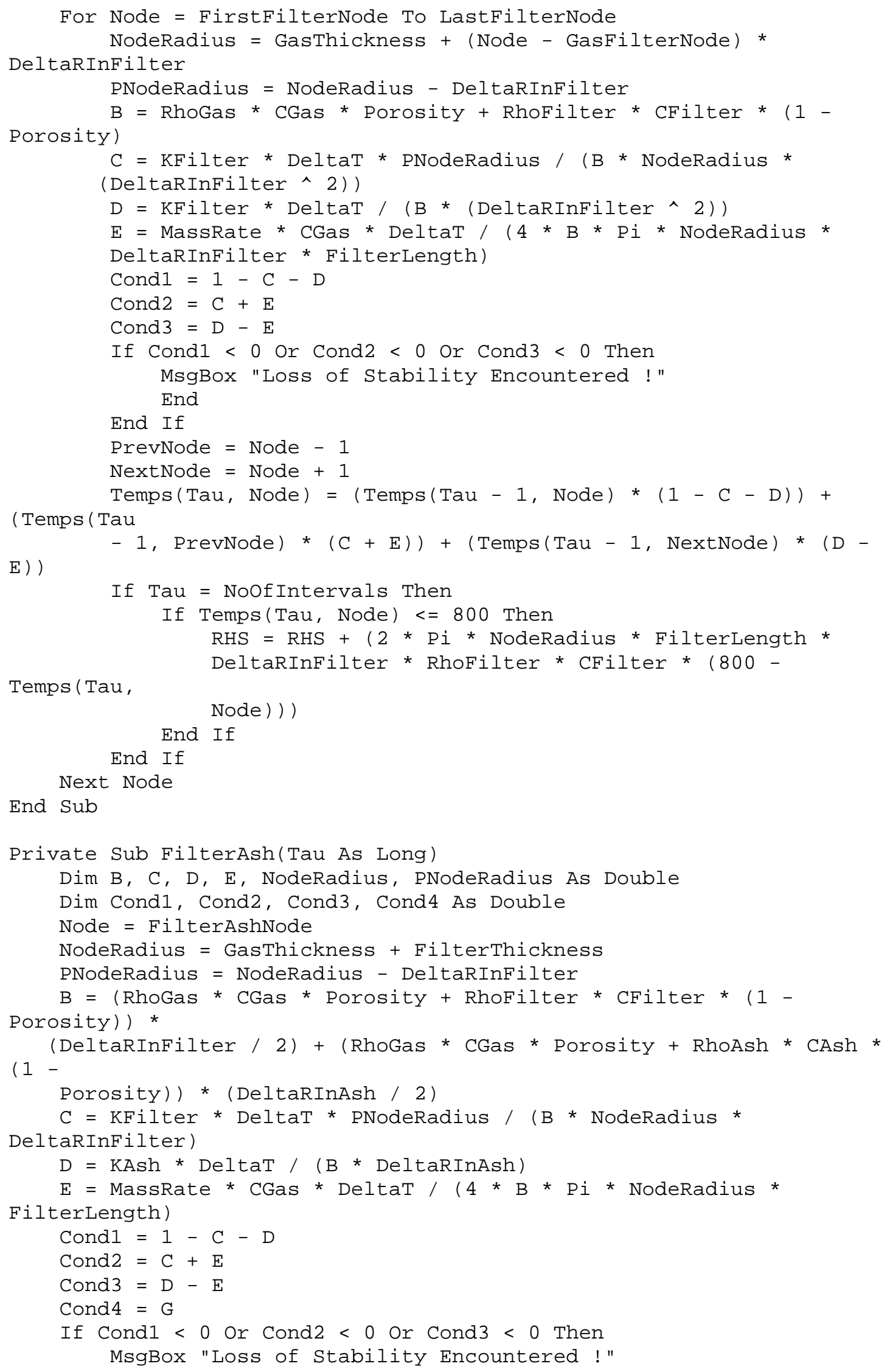




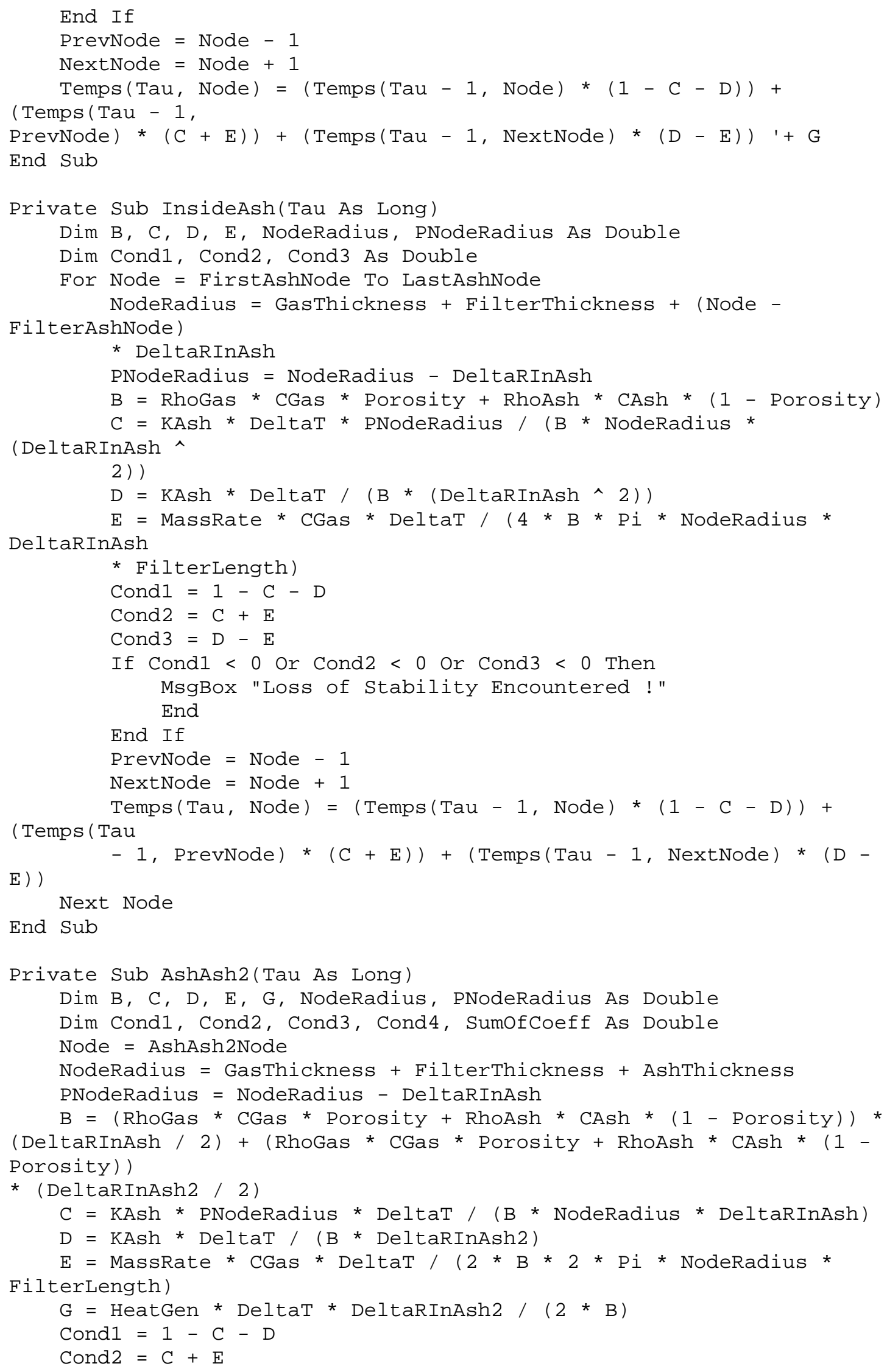




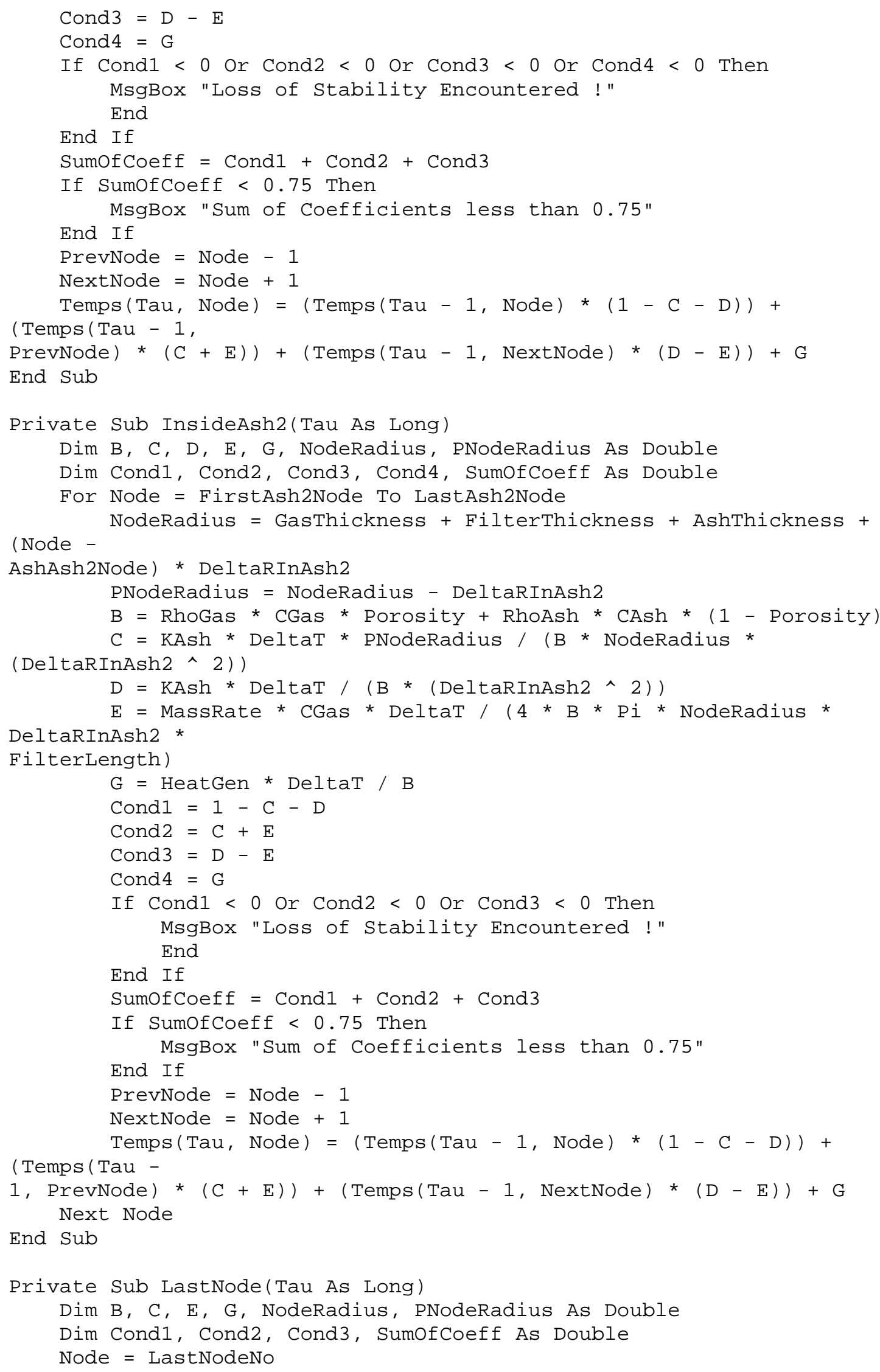




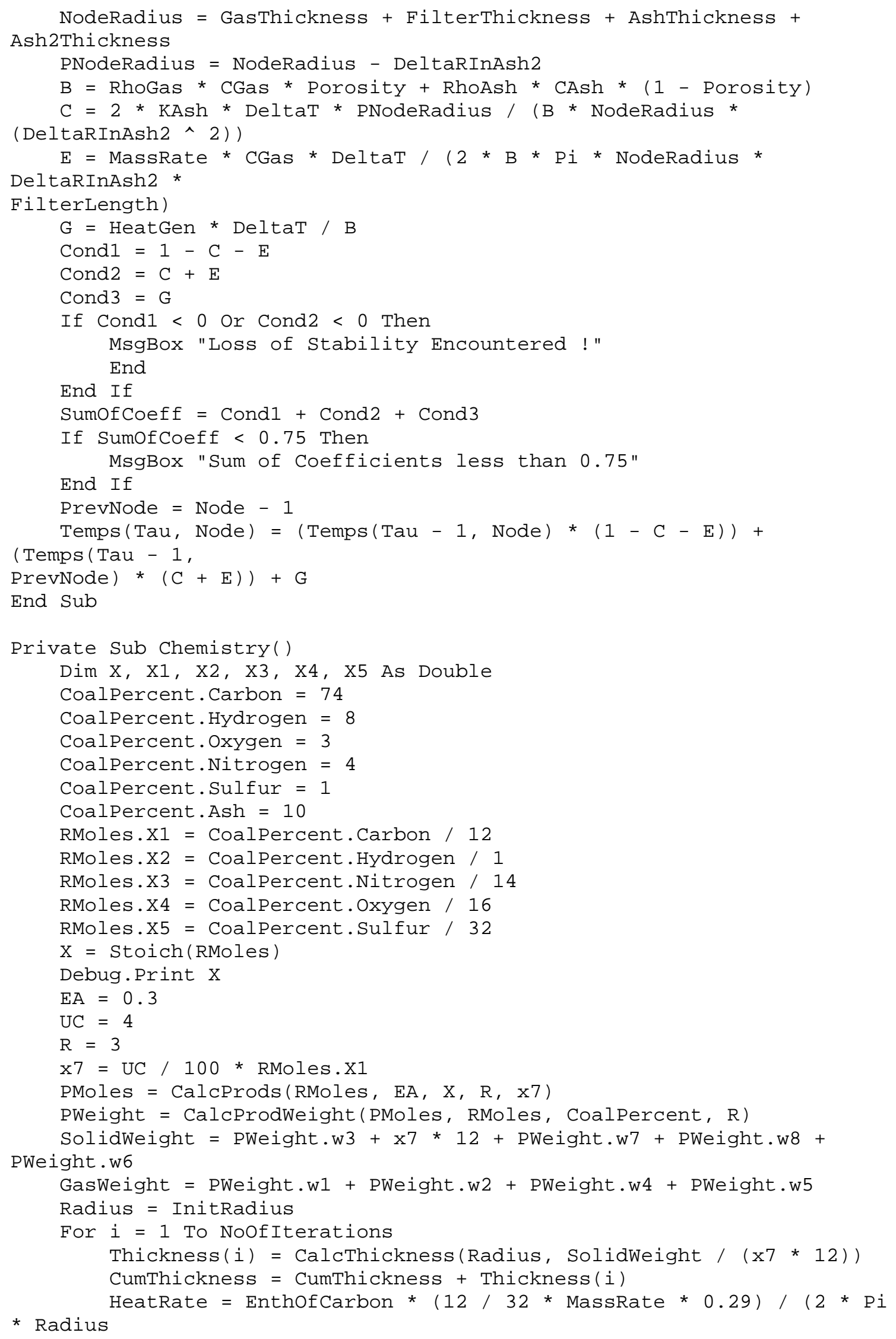




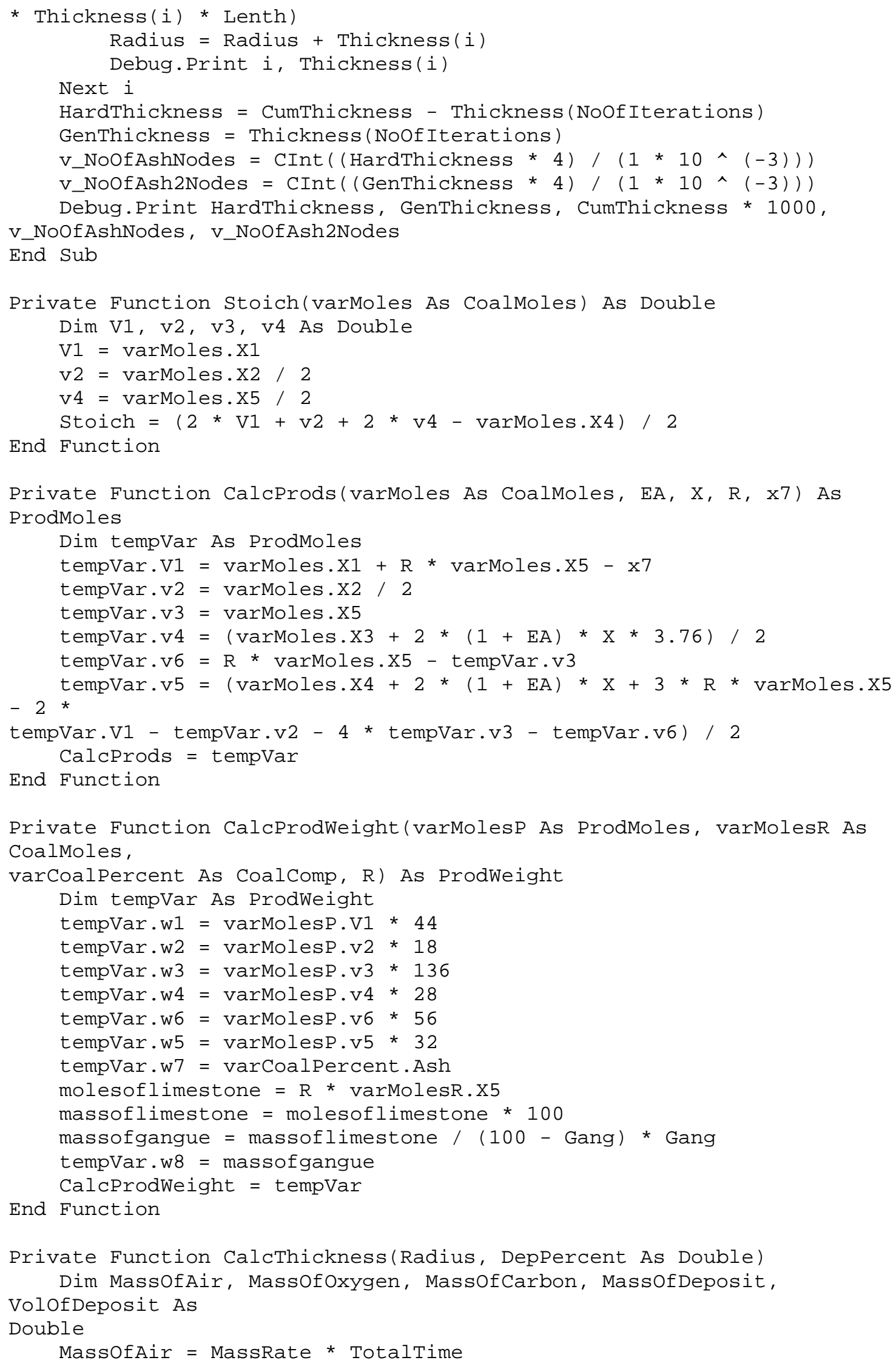




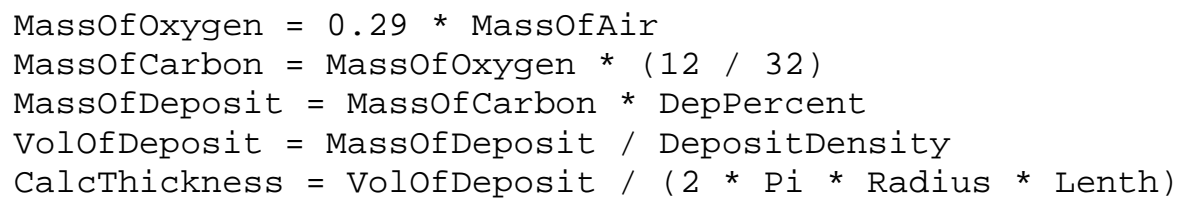




\title{
VITA
}

\author{
Name: $\quad$ Sharath J. Simha \\ Date of Birth: $\quad 20$ May, 1974 \\ Place of Birth: $\quad$ Bangalore, India \\ Education: \\ MS in Mechanical Engineering, West Virginia University \\ Date of Graduation: December 1998
}

BS in Mechanical Engineering, Bangalore University

Date of Graduation: August 1995 


\section{APPROVAL OF EXAMINING COMMITTEE}

Richard A. Dennis

Dr. Bruce S. Kang, Ph.D.

(Co-Advisor)

Dr. Eric K.Johnson, Ph.D.

(Chairman)

Date 